Aus dem Institut für Neuropathologie

(Prof. Dr. med. W. Brück)

der Medizinischen Fakultät der Universität Göttingen

\title{
Sequentielle Antibiose mit Rifampicin gefolgt von Ceftriaxon als neuroprotektiver Therapieansatz bei der bakteriellen Meningitis
}

\author{
Inaugural - Dissertation \\ zur Erlangung des Doktorgrades \\ der Medizinischen Fakultät der \\ Georg-August-Universität zu Göttingen
}

\author{
vorgelegt von \\ Valentin Stoltefaut \\ aus Frankfurt am Main \\ Göttingen 2015
}


Dekan:

Prof. Dr. rer. nat. H. K. Kroemer

1. Berichterstatter: Prof. Dr. Roland Nau

2. Berichterstatter: Prof. Dr. Dr. Helmut Eiffert

3. Berichterstatter: Prof. Dr. Martin Oppermann

Tag der mündlichen Prüfung: 28.06.2016 


\section{Inhaltsverzeichnis}

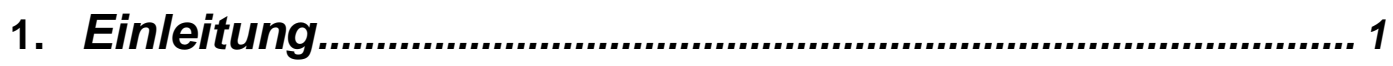

$1.1 \quad$ Epidemiologie und Symptomatik ........................................ 1

1.2 Pathogenese und -physiologie der bakteriellen Meningitis... 2

1.3 Neuronaler Schaden bei bakterieller Meningitis .................. 10

1.3.1 Nekrose................................................................... 10

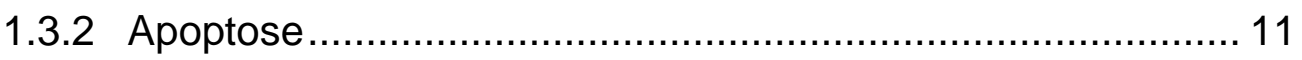

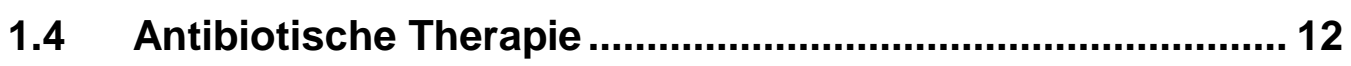

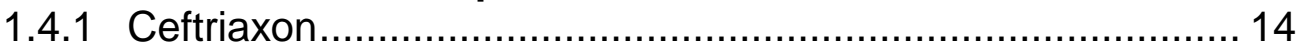

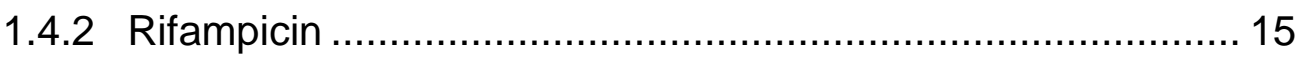

1.4.3 Tigezyklin .................................................................. 16

1.5 Adjuvante Therapie ............................................................... 17

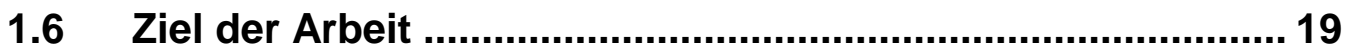

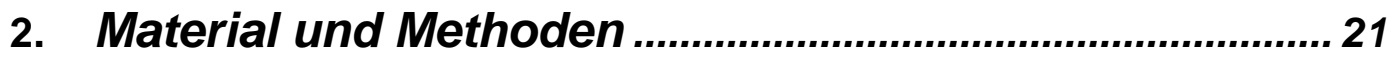

2.1 Testorganismen/Substanzen und Dosierungen ................... 21

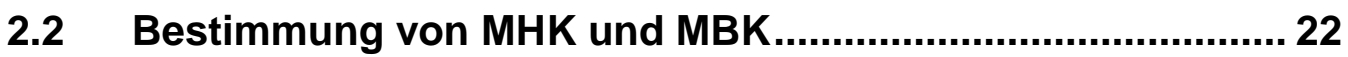

2.3 Kultivierung und Lagerung der Bakterienstämme................ 23

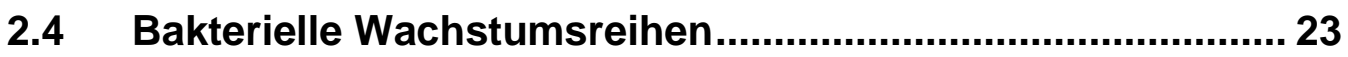

2.5 Bestimmung der Erregerkonzentration ................................ 24

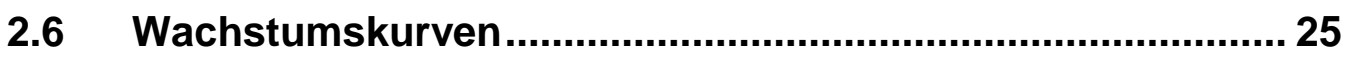

2.7 Nachweis und Quantifizierung von Pneumolysin ................. 25

2.8 Herstellung einer Standardreihe von Pneumolysin .............. 26

2.9 Herstellung der Polyacrylamidgele ........................................ 27

2.10 Vorbereitung der Proben und Standards ............................ 29

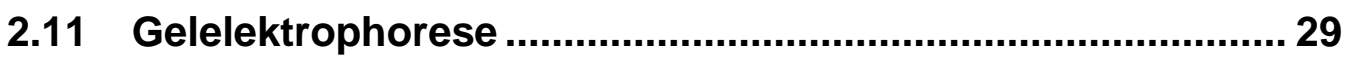

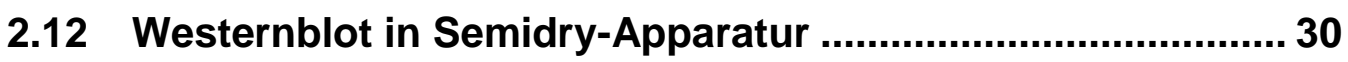

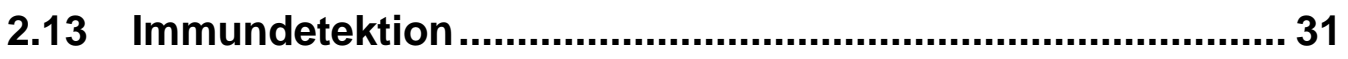

2.14 Tiermodell der bakteriellen Meningitis ............................... 32

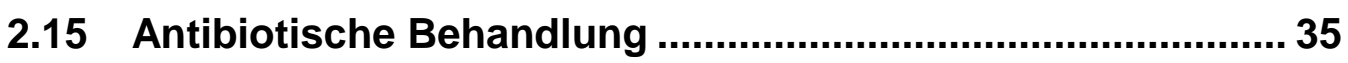

2.16 Gewebeentnahme, Fixation und Herstellung der Schnitte .. 36

2.17 Hämatoxylin-Eosin-Färbung (HE-Färbung) .......................... 37

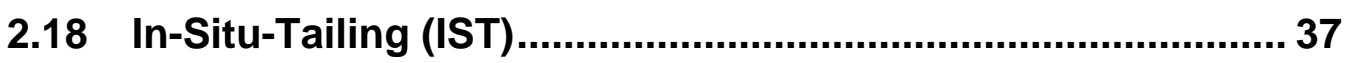

2.19 Quantifizierung apoptotischer Neurone ............................. 38

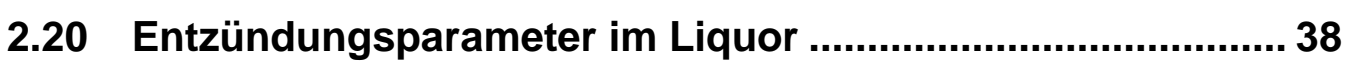




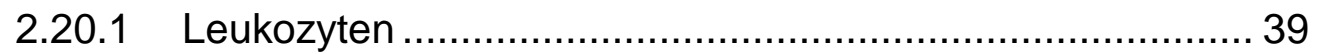

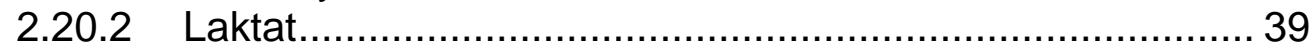

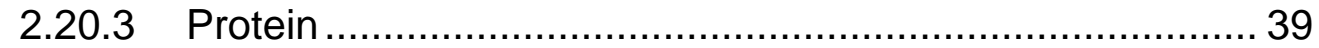

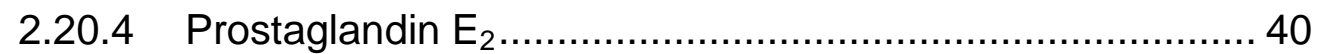

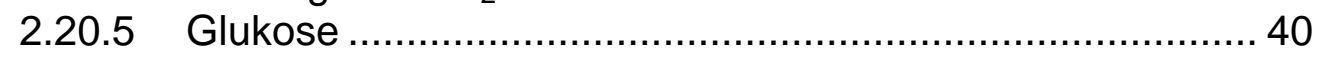

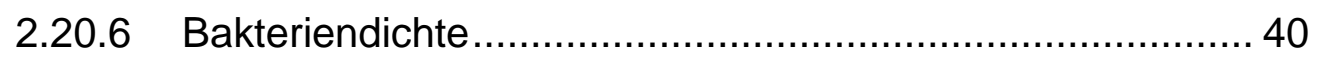

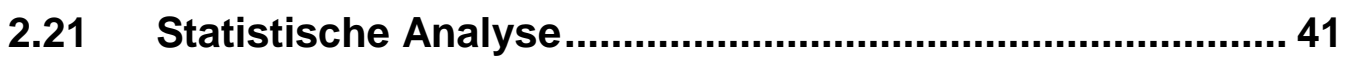

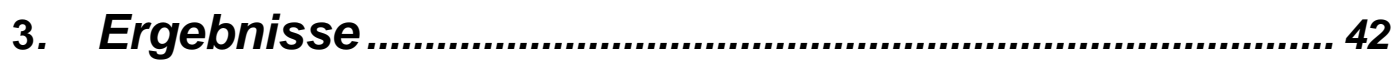

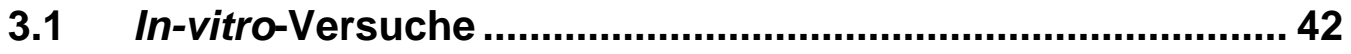

3.2 Tiermodell der bakteriellen Meningitis ................................ 45

3.3 Quantifizierung von Pneumolysin ........................................ 46

3.4 Entzündungsparameter im Liquor ...................................... 48

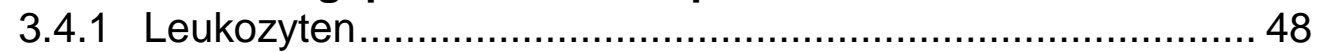

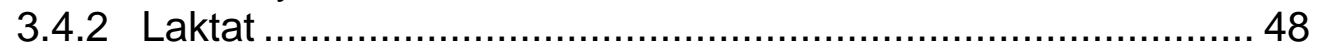

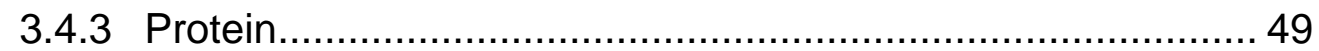

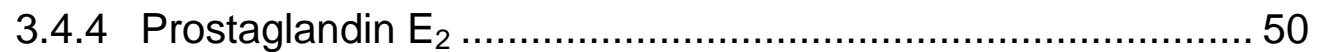

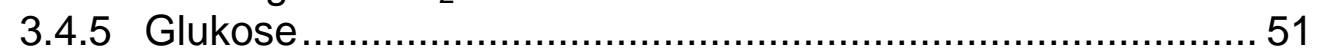

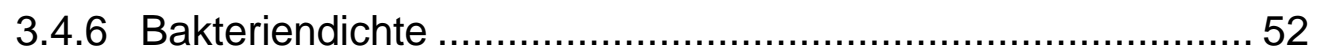

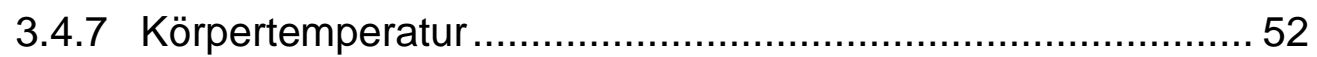

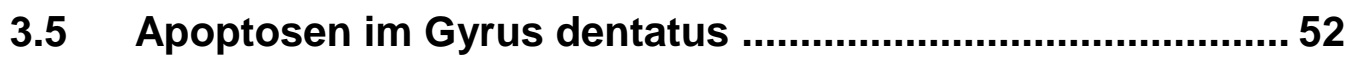

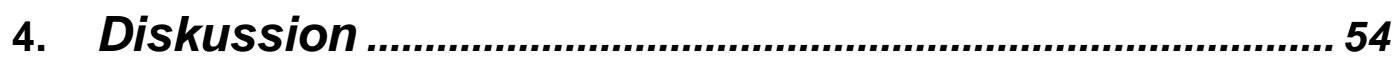

4.1 Optimierungsbedarf und aktuelle Ansätze in der Therapie der bakteriellen Meningitis ............................................................ 54

4.2 Die Bedeutung bakterieller Stoffwechselprodukte und

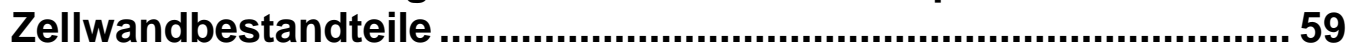

4.3 Nicht-bakteriolytische Antibiotika.......................................... 63

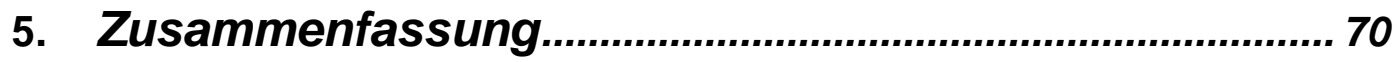

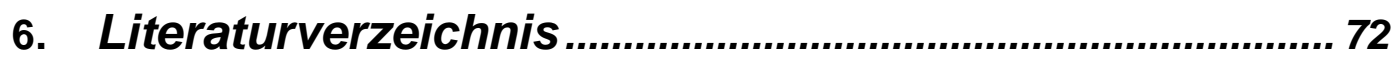

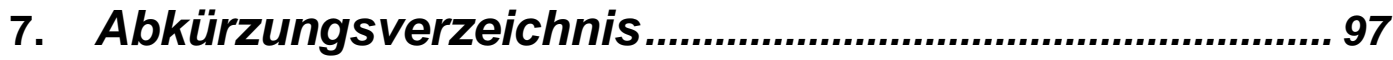




\section{Einleitung}

\subsection{Epidemiologie und Symptomatik}

Die bakterielle Meningitis ist eine schwere und lebensbedrohliche Infektionskrankheit des zentralen Nervensystems mit mehr als 1 Mio. betroffenen Patienten weltweit pro Jahr. Allein in Europa erkranken etwa 35.000 Menschen jährlich, wobei etwa $20 \%$ der Patienten versterben (Brouwer und van de Beek 2012). Das Erregerspektrum umfasst sowohl grampositive als auch gramnegative Erreger, je nach Alter und Gesundheitszustand des Patienten beziehungsweise prädisponierenden Faktoren. Bei den über 20-jährigen Patienten ist Streptococcus pneumoniae mit etwa 30-50\% Beteiligung häufigster Erreger der ambulant erworbenen bakteriellen Meningitis (Koedel 1996). Bei Kindern und in der Adoleszenz spielt Neisseria meningitidis eine wichtige Rolle. Seit Einführung der Impfung gegen Haemophilus influenzae Serotyp $b$ bei Kindern hat auch in dieser Altersgruppe die Bedeutung von S. pneumoniae als Erreger deutlich zugenommen (Dery und Hasbun 2007). Im Säuglingsalter gehören Gruppe B-Streptokokken und Escherichia coli zu den häufigeren Erregern, im höheren Lebensalter finden sich neben Pneumokokken auch gehäuft Infektionen mit Listeria monozytogenes als dritthäufigstem Erreger der bakteriellen Meningitis (Brouwer et al. 2006). Klinisch manifestiert sich die bakterielle Hirnhauterkrankung häufig mit den Symptomen Fieber, Nackensteife, Kopfschmerzen und Bewusstseinstrübung (van de Beek et al. 2004). Von besonderer Bedeutung sind die hohe Letalität und die häufig auftretenden Langzeitschäden bei den betroffenen Patienten. Trotz hoher Standards in der medizinischen Versorgung sterben in den Industrieländern ca. $25 \%$ der betroffenen Erwachsenen. Weniger als $50 \%$ haben ein zufriedenstellendes Outcome, bei dem es innen möglich ist, den Altag anschließend wieder selbständig zu bewältigen (Kastenbauer und Pfister 2003). Die auftretenden Folgeerkrankungen sind vielfältig. Am häufigsten kommt es zu 
Hörverlust (33,9\%), aber auch kognitive und motorische Ausfälle sowie visuelle Beeinträchtigungen oder ein Hydrozephalus können zurückbleiben (Edmond et al. 2010). Weitere häufige Folgeerscheinungen sind Schwindel (23\%), Müdigkeit (22\%), Gedächtnisstörungen (21\%) und Gangataxie (18\%) (Bohr et al. 1984). In einer Studie zum Hörverlust bei Kindern nach bakterieller Meningitis kam es bei einer PneumokokkenMeningitis in etwa $30 \%$ der Fälle, bei einer Meningokokken-Meningitis in ca. $10 \%$ der Fälle und bei einer Infektion des ZNS mit Haemophilus influenzae in durchschnittlich 6\% der Fälle zu einem Hörverlust (Dodge et al. 1984). Eine wichtige Rolle spielt auch die Beeinträchtigung von Lernvorgängen und Gedächtnis (Merkelbach et al. 2000, Schmidt et al. 2006). Vor Einführung einer antibiotischen Therapie verlief die PneumokokkenMeningitis fast immer letal (Winkelmann und Eckel 1935).

Trotz effektiver antibiotischer Therapie besteht nach wie vor eine hohe Letalität und ein hohes Risiko für bleibende neurologische Schäden. Dies macht die Suche nach verbesserten Therapiekonzepten dringend erforderlich.

\subsection{Pathogenese und -physiologie der bakte- riellen Meningitis}

Bei der Entstehung einer bakteriellen Meningitis unterscheidet man im Wesentlichen zwei Infektionswege. Zum einen können sich die Erreger hämatogen oder lymphogen ausbreiten, zum anderen per continuitatem wie im Sinne einer Durchwanderungsmeningitis nach Sinusitis, Mastoiditis oder Otitis. Für die Passage der Blut-Hirn-Schranke spielen zahlreiche Faktoren eine Rolle, die es den Bakterien ermöglichen, an die Wirtszellen zu binden und in sie einzudringen (s.u.). 
Etwa 4\% aller Erwachsenen sind asymptomatische Keimträger von $S$. pneumoniae (Regev-Yochay et al. 2004), während Kinder in bis zu 37\% der Fälle eine Besiedelung der Mukosa im Nasen-Rachenraum aufweisen (Bogaert et al. 2001).

Die Fähigkeit einiger Bakterien, die Mukosa des Nasen-Rachenraumes zu kolonisieren, ist eine wichtige Voraussetzung, um anschließend in das ZNS eindringen zu können. Dies gelingt mithilfe verschiedener Faktoren, die sich von Erreger zu Erreger unterscheiden.

In diesem Zusammenhang spielt die Pneumokokkenimpfung eine wichtige Rolle, da hierdurch die Anzahl der asymptomatischen Keimträger reduziert werden kann.

So wird empfohlen, Kinder bis zum Alter von 24 Monaten und Patienten über 60 Jahre gegen Pneumokokken zu impfen, um schwere Folgeerkrankungen zu vermeiden (RKI 2013).

Die Schleimhäute werden durch Lysozym und muköse Sekretion vor bakterieller Besiedelung geschützt (Shimada et al. 2008). S. pneumoniae ist in der Lage, sich mithilfe verschiedener Enzyme vor Lysozym zu schützen und somit diese erste Barriere zu umgehen (Davis et al. 2008). Durch die Sezernierung verschiedener Exoglykosidasen (Neuraminidase A, Betagalaktosidase A, N-Acetyl-Glukosaminidase, Neuraminidase B) kommt es zu einer geringeren Viskosität des Schleimes, wodurch eine effektive Clearance nicht mehr gewährleistet ist und es den Erregern leichter gelingt, die Schleimhaut zu besiedeln (Burnaugh et al. 2008). Zusätzlich beeinträchtigt das von Pneumokokken synthetisierte Hämolysin, Pneumolysin die ziliäre Clearance und erleichtert den Pneumokokken die Adhäsion (Feldman et al. 2002).

Eine wichtige Rolle bei der Bindung an das Epithel spielt der Faktor $A$ (PavA). PavA bindet an Fibronektin, moduliert andere Virulenzfaktoren von S. pneumoniae und unterstützt somit die Adhäsion an die Wirtszelle (Pracht et al. 2005; Noske et al. 2009). Im Mausmodell kommt es bei fehlender PavA-Synthese der Pneumokokken zu verringerter Adhäsion und 
Virulenz der Erreger (Pracht et al. 2005, Holmes et al. 2001). Auch Polysaccharidkapseln fördern die Kolonisierung der Mukosa und erschweren zugleich die Phagozytose sowie die Aktivierung des Komplementsystems, wodurch es leichter zu einer Bakteriämie kommen kann (Bogaert et al. 2010). S. pneumoniae kann an PAF (platelet activating factor) und das Oberflächenprotein PspC an polymere Immunglobulinrezeptoren binden. Dies sind wichtige Schritte, um nach der Kolonisierung die Transzytose zu ermöglichen (Cundell et al. 1995, Elm et al. 2004). Auch Pili scheinen bei der Anheftung an die Epithelzellen eine wichtige Rolle zu spielen (Bagnoli et al. 2008).

IgA-Proteasen, die in allen bekannten Subtypen von S. pneumoniae vorkommen, spalten spezifisch IgA und erleichtern somit ebenfalls die Kolonisierung der Mukosa (De Paolis et al. 2007). Den Angriffen durch das Komplementsystem entgehen die Bakterien durch verschiedene Faktoren wie Ply, PspC oder PspA. Diese verringern die Opsonierung der bakteriellen Zelloberfläche (Ply), stören den Faktor C3 bei der Anheftung an die Zelloberfäche (PspA) oder binden und inaktivieren den Faktor C3b (PspC) (Quin et al. 2007, Jarva et al. 2002).

Gelingt es den Bakterien in großer Zahl in die Blutbahn zu gelangen, ist eine Infektion des ZNS nach Durchdringen der Blut-Hirn-Schranke möglich.

Intravaskulär muss in erster Linie das Komplementsystem als Teil des unspezifischen, angeborenen Immunsystems überwunden werden. In diesem Fall ist die Polysaccharidkapsel einiger Stämme von S. pneumoniae die wichtigste Abwehrmaßnahme der Bakterien, um intravaskulär zu überleben. Sie reduziert als unspezifische Barriere die Anheftung verschiedener Komplementfaktoren und schützt vor Phagozytose (Abeyta et al. 2003, Kadioglu et al. 2008). Zum anderen schützen sich die Bakterien durch Inaktivierung bestimmter Faktoren des Komplementsystems durch Oberflächenproteine wie PspA und PspC (s.o). 
Schließlich muss das Bakterium noch die Blut-Hirn-Schranke überwinden, wobei die Bindung an Laminin-Rezeptoren der Gefäße eine besonders wichtige Rolle zu spielen scheint (Orihuela et al. 2009). Auch die Fähigkeit an den PAF-Rezeptor zu binden, spielt eine entscheidende Rolle im Rahmen der Adhäsion mit anschließender Transzytose (Ring et al. 1998), ebenso wie die Bindung an Vitronektin (Bergmann et al. 2009). In einer Studie, in der der Übertritt von Streptococcus suis an isolierten Zellen des Plexus choroideus von Schweinen untersucht wurde, zeigte sich, dass die Bakterien vermutlich auch direkt durch die Plexuszellen in den Liquor cerebrospinalis eindringen können, ohne den Weg über das Kapillarendothel zu nehmen (Tenenbaum et al. 2009). Sind die Bakterien im Liquor angelangt, können sie sich zunächst nahezu ungehemmt replizieren, da Abwehrmechanismen wie Komplement und Immunglobuline nur in sehr niedrigen Konzentrationen vorhanden sind. Erst wenn sich eine Entzündung manifestiert hat und die Blut-Hirn-Schranke gestört ist, wird das Immunsystem im Liquor aktiv (Quagliarello und Scheld 1992).

Bei der Erkennung der Pneumokokken durch Antigen-präsentierendeZellen (APC's) spielen Toll-like-Rezeptoren (TLR's) eine Schlüsselrolle. Bei Infektionen des ZNS werden diese Rezeptoren hochreguliert; im Mausmodell kam es im Rahmen einer Pneumokokken-Meningitis zur gesteigerten Expression von TLR2, TLR4 und TLR9 - mRNA (Böttcher et al. 2003). TLR2 erkennt LTAs und andere Zellwandbestandteile (Schröder et al. 2003). Bei Knock-out-Mäusen, die TLR2 nicht exprimieren konnten, kam es unter Inokkulation mit Pneumokokken zu vermehrten Komplikationen und erhöhten Bakterien-Titern (Echchannaoui et al. 2002, Koedel et al. 2003). TLR4 erkennt das Toxin Pneumolysin (Malley et al. 2003, Ebert et al. 2005) und TLR9 wird durch sich wiederholende CpG-Sequenzen bakterieller DNS aktiviert (Hemmi et al. 2000, Tauber et al. 2009). Die Stimulation von TLRs führte zur Aktivierung von MyD88, welches unabdingbar ist, um eine adäquate Immunantwort hervorzurufen (Koedel et al. 2004, Ribes et al. 2013). 
Tierexperimentell konnte nachgewiesen werden, dass vor allem Teile der Zellwand und Lipopolysaccharide (LPS) für die Entstehung einer Entzündungsreaktion verantwortlich sind. So verursachen bekapselte wie unbekapselte Stämme von $S$. pneumoniae eine Entzündungsreaktion der Meningen. Die Injektion von Polysaccharidkapseln führte im Tiermodell zu keiner Entzündung, die intrathekale Verabreichung der Zellwandbestandteile hingegen führte zu einer ausgeprägten Entzündungsreaktion (Tuomanen et al. 1985 b). Insbesondere die Zellwandbestandteile Teichonsäure und Lipoteichonsäure sind es, die nach Inokulation zu einer ausgeprägten Entzündungsreaktion führen. So können diese Zellwandbestandteile allein eine meningeale Entzündungsreaktion provozieren (Tuomanen et al. 1985 a, Tuomanen et al. 1985 b).

Wichtigste Auslöser einer Immunantwort sind Zellwandbestandteile (wie LPS bei gramnegativen Erregern oder LTA bei grampositiven Erregern), bakterielle DNA und bakterienspezifische Pathogenitätsfaktoren wie das Pneumolysin, die spontan während des Bakterienwachstums freigesetzt werden (Nau und Brück 2002). Diese proinflammatorischen bakteriellen Stoffwechselprodukte werden nach Gabe bakteriolytischer Antibiotika wie B-Laktam-Antibiotika oder Vancomycin in besonders hohen Konzentrationen freigesetzt (Nau und Eiffert 2002). Zu beachten ist auch, dass Antibiotikakonzentrationen deutlich über der minimalen Hemmkonzentration des jeweiligen Organismus im Allgemeinen zu einer geringeren Freisetzung bakterieller Stoffwechselprodukte führen als eine Antibiotikakonzen-tration, die nahe an der minimal inhibierenden Konzentration (MIC) liegt (Nau und Eiffert 2005, Stuertz et al. 1998).

Ein besonders wichtiger Pathogenitätsfaktor von $S$. pneumoniae ist Pneumolysin (Ply), da es sowohl direkt zytotoxisch wirkt als auch proinflammatorische Eigenschaften aufweist (Mitchell 2000). Es erleichtert den Pneumokokken die Besiedelung der Mukosa durch direkte Schädigung der ziliären Clearance (s.o.) und schützt sie vor den Angriffen des Kom- 
plementsytems, indem es die Opsonisation durch selbiges beeinträchtigt (Quin et al. 2007). Außerdem wird vermutet, das es die Blut-Hirn-Schranke schädigt und somit die Einwanderung in den Liquor fördert, da in vitro eine Schädigung der Endothelzellschicht beobachtet wurde (Zysk et al. 2001). Es wird von beinahe allen klinisch isolierten Stämmen von S. pneumoniae gebildet, so produzierten 112 von 113 Isolaten in einer klinischen Studie Pneumolysin (Kanclerski und Möllby 1987). Es gehört zur Gruppe der Cholesterol-abhängigen Zytolysine und ist in der Lage, transmembranäre Poren auszubilden, die zur Lyse der betroffenen Zelle führen (Kelly und Jedrzejas 2000). Das Ausmaß der Schädigung hängt dabei unmittelbar von der Konzentration und der Wirkungsdauer ab. Ply induziert einen massiven Einstrom von Calciumionen in die Zelle, unabhängig von den zelleigenen Calciumkanälen (Stringaris et al. 2002). Es aktiviert das Komplementsystem sowie zahlreiche Gene (Marriott et al. 2008), außerdem wirkt es neurotoxisch und apoptosefördernd (Braun et al. 2002, Stringaris et al. 2002). In niedrigen Dosen beeinträchtigt es die Funktion des Zytoskelettes (lliev et al. 2009). Auf ortsständige Zellen des Immunsystems wie Mikrogliazellen wirkt Pneumolysin, vor allem in geringeren Konzentrationen, proinflammatorisch; in höheren Konzentrationen reduziert es das Überleben der Zellen deutlich (Ebert et al. 2005). Welch wichtige Rolle dieses Protein spielt, wird daran deutlich, dass Stämme von $S$. pneumoniae, die aufgrund einer Mutation die Fähigkeit zur Pneumolysinbildung eingebüßt haben, deutlich weniger virulent sind $(\mathrm{Pa}-$ ton et al. 1993). Im Meningitis-Mausmodell resultierte die Infektion mit Plydefizienten Pneumokokken in einer geringeren Ausprägung der klinischen Symptome sowie längeren Überlebenszeit der Tiere; der Grad der meningealen Entzündung und der neuronale Schaden veränderte sich aber im Vergleich zu Ply-produzierenden Pneumokokken nicht statistisch signifikant (Wellmer et al. 2002). Bereits in früheren Studien gab es deutliche Hinweise auf eine verminderte Freisetzung von Ply unter Verwendung nicht-lytischer Antibiotika im Vergleich zur Behandlung mit lytischen Präparaten (Spreer et al. 2003). 
Durch die Immunantwort des Organismus kommt es zur Ausbildung der typischen klinischen Symptome wie Entzündung, Hirnödem und letztlich auch zu bleibenden neurologischen Schäden. Bei der bakteriellen Meningitis sind primär die Leptomeningen betroffen, es können aber auch andere Strukturen betroffen sein; so kann es zu einem ventrikulären oder auch subduralen Empyem kommen (Swartz 1984). Die Einwanderung von Leukozyten in den Liquor ist wichtig, um die Erreger zu bekämpfen, gleichzeitig können dadurch aber auch vermehrt Schäden im ZNS auftreten. Leukozyten setzten verschiedene ROS (reactive oxygen species) und RNS (reactive nitrogen species) frei, die das Hirngewebe erheblich schädigen können, aber auch die Pneumokokken selbst produzieren zellschädigende Substanzen wie $\mathrm{H}_{2} \mathrm{O}_{2}$; bakterielles $\mathrm{H}_{2} \mathrm{O}_{2}$ reagiert mit $\mathrm{NO}$, wobei das besonders aggressive Peroxynitrit entsteht (Hoffmann et al. 2006). Peroxynitrit reagiert mit der Zellmembran und schädigt diese (Klein et al. 2006). Des Weiteren kommt es zu DNA-Fragmentation und durch Aktivierung von PARP (Poly-ADP-Ribose-Polymerase) zum Energieverlust und Zelltod (Scheld et al. 2002).

Lipoteichonsäuren führen zu einer verstärkten Produktion und Freisetzung von MMP-9 (Metalloproteinasen) im Rattenmodell, die sowohl von ortsständigen als auch von eingewanderten Leukozyten freigesetzt werden (Hsieh et al. 2010). MMPs schädigen die Blut-Hirn-Schranke und erhöhen das Ausmaß des neuronalen Schadens (Sellner und Leib 2006).

Im Rahmen dieser Schrankenstörung nehmen Protein- und Laktatkonzentration zu, auch Prostaglandin $\mathrm{E}_{2}$ lässt sich verstärkt nachweisen, während die Glukosekonzentration abnimmt.

Hinweisend auf die Beteiligung der Zytokine bei der Ausbildung einer Entzündung und Schrankenstörung ist die Tatsache, dass die alleinige Inokulation von IL-1 $\beta$ und TNF- $\alpha$ in den Liquor eine Pleozytose auslösen kann (Quagliarello et al. 1991, Ramilo et al. 1990). Die Störung der Blut-HirnSchranke und die damit einhergehende gesteigerte Permeabilität des Gefäßendothels fürt zu einem vasogenen Hirnödem, wobei der Hauptmediator der Hyperämie im Gehirn Stickstoffmonoxid (NO) ist (Ködel 1996). 
Im Rahmen der Meningitis kommt es auch zu zerebrovaskulären Komplikationen. Eine retrospekive Studie mit 87 Patienten zeigte, wie häufig dies vorkommen kann: $21,8 \%$ arterielle und $9,2 \%$ venöse Komplikationen sowie 9,2\% hämorrhagische Zwischenfälle (Kastenbauer und Pfister 2003). Ursächlich dafür ist wahrscheinlich eine im Rahmen der Entzündung auftretende Koagulopathie, aber auch Veränderungen am Endothel und lokale Entzündungsreaktionen können die Perfusionsstörungen begünstigen (Vergouwen et al. 2010).

Durch die gesteigerte Bildung und Freisetzung toxischer Metabolite der Leukozyten sowie durch die Freisetzung bakterieller Endotoxine und Zellwandbestandteile kommt es zum Untergang zahlreicher Neurone mit der Folge eines zytotoxischen Hirnödems. Als Folge des Ödems kommt es zu einem erhöhten intrakraniellen Druck mit der Gefahr eines Einklemmungssyndroms sowie zu einer Minderperfusion des Gehirns. Persistiert diese Minderperfusion, wird die Autoregulation der zerebralen Gefäße gestört oder sogar aufgehoben (Tureen et al. 1990), wodurch das Hirnödem weiter verstärkt wird. Die Folge sind unkontrollierte Durchblutungsverhältnisse im Sinne einer Hypo- oder Hyperperfusion mit der Folge ischämischer Schäden (Quagliarello und Scheld 1992). Insgesamt unterscheidet man drei Formen des Hirnödems: das zytotoxische, das vasogene und das interstitielle Ödem (Fishman 1982). Bei der bakteriellen Meningitis treten meist Mischformen auf. 


\subsection{Neuronaler Schaden bei bakterieller Meningitis}

Unter Zelltod versteht man den irreversiblen Verlust der zellulären Struktur und Funktion. Er ist physiologisch im Rahmen der Embryogenese und bei der Zellerneuerung von Wechselgeweben. Der Zelltod tritt aber auch als Folge unterschiedlicher Arten der Zellschädigung auf. Man unterscheidet zwei Formen des Zelltodes: Nekrose und Apoptose (Buja et al. 1993).

Bei der bakteriellen Meningitis kommt es zu Apoptosen im Gyrus dentatus hippocampi (CA1-4) sowie zu Nekrosen im Neokortex und in anderen Hirnregionen (Nau et al. 1999 a, Zysk et al. 1996). Es können also während der Erkrankung beide Formen des Zelltodes auftreten.

\subsubsection{Nekrose}

Sie erfolgt nach einer massiven Zellschädigung durch eine plötzliche und schwere Beeinträchtigung des Zellstoffwechsels wie zum Beispiel Sauerstoffmangel, physikalische Einflüsse (Kälte, Wärme, Strahlung), Chemikalien oder auch bakterielle Toxine. Durch Störung des Energiestoffwechsels kommt es zum Mangel an ATP und infolgedessen zum Ausfall der transmembranären Ionenpumpen. Die Zelle verliert dadurch ihre Fähigkeit, den osmotischen Druck zu regulieren.

Zunächst kommt es zur Kondensation und Verklumpung des nukleären Chromatins, diese Prozesse sind prinzipiell noch reversibel. Es folgt das Anschwellen einzelner Organellen und schließlich der ganzen Zelle. Schließlich kommt es zur Pyknose, Karyorrhexis und Karyolyse sowie zu mitochondrialen Veränderungen, welche irreversibel sind. Letztlich rupturieren die Plasmamembran und die Membranen der Organellen (Buja et al. 1993), die Freisetzung des Zellinhaltes führt anschließend zu einer 
Entzündungsreaktion (Cohen 1993). Charakteristisch sind auch Veränderungen des Elektrolythaushaltes, so kommt es beispielsweise zum Anstieg des intrazellulären Kalziumspiegels (Buja et al. 1993, Morris et al. 1989).

\subsubsection{Apoptose}

Die Apoptose unterscheidet sich grundlegend von der Nekrose, da sie ein geordneter, nach einem bestimmten Muster ablaufender Prozess ist, der nicht zur Entzündung führt. Erstmals wurden diese Vorgänge 1972 beschrieben (Kerr et al. 1972): Zunächst bilden sich Ausstülpungen entlang der Plasmamembran (Zeiosis). Es kommt zum Schrumpfen der Zelle und zur Kondensation des Zytoplasmas bei ansonsten unauffälligen Organellen (Wyllie 1981). Im Zellkern kommt es zu Chromatinverdichtungen, schließlich zerfällt er in kleine Kügelchen. Die Zelle zerfällt in die sogenannten apoptotischen Körperchen, membranumschlossene Fragmente, die anschließend phagozytiert werden (Schwartz und Osborne 1993). Da keine Zellbestandteile freigesetzt werden wie dies bei der Nekrose der Fall ist, kommt es auch zu keiner Entzündungsreaktion.

Es gibt eine ganze Reihe von Genen, die bei der Apoptose eine wichtige Rolle spielen und diese entweder fördernd oder hemmend beeinflussen. Die Genprodukte von p53 treiben myeloide und epitheliale Zellen in die Apoptose (Yonish-Rouach et al. 1991, Shaw et al. 1992), dagegen wirkt bcl-2 antiapoptotisch (Nunez et al. 1990, Vaux et al. 1988). Physiologischerweise spielt die Apoptose eine wichtige Rolle während der Embryogenese und der Zelldifferenzierung von Wechselgeweben. Außerdem ist das Immunsystem in der Lage über die zytotoxischen T-Zellen die Apoptose bei anderen Zellen zu induzieren (Sellins und Cohen 1991). Auch können pathologische Vorgänge wie Entzündung, Tod von Tumorzellen (Williams 1991) oder virale Infektionen (Vaux et al. 1994) zur Apoptose führen. Ein Anstieg des zytosolischen Kalziums wirkt ebenfalls 
Apoptosefördernd (McConkey et al. 1989), während Entzündungsmediatoren wie GM-CSF, C5a und LPS bei neutrophilen Granulozyten einen hemmenden Einfluss auf die Apoptose ausüben (Lee et al. 1993). Im Rahmen einer Pneumokokken-Meningitis können von den Erregern freigesetzte Toxine wie $\mathrm{H}_{2} \mathrm{O}_{2}$ oder Pneumolysin ebenfalls die Apoptose induzieren (Bermpohl et al. 2005). Besonders häufig kommt es zu neuronalen Apoptosen im Gyrus dentatus der Formatio hippocampi (Meli et al. 2002, Zysk et al. 1996, Leib et al. 1996, Nau et al. 1999 a). Sie kann sowohl Caspasen-abhängig als auch Caspasen-unabhängig induziert werden, beide Mechanismen kommen bei der Pneumokokken-Meningitis zum Tragen (Mitchell et al. 2004).

Es gibt also zahlreiche Substanzen und Mechanismen, die letztlich zur Auslösung des morphologischen Bildes der Apoptose führen können.

\subsection{Antibiotische Therapie}

Die antibiotische Therapie der bakteriellen Meningitis richtet sich nach dem auslösenden Erreger. Da es sich bei der bakteriellen Meningitis um einen Notfall handelt, muss möglichst schnell mit der antibiotischen Therapie begonnen werden.

Eine antibiotische Therapie sollte innerhalb der ersten 30 Minuten nach Ankunft in der Notaufnahme begonnen werden. In Studien fanden sich längere Intervalle, durchschnittlich zwischen 2 und 5 Stunden, bis zum Behandlungsbeginn (Bryan et al. 1986).

Eine Verzögerung des Beginns der Antibiose wiederum korrelierte direkt mit einem Anstieg der Sterblichkeit, so zeigte sich nach bereits 4 bis 6 Stunden Verzögerung ein sprunghafter Anstieg der Letalität (Proulx et al. 2005, Auburtin et al. 2006). 
Die kalkulierte antibiotische Therapie der bakteriellen Meningitis in Deutschland basiert auf einer Therapie mit einem Cephalosporin der dritten Generation (z.B. Ceftriaxon oder Cefotaxim) in Kombination mit einem Aminopenicillin (z.B. Ampicillin) parenteral. Nach erfolgtem Erregernachweis muss dann entsprechend des Antibiogramms die Therapie angepasst werden.

Eine Übersicht über die geltende Leitlinie bei Diagnostik und Therapie der bakteriellen Meningitis geben die folgenden Tabellen der DGN (Deutsche Gesellschaft für Neurologie).

(Auszug aus: Leitlinien für Diagnostik und Therapie in der Neurologie, Stand: September 2012, DGN):

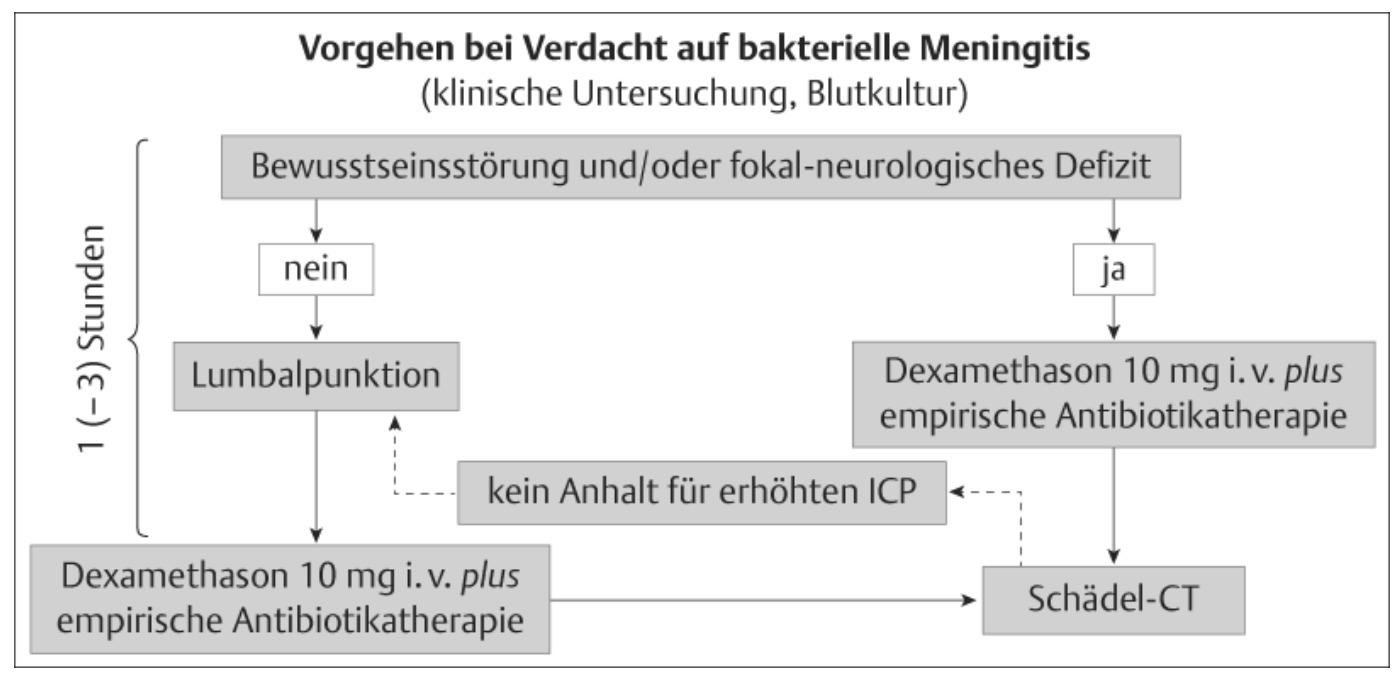

Abbildung 1: Diagnostisches und therapeutisches Prozedere bei Verdacht auf bakterielle Meningitis (DGN, 2012). 


\begin{tabular}{|c|c|}
\hline Altersgruppe & Empfohlenes Antibiotikaregime \\
\hline Neugeborene & Cefotaxim plus Ampicillin ${ }^{1}$ \\
\hline Kleinkinder und Kinder & Cephalosporin der 3. Generation 2, 3 \\
\hline \multicolumn{2}{|l|}{ Erwachsene: } \\
\hline $\begin{array}{l}\text { - gesund, keine Abwehrschwäche, ambulant } \\
\text { erworben („community-acquired“) }\end{array}$ & Cephalosporin der 3. Generation ${ }^{2}$ plus Ampicillin ${ }^{4}$ \\
\hline $\begin{array}{l}\text { - nosokomial (z. B. nach neurochirurgischer } \\
\text { Operation oder Schädel-Hirn-Trauma) }\end{array}$ & $\begin{array}{l}\text { Vancomycin plus Meropenem oder Vancomycin plus } \\
\text { Ceftazidim }{ }^{5} \text { (plus Metronidazol bei operativem } \\
\text { Zugang durch Schleimhäute) }\end{array}$ \\
\hline - abwehrgeschwächte, ältere Patienten & Cephalosporin der 3. Generation plus Ampicillin \\
\hline - Shunt-Infektion & $\begin{array}{l}\text { Vancomycin plus Meropenem oder Vancomycin plus } \\
\text { Ceftazidim }\end{array}$ \\
\hline \multicolumn{2}{|c|}{$\begin{array}{l}1 \text { Zusätzlich kann ein Aminoglykosid - insbesondere bei schwerstkranken Patienten - eingesetzt werden } \\
\text { (DGPI 2009). }\end{array}$} \\
\hline \multicolumn{2}{|l|}{2 z. B. Cefotaxim oder Ceftriaxon } \\
\hline \multicolumn{2}{|c|}{3 laut Empfehlungen der Deutschen Gesellschaft für Pädiatrische Infektiologie (DGPI 2009) } \\
\hline \multirow{4}{*}{\multicolumn{2}{|c|}{$\begin{array}{l}4 \text { In Regionen mit einem hohen Anteil Penicillin-resistenter Pneumokokken (z. B. Frankreich, Spanien, } \\
\text { Ungarn, Australien, Neuguinea, Südafrika und in einzelnen Gebieten in Amerika) wird in der } \\
\text { Initialbehandlung eine Kombinationstherapie mit Ceftriaxon + Vancomycin + Ampicillin oder Ceftriaxon + } \\
\text { Rifampicin + Ampicillin empfohlen. In der Schweiz sind etwa } 10 \% \text { der Pneumokokken gegenüber } \\
\text { Penicillinen nicht sensibel. }\end{array}$}} \\
\hline & \\
\hline & \\
\hline & \\
\hline \multicolumn{2}{|c|}{$\begin{array}{l}5 \text { oder Vancomycin plus Cefepim. Einheitliche Empfehlungen liegen in der Literatur nicht vor. Bei } \\
\text { nachgewiesener Staphylokokken-Ventrikulitis stellt die intraventrikuläre Vancomycingabe (z. B. } 10 \text { mg/d bei } \\
\text { Erwachsenen) eine wichtige Therapieoption dar (Pfausler et al. 2003). }\end{array}$} \\
\hline
\end{tabular}

Abbildung 2: Initiale Antibiotikatherapie der bakteriellen Meningitis bei noch ausstehendem Erregernachweis (DGN, 2012).

\subsubsection{Ceftriaxon}

Ceftriaxon ist ein Cephalosporin der dritten Generation und gehört zur Gruppe der B-Laktam-Antibiotika mit breitem Wirkungsspektrum. Es hat eine lange Halbwertszeit (mind. $8 \mathrm{~h}$ ), eine hohe Plasmaproteinbindung und es wird sowohl über die Leber als auch über die Nieren ausgeschieden (Dailly et al. 2012). Seine Wirkung basiert auf einer Synthesehemmung des Mureingerüstes der Zellwand (Estler 1995), wobei es nur auf proliferierende Bakterien wirkt. Durch den Angriff auf die Zellwand wirkt es bakteriolytisch. Insbesondere bei Pneumokokken tritt die Destabilisierung 
der Zellwand durch den Angriff am Muramyl-Gerüst sehr schnell ein (Figueiredo et al. 1992, Nau et al. 1997). Durch diese Destabilisierung kommt es rasch zur Freisetzung proinflammatorischer Zellwandbestandteile (Tuomanen et al. 1985 a, Tuomanen et al. 1985 b). Ceftriaxon ist bei ZNS-Infektionen durch verschiedene Erreger, aber auch im Rahmen vieler anderer Infektionen einsetzbar. Es passiert in ausreichendem Maße die Blut-Hirn-Schranke im Falle entzündeter Meningen, aber auch bei nicht entzündeten Meningen, so das therapeutisch wirksame Konzentrationen im ZNS erreicht werden (Nahata et al. 1986, Nau et al. 1993). Es ist wirksam gegenüber Haemophilus influenzae, Neisseria meningitidis, Borrelia burgdorferi, sowie gegenüber den meisten gramnegativen aeroben Stäbchen. Eine etwas geringere Empfindlichkeit weisen grampositive Kokken wie Staphylokokken oder Penicillin G-resistente Pneumokokken auf (Klugman 1990, Nau 1992). Trotzdem ist Ceftriaxon bei Infektionen mit Pneumokokken mit verminderter Empfindlichkeit gegenüber Penicillin (Penicillin MHK 0,1-1,0 mg/l) das Antibiotikum der Wahl (Rockowitz und Tunkel 1995).

\subsubsection{Rifampicin}

Rifamycine stellen eine Gruppe primär bakterizider Antibiotika dar. Rifampicin als Vertreter dieser Substanzgruppe in der vorliegenden Studie hemmt die DNA-abhängige RNA-Polymerase und somit die RNA- und Proteinbiosynthese der Bakterien. Es bindet an die $\beta$-Untereinheit der RNA-Polymerase und verhindert dadurch die Translation (Vesely et al. 1998). Es ist bakterizid, aber nicht bakteriolytisch. Rifamycine haben im Vergleich zu anderen Antibiotika die stärkste antimykobakterielle Aktivität, wobei es auch gegenüber fast ruhenden Erregern noch wirksam ist (Estler, Pharmakologie und Toxikologie, 1995). Des Weiteren besteht eine hohe Aktivität gegenüber häufigen Meningitiserregern wie $S$. pneumoniae, $N$. meningitidis, H. influenzae und L. monozytogenes (Hof 2003, Yogev 
und Guzman-Cottrill 2005). So wird es prophylaktisch den Kontaktpersonen eines an Meningokokken- oder $H$. influenzae- Meningitis erkrankten Patienten verabreicht (Leitlinien der DGN 2012). Im Gegensatz zu bakteriolytischen Antibiotika induziert Rifampicin keine zusätzliche Freisetzung proinflammatorischer und toxischer bakterieller Bestandteile ( $\mathrm{Nau}$ und Eiffert 2005, Spreer et al. 2003). Auch die Letalität ist unter einer Therapie mit Rifampicin im Tiermodell bei Meningitis und Sepsis niedriger als unter einer Therapie mit einem B-Laktam Antibiotikum (Nau und Eiffert 2002, $\mathrm{Nau}$ et al. 1999 b). Aufgrund seiner günstigen pharmakokinetischen Eigenschaften (ausgeprägte Lipophilie) gelangt es schnell ins ZNS und wird aus dem Liquor langsamer eliminiert als aus dem Serum (Nau et al. 1992, Nahata et al. 1990). Es ist gegen die meisten Erreger der bakteriellen Meningitis wirksam (s.o.), ohne dass es bislang signifikante Resistenzen gibt. Es gibt daher bereits die Empfehlung zur Kombinationstherapie mit Rifampicin und Ceftriaxon für die Behandlung der bakteriellen Meningitis in Gebieten mit Penicillin-resistenten Pneumokokken (Klugman et al. 1995, Tunkel et al. 2004). Trotzdem sollte es wegen der potentiellen Gefahr der raschen Resistenzbildung nur in Kombination mit anderen Antibiotika verabreicht werden.

\subsubsection{Tigezyklin}

Tigezyclin, ein Minocyclin-Derivat, gehört zur Gruppe der GlycylcyclinAntibiotika, einer Weiterentwicklung der Tetracyclin-Antibiotika. Die Wirkung basiert auf einer reversiblen Bindung an die 30S-Untereinheit der bakteriellen Ribosomen, wodurch die Proteinbiosynthese gehemmt wird (Rose und Rybak 2006). Glycylcycline weisen eine hohe Aktivität gegenüber grampositiven und gramnegativen Erregern auf sowie gegenüber Anaerobiern und multi-resistenten Keimen; außerdem erwiesen sie sich in Studien als effektive Behandlungsmöglichkeit bei komplizierten Infektionen der Haut und komplizierten intraabdominellen Infektionen (Rose und 
Rybak 2006). Sie sind wirksam gegen Methicillin-resistente Staphylokokken (MRSA), Penicillin-resistente Streptococcus pneumoniae - Stämme und gegen Vancomycin-resistente Enterokokken (Zhanel et al. 2004). Eine gute Wirksamkeit besteht auch gegenüber einigen gramnegativen Bakterien: Acinetobacter baumannii, Beta-Laktamase-produzierende Klebsiella pneumoniae und Escherichia coli (Rose und Rybak 2006). Es zeigte sich eine gute Gewebegängigkeit von Tigezyklin für Lunge und Kolon, die Konzentration von Tigezyklin im Liquor dagegen ist deutlich niedriger (Rodvold et al. 2006). Bei nicht entzündeten Meningen war die Liquorkonzentration 18 bis 24 Stunden nach Injektion höher als 1,5 Stunden nach der Gabe von Tigezyklin (1.5h: 0.016-0.095 mg/L; 18-24h: 0.33-0.52 mg/L). Diese Werte lagen aber immer noch deutlich unter den Konzentrationen, die im Liquor nach Gabe von Doxycyclin erreicht werden (0.10-2.00 mg/L); es sollten also Studien folgen, bei denen die Penetration in den Liquor im Falle entzündeter Meningen untersucht wird, bevor Tigezyklin bei ZNSInfektionen zur Anwendung kommt (Rodvold et al. 2006).

\subsection{Adjuvante Therapie}

Verschiedene adjuvante Therapieansätze sollen den mit der Bakteriolyse einhergehenden neuronalen Schaden begrenzen. Von diesen Ansätzen scheinen allerdings nur wenige einen positiven Effekt zu haben, einer davon ist die adjuvante Therapie mit Dexamethason.

Es konnte gezeigt werden, dass Patienten nach einer PneumokokkenMeningitis signifikant häufiger kognitive Defizite aufwiesen als Patienten, die eine Meningokokken-Meningitis durchgemacht hatten (Weisfelt et al. 2006 b). Der auslösende Erreger scheint eine wichtige Rolle bei der Wahl der adjuvanten Therapie zu spielen. So konnte die Rate an Hörschäden im Falle einer Infektion mit $H$. influenzae $b$ bei Kindern durch den frühzeitigen Einsatz von Dexamethason gesenkt werden (Odio et al. 1991), 
gleichzeitig kommt es bei einer Infektion mit Cephalosporin-resistenten Pneumokokken durch die begleitende Therapie mit Dexamethason möglicherweise zu nachteiligen Effekten (Esposito et al. 2013). Sowohl bei Erwachsenen als auch bei Kindern mit Meningokokken-Meningitis gibt es derzeit keinen Anhalt, die begleitende Glukokortikoidgabe zu empfehlen (Esposito et al. 2013). Ein eindeutig nachteiliger Effekt der Therapie mit Dexamethason im Rahmen einer Meningokokken-Meningitis konnte bislang allerdings ebenfalls nicht erbracht werden (Heckenberg et al. 2012). Es muss also im Einzelfall und abhängig vom auslösenden Erreger entschieden werden, ob eine Therapie mit Glukokortikoiden nach erfolgtem Behandlungsbeginn fortgesetzt werden soll. Entsprechend der aufgeführten Ergebnisse vorrangegangener Studien empfiehlt die DGN den Abbruch der Therapie mit Dexamethason, sobald Meningokokken isoliert wurden.

Trotz der teils potentiell negativen und schädigenden Effekte einer adjuvanten Glukokortikoidtherapie (Zysk et al. 1996) gibt es keinen eindeutigen Anhalt für nachweisbare Schäden der kognitiven Funktionen bei betroffenen Patienten (Weisfelt et al. 2006 b). Bei der Auswertung von 25 Studien mit insgesamt über 4000 Patienten aller Altersgruppen wurde kein signifikanter Rückgang der Mortalität beschrieben, allerdings ein Rückgang von Hörschäden sowie neurologischen Folgeschäden (Brouwer et al. 2013).

Aufgrund der aktuellen Datenlage wird die adjuvante Therapie mit Dexamethason von der DGN im Falle einer ambulant erworbenen Meningitis empfohlen und nach erfolgtem Erregernachweis entsprechend angepasst (DGN 2012). 


\subsection{Ziel der Arbeit}

Ziel der Arbeit war es, einen neuen Ansatz in der Therapie der bakteriellen Meningitis zu überprüfen. Die Idee des sequentiellen Behandlungskonzeptes mit Rifampicin war es, den neuronalen Schaden, der indirekt durch die Gabe von $\beta$-Laktam-Antibiotika und die darauffolgende Bakteriolyse erhöht wird, signifikant zu reduzieren, um so das Langzeitergebnis der Patienten zu verbessern und bleibende Schäden zu mindern. Die alleinige Gabe bakteriolytischer Antibiotika führt zu einer verstärkten Freisetzung proinflammatorischer Substanzen und in der Folge zu einer stärkeren Entzündungsreaktion mit ausgeprägter Gewebsschädigung (Nau und Eiffert 2005). Im Tiermodell wurde dieses Behandlungskonzept, basierend auf einer nicht-bakteriolytischen, kurzen Vorbehandlung mit Rifampicin und der anschließenden Gabe von Ceftriaxon überprüft. In früheren Versuchen hatte sich bereits gezeigt, das die Vorbehandlung mit Rifampicin und die anschließende Gabe von Ceftriaxon im Intervall nach 6 Stunden zu einer signifikant niedrigeren Freisetzung von Pneumolysin führte (Spreer et al. 2003). Da ein derart langes Intervall in der Klinik nicht umsetzbar ist (empfohlen wird die möglichst frühzeitige Gabe eines ß-Laktam-Antibiotikums) wählten wir ein kurzes Intervall von nur 1 Stunde.

Trotz der stark verminderten Freisetzung proinflammatorischer Stoffwechselprodukte unter einer Therapie mit Rifampicin wäre eine Monotherapie mit diesem Wirkstoff nicht indiziert, da ansonsten die Gefahr der Resistenzentwicklung bestünde. Insofern stellt das vorliegende Konzept einen vielversprechenden Ansatz dar; zum einen, um den neurologischen Begleitschaden deutlich zu reduzieren und zum anderen, um eine gleichermaßen wirkungsvolle Behandlung zu gewährleisten.

Dieses Konzept wurde in vitro in Bakterienkulturen und im Kaninchenmodell der bakteriellen Meningits in vivo überprüft.

Zur Überprüfung hinsichtlich der Effektivität der Vorbehandlung mit Rifampicin wurden Liquorproben von jedem Tier entnommen und auf die 
Protein/Laktat-Konzentrationen sowie Leukozytenzahlen, Prostaglandin $E_{2}$, DNS und Pneumolysingehalt hin untersucht. Die Quantifizierung von Apoptosen im ZNS, die den neuronalen Schaden widerspiegeln, erfolgte histologisch. 


\section{Material und Methoden}

\subsection{Testorganismen/Substanzen und Dosierungen}

In dieser Studie wurde ein Penicillin-sensitiver Stamm von Streptococcus pneumoniae Typ 3 eingesetzt, der von einem Patienten mit bakterieller Meningitis isoliert worden war (freundlicherweise überlassen von M.G. Täuber, Universität Bern, Schweiz).

S. pneumoniae wurde kultiviert und aliquotiert bei einer Konzentration von $10^{10}$ (Kolonie-bildende Einheiten $/ \mathrm{ml} ; \mathrm{CFU} / \mathrm{ml}$ ) und bei $-80^{\circ} \mathrm{C}$ aufbewahrt. MIC (minimal inhibitory concentration) und MBC (minimal bactericidal concentration) lagen bei $0,015 \mu \mathrm{g} / \mathrm{ml}$ und $0,03 \mu \mathrm{l} / \mathrm{ml}$ für Ceftriaxon und bei $0,03 \mu \mathrm{g} / \mathrm{ml}$ und $0,06 \mu \mathrm{g} / \mathrm{ml}$ für Rifampicin.

Des Weiteren wurde E. coli verwendet (freundlicherweise überlassen von G. Zysk), ein Isolat aus einem Säugling mit Meningitis (Serotyp O18/K1). Das Stamm-Inokulum enthielt $4 \times 10^{10} \mathrm{CFU} / \mathrm{ml}$.

Folgende Pharmaka wurden verwendet:

- Ceftriaxon (Rocephin®, Hoffmann-La Roche, Grenzach-Wyhlen, Deutschland), Dosierung: $125 \mathrm{mg} / \mathrm{kg} \mathrm{KG}$ i.v. als Einmalgabe

- Rifampicin (Rifa®, Grünenthal, Stolberg, Deutschland), Dosierung: $20 \mathrm{mg} / \mathrm{kg} \mathrm{KG}$ i.v. als Einmalgabe

- Tigezyklin (Tygacil, Wyeth Pharmaceuticals, Hampshire, UK)

- Anästhesie mit Ketamin (CP-Plasma, Burgdorf), 25 mg/kg KG; XylazinHydrochlorid (Rompun, Bayer AG, Leverkusen), $5 \mathrm{mg} / \mathrm{kg} \mathrm{KG;} \mathrm{Urethan}$ (Sigma, Taufkirchen), 0,15 mg/ml, Verabreichung in Dosen von 5-10 ml; Tötung der Tiere mit Thiopental (Trapanal,Byk Gulden, Konstanz). 


\subsection{Bestimmung von MHK und MBK}

Die minimale Hemmkonzentration (MHK) definiert die niedrigste Konzentration einer Substanz, bei der eine bakterielle Vermehrung der zu testenden Keime mit bloßem Auge nicht mehr wahrgenommen werden kann.

Die minimale bakterizide Konzentration (MBK) ist festgelegt als die niedrigste Konzentration eines Antibiotikums, bei der die inokulierte Keimzahl um $99,9 \%$ reduziert wird.

Es wurden die MHK und MBK von Tigezyklin bei den Erregern E. coli und S. peumoniae bestimmt, wobei Tigezyklin nur bei den in vitro Versuchen zum Einsatz kam.

Zur Bestimmung der MHK wurden $60 \mathrm{ml}$ TSB (tryptic soy broth) mit $5 \mu \mathrm{l}$ des Inokulums $\left(10^{10} \mathrm{CFU} / \mathrm{ml}\right)$ von $S$. pneumoniae beimpft und weitere $50 \mathrm{ml}$ TSB wurden mit $8 \mu \mathrm{l}$ des Inokulums $\left(1,5 \times 10^{7} \mathrm{CFU} / \mathrm{ml}\right)$ von $E$. coli beimpft. Von diesen Ansätzen wurde jeweils eine Verdünnungsreihe mit abnehmenden Antibiotikakonzentrationen angefertigt, die Proben wurden für 24 Stunden bei $37^{\circ} \mathrm{C}$ inkubiert. Für jeden der zu kontrollierenden Keime wurden 2 Kontrollproben ohne Antibiotika mit inkubiert. Anschließend wurde die MHK abgelesen: Kulturen, in denen es zu keinem sichtbaren Wachstum (Trübung) mehr gekommen war, enthielten die MHK des verwendeten Antibiotikums.

Die Probe, in der als erstes keine Trübung mehr auftrat, sowie die übrigen Proben ohne sichtbare Trübung wurden 1:10 mit NaCl verdünnt. Von dieser Verdünnung wurde jeweils $1 \mathrm{ml}$ auf Blutagar ausgeplattet und für weitere 24 Stunden bei $37^{\circ} \mathrm{C}$ bebrütet. Anhand des Wachstums auf den Platten konnte so auch die MBK ermittelt werden. 


\subsection{Kultivierung und Lagerung der Bakterien- stämme}

Streptococcus pneumoniae Typ 3 wurde auf Blutagar vermehrt. Dazu wurden sechs Blutagarplatten mit einer Keimlösung beimpft und für 24 Stunden bei $37^{\circ} \mathrm{C}$ bebrütet. Anschließend wurde auf die ersten beiden Platten je $1 \mathrm{ml} \mathrm{NaCl}$ gegeben, dann wurden die Kolonien mit einem sterilen Schaber vorsichtig abgetragen. Diese Lösungen wurden auf die dritte Platte übertragen, hier ohne vorherige Zugabe von $\mathrm{NaCl}$. Nach erneutem Lösen der Kolonien mittels Schaber auf der dritten Platte wurde die so gewonnene Erregersuspension in ein Eppendorfgefäß gegeben und anschließend zu Proben von je $20 \mu \mathrm{l}$ aliquotiert und bei $-80^{\circ} \mathrm{C}$ aufbewahrt. Analog zu diesem Vorgehen wurde mit den drei anderen Blutagarplatten verfahren. Die Keimzahlbestimmung der Aliquots erfolgte über eine Verdünnungsreihe (siehe Keimzahlbestimmung), wobei sich eine Keimdichte von $10^{10} \mathrm{CFU} / \mathrm{ml}$ ergab.

Die gleiche Vorgehensweise kam zur Kultivierung von E. coli zum Einsatz.

\subsection{Bakterielle Wachstumsreihen}

Für jeden Versuch wurde eine Flasche TSB (tryptic soy broth), die $500 \mathrm{ml}$ der Nährlösung enthielt, mit $5 \mu \mathrm{l}$ der aliquotierten Keimlösung ( $1 \mathrm{x}$ $10^{10} \mathrm{CFU} / \mathrm{ml}$ ) beimpft und für 10 Stunden bei $37^{\circ} \mathrm{C}$ bebrütet. Dann erfolgte die Aufteilung während der logarithmischen Wachstumsphase auf 6 mal $80 \mathrm{ml}$ und nach Antibiotikabeigabe die weitere Bebrütung für 12 Stunden bei $37^{\circ} \mathrm{C}$. Eine der 6 Kulturen diente als Kontrolle $(A)$ und wurde ohne die Zugabe von Antibiotika weiter kultiviert. Den anderen Subkulturen (B - F) 
wurden Antibiotika zugesetzt. Die zugesetzten Mengen an Antibiotika richteten sich nach laut Literaturangaben im Liquor erreichbaren Konzentrationen, die in vivo während der Behandlung bei einer Infektion des ZNS erreicht werden: $8 \mu \mathrm{g} / \mathrm{ml}$ für Ceftriaxon (Klugman et al. 1995) und $3 \mu \mathrm{g} / \mathrm{ml}$ für Rifampicin (Nahata et al. 1990). Drei der Kulturen wurden mit nur einem Antibiotikum beimpft $(B=$ Cef $(8 \mu \mathrm{g} / \mathrm{ml}), C=$ Rifa $(3 \mu \mathrm{g} / \mathrm{ml}), F=$ Tige $(0,1$ $\mu \mathrm{l} / \mathrm{ml})$ ), zwei weitere $(D, E)$ jeweils zuerst mit Rifa $(3 \mu \mathrm{g} / \mathrm{ml})$ und nach 30 $\min (\mathrm{E})$ beziehungsweise zwei Stunden (D) mit Ceftriaxon $(8 \mu \mathrm{g} / \mathrm{ml})$. Zum Zeitpunkt 0, 3, 6, 9 und 12 Stunden nach Zugabe der Antibiotika wurde die Keimzahl in den Proben bestimmt. Hierzu wurde jeweils $3 \times 1 \mathrm{ml}$ Flüssigkeit aus allen Proben entnommen.

\subsection{Bestimmung der Erregerkonzentration}

Zur Bestimmung der Erregerkonzentration der jeweiligen Probe wurde zunächst eine Verdünnungsreihe nach folgendem Schema hergestellt: Aus der jeweiligen $1 \mathrm{ml}$-Probe wurden $10 \mu \mathrm{l}$ entnommen und in einem Eppendorfgefäß mit $90 \mu \mathrm{l} \mathrm{NaCl}$ verdünnt (1:10). Aus diesem Eppendorfgefäß wiederum wurden $50 \mu \mathrm{l}$ entnommen und in einem weiteren Eppendorfgefäß mit $450 \mu \mathrm{l} \mathrm{NaCl}$ gemischt, um eine weitere 1:10 Verdünnung zu erhalten. Dieser Verdünnungsschritt kam weitere sechsmal zur Anwendung, wobei jedes Mal $50 \mu \mathrm{l}$ der vorherigen Verdünnung mit $450 \mu \mathrm{l} \mathrm{NaCl}$ in einem neuen Eppendorfgefäß verdünnt wurden. Nach jedem Verdünnungsschritt wurden die Proben für einige Sekunden gemischt, um eine gleichmäßige Vermischung der Erreger zu gewährleisten. Anschließend wurden von jeder Probe einer Verdünnungsreihe je $10 \mu \mathrm{l} /$ Feld auf eine in Felder unterteilte Blutagarplatte ausgeplattet und die Keimzahl nach 24 Stunden im Brutschrank bei $37^{\circ} \mathrm{C}$ abgelesen. Dies erlaubte eine Bestimmung der Keimzahl von bis zu $10^{10} \mathrm{CFU} / \mathrm{ml}$. 


\subsection{Wachstumskurven}

Die Abnahme der Bakterienkonzentration nach der Antibiotikagabe wurde logarithmisch gegen die Zeit dargestellt. Mittels Logarithmisch-linearer Regression wurde die Veränderung der Erregerkonzentration über die Zeit bestimmt ( $\Delta \log C F U / \mathrm{ml} / \mathrm{h}$ ). Insgesamt wurden zu jedem Zeitpunkt (0, 3, 6, 9 und 12 Stunden) 3 Proben eines jeden Ansatzes von je $1 \mathrm{ml}$ entnommen. Eine Probe wurde für die Verdünnungsreihe und die Messung der optischen Dichte im Photometer verwendet, die zu jedem Abnahmezeitpunkt ermittelt wurde. Mittels der optischen Dichte konnte das Ende der logarithmischen Wachstumsphase abgeschätzt werden; die Trübung der Proben entsteht zum einen durch die entsprechende Keimlast, zum anderen durch die Antibiotika-induzierte und die spontane Lyse. Die anderen zwei Proben wurden bei $3000 x g$ für 10 min zentrifugiert und die Überstände $(2 \times 500 \mu \mathrm{l}, 1 \times 20 \mu \mathrm{l})$ bei $-80^{\circ} \mathrm{C}$ aufbewahrt. Sie dienten der Quantifizierung von Pneumolysin und bakterieller DNS (DNS-Nachweis durchgeführt von Frau A. Höcht). Das Experiment fand sechs Mal an jeweils verschiedenen Tagen statt.

\subsection{Nachweis und Quantifizierung von Pneumolysin}

Die Pneumolysin-Konzentrationen aus den Kulturen und den LiquorProben wurden durch quantitatives Immunoblotting bestimmt (Spreer et al. 2003): Die Proteine in den Proben wurden durch SDS-Polyacrylamid-GelElektrophorese (SDS-PAGE) aufgetrennt und auf eine Nitrozellulosemembran übertragen $\left(0,8 \mathrm{~mA} / \mathrm{cm}^{2}\right.$ bei $\left.30 \mathrm{~V}\right)$. Anschließend wurden die entsprechenden Banden mittels Markierung durch 
Pneumolysin-spezifische Antikörper (Immundetektion, s.u.) sichtbar gemacht.

\subsection{Herstellung einer Standardreihe von Pneumolysin}

Zur Herstellung der Standardreihe wurde rekombinantes Pneumolysin (freundlicherweise zur Verfügung gestellt von T. Mitchell, University of Glasgow, UK) in einer Konzentration in der Stammlösung von $300 \mu \mathrm{g} / \mathrm{ml}$ verwendet.

Für den SDS-Probenpuffer (1xPB = einfach konzentrierter Probenpuffer) wurden folgende Substanzen benötigt:

- $3 \mathrm{ml}$ Glycerin $100 \%$

- 7,5 ml SDS (sodium dodecyl sulfate) $10 \%$ in $\mathrm{H}_{2} \mathrm{O}$

- 4,5 ml 1M Tris-Cl pH 6,8

- 14,7 ml $\mathrm{H}_{2} \mathrm{O}$ bidest

- $100 \mu \mathrm{l}$ Bromphenolblau

- 480 mg DTT (Dithiothreitol)

- $300 \mu$ l Albuminlösung $(1 \mu \mathrm{g} / \mathrm{ml})$ auf $\mathrm{H}_{2} \mathrm{O}$ Basis

Vorverdünnung: $180 \mu \mathrm{l}$ des Probenpuffers wurden mit $20 \mu \mathrm{l}$ der Pneumolysinlösung vermischt, die Ply-Konzentration lag nun bei $30 \mu \mathrm{g} / \mathrm{ml}$, und für 4 min bei $99^{\circ} \mathrm{C}$ erhitzt. Anschließend wurden die Proben durch kurze Zentrifugation vor Öffnen des Gefäßes sedimentiert. Von dieser Vorverdünnung wurden $100 \mu \mathrm{l}$ in $10 \mathrm{ml}$ des Probenpuffers gegeben, hiernach lag die Konzentration des Ply bei $0,3 \mu \mathrm{g} / \mathrm{ml}$ (=300 pg/ $\mu$ l beziehungsweise $\quad 3000 \mathrm{pg} / 10 \mu \mathrm{l})$. Anschließend wurden durch weitere Verdün- 
nungsschritte Standards von 10 bis $1000 \mathrm{pg} / 10 \mu \mathrm{l}$ hergestellt, aliquotiert und bei $-20^{\circ} \mathrm{C}$ bis zur Weiterverarbeitung aufbewahrt.

\title{
2.9 Herstellung der Polyacrylamidgele
}

Folgende Substanzen und Lösungen wurden für die SDS-PAGE verwendet:

Trenngelpuffer:

Sammelgelpuffer:

SDS-Lösung:

APS-Lösung:

AA-Lösung:

Isopropanol:

10x Laufpuffer:

1x SDS-Laufpuffer:

\author{
$0,75 \mathrm{M}$ Tris- $\mathrm{HCl}, \mathrm{pH} 8,8$ \\ $0,25 \mathrm{M}$ Tris- $\mathrm{HCl}, \mathrm{pH} 6,8$ \\ Natriumdodecylsulfat (SDS), $10 \%$ \\ Ammoniumpersulfat (APS), $10 \%$ \\ Acrylamid (AA); 30\%T, 2,6\%C \\ zur Überschichtung der Trenngele \\ $30,2 \mathrm{~g}$ Tris und 142,6 g Glycin gelöst in $11 \mathrm{H}_{2} \mathrm{O}$ \\ $100 \mathrm{ml} 10 x$ Laufpuffer \\ $10 \mathrm{ml}$ SDS $10 \%$ \\ $890 \mathrm{ml} \mathrm{H} \mathrm{H}_{2} \mathrm{O}$ \\ $200 \mathrm{ml} 10 x$ Laufpuffer \\ $1400 \mathrm{ml} \mathrm{H} 2 \mathrm{O}$ \\ $400 \mathrm{ml}$ Methanol
}

Blotpuffer:

Für den Nachweis von Ply (53 kD) wurden Trenngele mit 7,5\% AcrylamidAnteil $(T)$ hergestellt, der Vernetzungsgrad (C) betrug dabei 2,6\%. Zur Herstellung von 6 Gelen wurden folgende Substanzen und Dosierungen eingesetzt:

Acrylamid-Lösung (30\%T; 2,6\%C): $\quad 15,0 \mathrm{ml}$

Trenngelpuffer: $\quad 30,0 \mathrm{ml}$

$\mathrm{H}_{2} \mathrm{O}$ : $\quad 14,4 \mathrm{ml}$ 
SDS-Lösung:

$600 \mu \mathrm{l}$

APS-Lösung:

$510 \mu \mathrm{l}$

Temed:

$120 \mu \mathrm{l}$

Nach Vorbereitung der Höfer-Kammer und nach Zugabe der Startersubstanzen (APS, Temed) wurde die Lösung in die Höfer Kammer gegossen und die Lösung mit Isopropanol überschichtet, damit eine möglichst glatte Oberfläche entstehen konnte. Anschließend polymerisierten die Gele für 2 Stunden bei Raumtemperatur aus. Für die Kammer wurden $10 \times 8 \mathrm{~cm}$ große Glasplatten und Spacer der Stärke $1,5 \mathrm{~mm}$ verwendet. Nach dem Polymerisieren wurde der Überstand aus Isopropanol mit $\mathrm{H}_{2} \mathrm{O}$ abgespült und die Sammelgele wurden auf die Trenngele aufgebracht. Die Sammelgele enthielten einen Acrylamidanteil von 4\%. Zur Herstellung von 6 Sammelgelen wurden folgende Materialien benötigt:

Sammelgelpuffer:

$7,5 \mathrm{ml}$

Acrylamid-Lösung (30\%T; $2,6 \% \mathrm{C})$ :

$2,1 \mathrm{ml}$

$\mathrm{H}_{2} \mathrm{O}$ :

$5,1 \mathrm{ml}$

SDS-Lösung:

$150 \mu \mathrm{l}$

Bromphenolblau, 1\%:

$36 \mu \mathrm{l}$

APS-Lösung:

$150 \mu \mathrm{l}$

Temed:

$15 \mu \mathrm{l}$

Die Lösung wurde in die Höfer-Kammer auf die Trenngele pipettiert. Direkt danach wurden Kämme in die Zwischenräume gesteckt, so dass 15 Probentaschen entstanden, in die später die Standards und die zu untersuchenden Ply-Proben eingebracht wurden. Die Sammelgele polymerisierten für 45 min bei Raumtemperatur aus. Anschließend wurden die Gele aus der Höfer Kammer entfernt und konnten in einer feuchten Kammer bei $4^{\circ} \mathrm{C}$ für bis zu 2 Wochen gelagert werden. Zur Befeuchtung diente eine Lösung aus 10,0 ml Trenngelpuffer, 10,0 ml $\mathrm{H}_{2} \mathrm{O}$ und $200 \mu \mathrm{l} \mathrm{SDS-Lösung.}$ 


\subsection{Vorbereitung der Proben und Standards}

Vor Beginn der Elektrophorese mussten die Proben und Standards vorbereitet werden. Dazu wurden die zu untersuchenden Proteine in Probenpuffer mittels Erhitzen auf $95^{\circ} \mathrm{C}$ für 3-5 min denaturiert. Zuvor wurde ein doppelt konzentrierter Probenpuffer (2 x PB) hergestellt:

$\begin{array}{ll}\text { Glycerin: } & 2,0 \mathrm{ml} \\ \text { SDS-Lösung: } & 5,0 \mathrm{ml} \\ \text { 1 M Tris-HCL: } & 3,0 \mathrm{ml} \\ \text { Bromphenolblau : } & 200 \mu \mathrm{l}\end{array}$

Der 2 x PB wurde bei $4^{\circ} \mathrm{C}$ gelagert, bei Bedarf mit 0,031 g/ml Dithiothreitol (DTT) gemischt und im Verhältnis 1:1 zu den Proben gegeben bevor sie erhitzt wurden. Nach dem Erhitzen wurden die Proben kurz zentrifugiert und dann für die Elektrophorese in die Sammelgeltaschen gegeben. Diese wurden dafür zuvor in die Elektrophorese-Apparatur eingespannt, die Elektrophorese wurde in SDS-Laufpuffer (s.o.) durchgeführt.

\subsection{Gelelektrophorese}

Hierzu wurde ein zu diesem Zweck hergestelltes Gel (s.o.) mit 15 Probenkammern verwendet, wobei in die jeweils erste und letzte Kammer $4 \mu \mathrm{l}$ eines Proteinmarkers (New England Biolabs $\mathrm{GmbH}$ ) gegeben wurden, dessen Banden aus Proteinen definierten Molekulargewichtes den Bereich anzeigten, in welchem die 53 kDa großen Proteine liefen und somit bei der 
Vorbereitung zur Immundetektion als Orientierungshilfe dienten. In die übrigen Kammern wurden die Pneumolysin-Standards (s.o.), sowie die zu untersuchenden Proben nach entsprechender Vorbereitung (s. 2.7) hinein gegeben. Für die Elektrophorese wurden 10-15 mA pro Gel angelegt, bis die Farbfront der Proben das Trenngel erreicht hatte, danach wurde die Stromstärke auf 20-25 mA erhöht. Hatte die Farbfront den unteren Rand des Trenngels erreicht, wurde die Elektrophorese beendet. Das Gel zwischen Glas und Metallplatte wurde herausgenommen und $5 \mathrm{~min}$ in Blotpuffer (s.o.) äquilibriert.

\subsection{Westernblot in Semidry-Apparatur}

Beim Westernblot werden die zuvor in der SDS-PAGE aufgetrennten Proteine auf eine Trägermembran (hier Nitrozellulosemembran) übertragen (Burnette 1981).

Für dieses Blotten wurde eine Nitrozellulosemembran entsprechend der Größe des Gels zugeschnitten und beschriftet, da immer mindestens 2 Gele mit verschiedenen Proben verarbeitet wurden. Die Membran wurde zusammen mit dem Gel 5 min in Blotpuffer äquilibriert. Anschließend wurden Gel und Membran zwischen 3 Lagen Filterpapier, die mit Blotpuffer getränkt waren, (jeweils oben und unten) in die Blot-Apparatur gelegt. Dabei wurde darauf geachtet, dass sich keine Luftblasen zwischen dem Gel und der Membran befanden. Es wurde eine Stromstärke von $0,8 \mathrm{~mA} / \mathrm{cm}^{2}$ gewählt, wobei eine Spannung von etwa $30 \mathrm{~V}$ entstand, das Blotten dauerte 1 Stunde. Danach wurde die Membran entnommen, kurz in Aqua bidest gewässert und zum Trocknen bei Zimmertemperatur aufgehängt. Durch diesen Trockenvorgang wurde eine festere Bindung der übertragenen Eiweiße an die Nitrozellulose-Trägermembran erzielt. 


\subsection{Immundetektion}

Folgende Lösungen wurden für die Immundetektion benötigt und bei Bedarf hergestellt:

- PBS (Phosphate buffered saline), $\mathrm{pH} 7,5: \quad 8,0 \mathrm{~g} \mathrm{NaCl}$

$0,2 \mathrm{~g} \mathrm{KCl}$

$1,44 \mathrm{~g} \mathrm{Na}_{2} \mathrm{HPO}_{4}$

$0,24 \mathrm{~g} \mathrm{KH}_{2} \mathrm{PO}_{4}$ wurden in $800 \mathrm{ml} \mathrm{H}_{2} \mathrm{O}$ bidest gelöst, mit $\mathrm{HCl}$ auf $\mathrm{pH} 7,4$ eingestellt und mit Aqua bidest auf 1 l aufgefüllt

- PBS-T (Waschpuffer): PBS $+0,1 \%$ Tween 20

- Blockpuffer: $10 \%$ Magermilchpulver in PBS-T gelöst unter $\mathrm{pH}$ Korrektur auf 7,4

Nach dem Trocknen wurde die Membran für 1-2 Stunden mit Blockpuffer auf einem Schüttler geblockt. Nach zweimaligem kurzem Waschen mit PBS-T (s.o.) erfolgte die Inkubation mit dem ersten AK für 8-10 Stunden bei Raumtemperatur. Hierbei handelte es sich um einen monoklonalen Murin-AK gegen rekombinantes Pneumolysin von Mäusen (NCL-SPNm, Novocastra Laboratories, Newcastle upon Tyne, UK). Der AK wurde 1:100 mit Blockpuffer verdünnt und die Membranen in einer feuchten Kammer mit der Lösung für 8-10 Stunden überschichtet. Nach Inkubation mit dem ersten AK folgten mehrere Waschvorgänge ( $2 \times$ kurz, $5 \times 10 \mathrm{~min}$ ) mit PBS$\mathrm{T}$ auf dem Schüttler. Anschließend folgte die Inkubation mit dem 2. AK, einem Peroxidase-gekoppelten Ziegen-Anti-Maus-AK (Jackson 
Immunoresearch Laboratories, West Grove, PA) für 4 Stunden. Der 2. AK wurde zuvor 1:5000 mit Blockpuffer verdünnt. Danach folgten erneut mehrere Waschvorgänge mit PBS-T ( 2 x kurz, 5 x 10 min). Die Reaktion wurde durch Behandlung mit $\mathrm{ECL}+{ }^{\circledR}$ Western blotting detection reagents und anschließender Detektion des Chemolumineszenz-Signals und Entwicklung auf einem speziellen Fotofilm (Hyperfilm ECL®) sichtbar gemacht (beides: Amersham Pharmacia Biotech, Little Chalfont, Buckinghamshire, UK). Dazu wurden die Membranen nach dem letzten Waschvorgang mit den ECL-Lösungen entsprechend den Herstellerangaben für 5 min überschichtet $\left(0,1 \mathrm{ml} / \mathrm{cm}^{2}\right)$. Die ECL-Lösung wurde mit saugfähigem Papier vorsichtig entfernt und die Membran zwischen 2 Klarsichtfolien einer Fotokassette gelegt. Nach dem Transport in eine Dunkelkammer erfolgte dort die Belichtung und Entwicklung der Filme mit den entsprechenden Lösungen. Dabei wurden von jeder Membran mehrere Filme mit unterschiedlichen Belichtungszeiten angefertigt (meist 2, 5 und 10 min Belichtungszeit). Pneumolysin stellte sich als Bande bei $53 \mathrm{kDa}$ dar. Für die Quantifizierung wurde eine Standardreihe aus rekombinantem Pneumolysin auf alle Immunoblotts mit aufgetragen. Proben, deren ChemolumineszenzSignal außerhalb des linearen Bereiches der Standardreihe lag, wurden verdünnt und erneut ausgewertet. Für die Auswertung der Filme mittels Densitometrie wurde das Programm NIH Image 1.62 verwendet.

\subsection{Tiermodell der bakteriellen Meningitis}

Für die vorliegende Studie wurde das Kaninchen-Meningitis-Modell gewählt. Bereits in früheren Studien hat sich dieses Modell bewährt und konnte für verschiedene Fragestellungen erfolgreich eingesetzt werden. So konnten am Kaninchenmodell der bakteriellen Meningitis wichtige 
Erkenntnisse bezüglich Pathogenese und Pathophysiologie sowie möglicher neuer Therapieansätze gewonnen werden. Aufgrund der anatomischen Gegebenheiten ist bei Kaninchen die suboccipitale Liquorpunktion im Vergleich zu anderen Tieren wie Ratten oder Mäusen relativ einfach. Außerdem verfügen Kaninchen im Gegensatz zu kleineren Tieren über ausreichend Liquor (2-3 ml), so dass bei jeder Punktion problemlos bis zu $0,2 \mathrm{ml}$ entnommen werden können und nicht unnötig viele kleinere Tiere getötet werden müssen, um die benötigten Liquormengen zu gewinnen. Erst diese etwas größeren Mengen an Liquor wiederum ermöglichen umfangreiche Untersuchungen (Zytologie, Bakterienzahl, Entzündungsparameter), mit denen der Krankheitsverlauf und gegebenenfalls die Wirksamkeit neuer Therapieansätze ausreichend untersucht werden können. AuBerdem hat das Modell den Vorteil, dass ein Tier seriell punktiert werden kann und anschließend aus demselben Tier eine Quantifizierung des Neuronenschadens mittles histochemischer Aufarbeitung möglich ist. Man vermutet, dass die pathophysiologischen Vorgänge im Organismus dieser Tiere stark denen des Menschen im Falle einer bakteriellen Meningitis ähneln. Der Liquor wurde nach der Gewinnung auf seinen Laktat-, Protein-, Glucose- und Prostaglandin $\mathrm{E}_{2}$ - Gehalt hin analysiert, des weiteren wurde die Zellzahl bestimmt sowie die Konzentration an Pneumolysin. Nach Versuchsende wurden die Hirne der Tiere entnommen, in Formalin fixiert und anschließend histologisch aufgearbeitet. Besonders wichtig war hierbei die Analyse der Formatio hippocampi bezüglich der Apoptosen in diesem Areal:

Die Formatio hippocampi ist Teil des limbischen Systems, bestehend aus Hippocampus, Gyrus dentatus, Subiculum und entorhinalem Kortex.

Der Hippocampus liegt an der Medialwand und dem Boden des Seitenventrikelunterhorns. Im Querschnitt wird die Struktur des Ammonshorns sichtbar, das in 4 Regionen unterteilt wird: CA1 bis CA4. Die Formatio hippocampi ist besonders anfällig gegenüber ischämischen und toxischen Einflüssen (Zilles 1987) und eine Schädigung führt zu schweren neuropsychologischen Defiziten. Sie spielt eine wichtige Rolle bei kogniti- 
ven Fähigkeiten und ist bei Lernvorgängen sowie der Gedächtnisbildung beteiligt (Scoville und Milner 1957). Bei mehr als der Hälfte der an Meningitis verstorbenen Patienten lassen sich im Gyrus dentatus der Formatio hippo-campi Apoptosen nachweisen (Nau et al. 1999 a).

Die Tierexperimente wurden in Übereinstimmung mit den nationalen Richtlinien für Tierversuche durchgeführt und von der Bezirksregierung Braunschweig, Niedersachsen, genehmigt. Die Tiere wurden gewichtsadaptiert durch intramuskuläre Gabe von Ketamin (25 mg/kg KG) und Xylazin ( 5 $\mathrm{mg} / \mathrm{kg} \mathrm{KG}$ ) anästhesiert. Dann wurden den Tieren (Weiße neuseeländische Kaninchen, Mindestgewicht $2 \mathrm{~kg}$, Charles River, Sulzfeld, Deutschland) Ohren und Nacken rasiert, um die folgenden Punktionen zu erleichtern. Am rechten Ohr wurde ein venöser und am linken ein arterieller Zugang gelegt. Der venöse Zugang diente zur Aufrechterhaltung der Narkose und zur Verabreichung der Antibiose, der arterielle zur Blutentnahme. Anschließend wurde der suboccipitale Liquorraum der Tiere punktiert, und es wurde $300 \mu \mathrm{l}$ Liquor entnommen. Im Rahmen dieser ersten Punktion wurden die Tiere dann mit $300 \mu \mathrm{l}$ einer Kochsalzlösung infiziert, die $10^{5}$ (4.8-6,0) CFU S.pneumoniae enthielt. Liquor und arterielles Blut wurden zum Zeitpunkt 0 (Infektion), 12, 14, 18 und $24 \mathrm{~h}$ entnommen, außerdem wurde jeweils die Körpertemperatur rektal gemessen. Es wurde jeweils eine Liquorentnahme von $300 \mu \mathrm{l}$ pro Tier angestrebt, diese Menge konnte in Einzelfällen nicht eingehalten werden. Zu jedem Zeitpunkt wurden die Leukozyten im Liquor gezählt und die Bakteriendichte mittels Verdünnungsreihe (s.o.), Ausplatten auf Blutagar und anschließendem Bebrüten bei $37^{\circ} \mathrm{C}$ für 24 Stunden bestimmt. Dazu wurden jeweils $10 \mu \mathrm{l}$ des entnommenen Liquors verwendet, der Rest der Proben (Liquor und EDTABlut) wurde sofort bei $3000 \mathrm{~g}$ für 10 min zentrifugiert. Die Überstände wurden in Eppendorfgefäße überführt. Überstände und Sediment wurden mit Stickstoff überspült und in flüssigem Stickstoff schockgefroren. Danach wurden die Proben bei $-80^{\circ} \mathrm{C}$ zur späteren Weiterverarbeitung aufbewahrt. 12 Stunden nach der Infektion wurde zusätzlich untersucht, ob es im 
Rahmen der schweren Infektion auch zu einer begleitenden Bakteriämie gekommen war. Dazu wurden $110 \mu \mathrm{l}$ frisches Blut in $990 \mu \mathrm{l} \mathrm{NaCl}$ gegeben und $1 \mathrm{ml}$ dieser Lösung auf Blutagar ausgeplattet (Nachweisgrenze $10^{1}$ $\mathrm{CFU} / \mathrm{ml}$ ). Die restlichen $100 \mu \mathrm{l}$ wurden mit $900 \mu \mathrm{l} \mathrm{NaCl}$ ein weiteres Mal 1:10 verdünnt und ebenfalls ausgeplattet (Nachweisgrenze $10^{2} \mathrm{CFU} / \mathrm{ml}$ ). Das Ergebnis konnte nach 24 Stunden Inkubation bei $37^{\circ} \mathrm{C}$ abgelesen werden. Die Anästhesie wurde über die gesamte Dauer des Experiments (24 h) durch intravenöse Gabe von Urethan aufrechterhalten. Die Tiere wurden $24 \mathrm{~h}$ nach der Infektion mit $2 \mathrm{ml}(25 \mathrm{mg} / \mathrm{ml})$ Thiopental i.v. getötet. Die Hirne wurden zur weiteren Analyse des neuronalen Schadens entnommen und zunächst in 4\%iger Paraformaldehydlösung fixiert.

\subsection{Antibiotische Behandlung}

Vor Infektion wurden die Tiere zufällig in zwei Gruppen unterteilt: In eine Versuchsgruppe, die mit Rifampicin vorbehandelt werden sollte und eine Kontrollgruppe für die Standardbehandlung mit Ceftriaxon (CRO). 12 Stunden nach Infektion erhielt die Versuchsgruppe Rifa (20 mg/kg KG) als Kurzinfusion, gefolgt von einer CRO-Gabe eine Stunde später. Die Kontrolltiere erhielten eine intravenöse Gabe von CRO 12 Stunden nach der Infektion (125 mg/kg KG) als Kurzinfusion. Die Antibiotika-Dosen wurden so gewählt, dass im Liquor der Kaninchen ähnliche Konzentrationen erreicht wurden wie sie auch unter entsprechender Therapie beim Menschen erreicht werden. Für Rifampicin wurde die für Kinder mit bakterieller Meningitis maximal empfohlene Dosis verwendet (Tunkel et al. 2004). Für CRO wurde die Dosis anhand pharmakokinetischer Erkenntnisse bei Kaninchenversuchen ermittelt (Friedland et al. 1993 a). Die Anzahl der Tiere betrug in jeder Gruppe 12. 


\subsection{Gewebeentnahme, Fixation und Her- stellung der Schnitte}

Direkt nach Tötung der Tiere wurden ihre Hirne entnommen, in $4 \%$ iger Paraformaldehydlösung fixiert (für 24 h) und anschließend in Paraffin eingebettet:

Nach der Fixierung wurden die Hirne für 30-60 min gewässert. AnschlieBend folgte die Entwässerung in einer Ethanollösung und direkt im Anschluss die Einbettung in Paraffin:

\begin{tabular}{|c|c|c|c|}
\hline $50 \%$ & - & $1 \mathrm{~h}$ & $100 \%-$ \\
\hline $70 \%$ & - & $1 \mathrm{~h}$ & $100 \%-$ \\
\hline $80 \%$ & - & $1 \mathrm{~h}$ & Xylol - \\
\hline $80 \%$ & - & $1 \mathrm{~h}$ & Xylol - \\
\hline $96 \%$ & - & $1 \mathrm{~h}$ & Paraffin \\
\hline $96 \%$ & - & $1 \mathrm{~h}$ & Paraffin \\
\hline
\end{tabular}

Nach jeder Inkubation der Hirne wurde die Lösung erneuert. Nach dem letzten Schritt wurden die Hirne in einer Edelstahlform in flüssigem Paraffin eingebettet und vor der Weiterverarbeitung mindestens 12 Stunden bei Raumtemperatur ausgehärtet. Anschließend wurde von jedem Tier von der linken Hemisphäre eine Schnittserie mit Schnitten von $1 \mu \mathrm{m}$ Dicke angefertigt. Die Schnitte wurden in ein warmes (ca. $35^{\circ} \mathrm{C}$ ) Wasserbad gegeben, glatt gezogen und schwimmend auf den Objektträger aufgebracht. Die Trocknung erfolgte über Nacht in einem Wärmeschrank bei $37^{\circ} \mathrm{C}$, danach konnten die Schnitte bis zur Weiterverarbeitung bei Raumtemperatur aufbewahrt werden. Ein Teil der Schnitte wurde entparaffiniert und mit Hämatoxylin-Eosin gefärbt, der andere Teil wurde verwendet, um mittels In-Situ-Tailing die Neurone mit fragmentierter DNA sichtbar zu machen. 


\subsection{Hämatoxylin-Eosin-Färbung (HE-Färbung)}

Die Hämatoxylin-Eosin-Färbung (HE) wurde nach neuropathologischem Standardprotokoll durchgeführt.

Zunächst wurden die hierzu angefertigten Schnitte entparaffiniert, anschließend erfolgte die 5-10-minütige Inkubation in Hämalaunlösung. Danach folgte die Differenzierung in $\mathrm{HCl}$-Alkohol und nach gründlichem Abspülen mit Leitungswasser die 5-minütige Inkubation im Eosinbad.

Nach dieser Prozedur zeigten sich die Zellkerne im Präparat blau, das Plasma rosa gefärbt.

\subsection{In-Situ-Tailing (IST)}

Das In-Situ-Tailing ist eine Methode zum Nachweis fragmentierter DNS im Zellkern. Hierbei werden die 3'-Hydroxylenden von einzel- oder doppelsträngiger DNS mit Digoxigenin-markierten Desoxiribonukleosidtriphophaten gekoppelt. Als Katalysator dient terminale Transferase. Die Farbreaktion der markierten Zellkerne wird durch einen gegen Digoxigenin gerichteten Antikörper sichtbar gemacht.

Hierzu wurden die Proben entparaffiniert, hydriert und mit $100 \mu \mathrm{g} / \mathrm{ml}$ Proteinkinase $\mathrm{K}$ (Sigma-Aldrich, Steinheim) für $15 \mathrm{~min}$ bei $37^{\circ} \mathrm{C}$ inkubiert. Anschließend folgte die Inkubation mit dem Tailing-Mix für $60 \mathrm{~min}$ bei $37^{\circ} \mathrm{C}$. Nach Blocken mit fetalem Kälberserum für 15 min bei Raumtemperatur wurden die Proben für 1 Stunde mit Phosphatase-konjugierten AntiDigoxigenin-Antikörpern (die AK wurden 1:250 in 10\%igem fetalem Kälberserum verdünnt) bei Raumtemperatur inkubiert. Die Aktivität der konju- 
gierten alkalischen Phosphatase wurde mit Nitro-blue-Tetrazolium/5Bromo-4-Chloro-3-Indoyl-Phosphat-Lösung dargestellt. Anschließend folgte die Gegenfärbung mit Kernechtrot-Aluminiumsulfat-Lösung. Alle Reagenzien stammten von Boehringer-Mannheim, Deutschland.

\subsection{Quantifizierung apoptotischer Neurone}

Vier Proben der linken Hemisphäre jeden Tieres wurden histologisch unter Verwendung des Analysis Software Imaging System (BX51; Olympus, Hamburg; Software AnalySIS $\circledast 3.2$; Soft Imaging System GmbH, Münster) analysiert. Dazu wurden zunächst die Grenzen des Gyrus dentatus markiert und seine Fläche ausgemessen. Danach wurden die mittels In-situTailing sichtbar gemachten apoptotischen Zellen des Gyrus dentatus ausgezählt. Die HE-angereicherten Schnitte zeigten morphologische Korrelate der Apoptose in den gleichen Neuronen. Die Dichte der apoptotischen Neuronen wurde als Zahl der markierten Zellen $/ \mathrm{mm}^{2}$ im Gyrus dentatus des Hippocampus in der HE-gefärbten Probe ausgezählt. Es wurde jeweils der Mittelwert aus 4 Schnitten eines Tieres bestimmt.

\subsection{Entzündungsparameter im Liquor}

Zur Bestimmung von Prostaglandin $\mathrm{E}_{2}$, Laktat, Protein und Glukose wurden die bei $-80^{\circ} \mathrm{C}$ eingefrorenen Liquorüberstände verwendet. Die Leukozyten wurden unter dem Mikroskop ausgezählt. 


\subsubsection{Leukozyten}

Unmittelbar nach der Entnahme und vor der Zentrifugation wurde - nach Färbung des Liquors mit Karbolfuchsinlösung - die Leukozytenzahl zu den Abnahmezeitpunkten 12, 14, 18 und 24 Stunden mithilfe einer FuchsRosenthal-Kammer unter dem Mikroskop bestimmt.

\subsubsection{Laktat}

Das im Liquor enthaltene Laktat wurde enzymatisch bestimmt (Rolf Greiner Biochemica, Flacht, Deutschland). Hierzu wurden $5 \mu \mathrm{l}$ der entsprechenden Probe mit $300 \mu$ des Laktatreagenz gemischt. Nach 10-minütiger Inkubation bei Raumtemperatur folgte die Messung der Werte mit dem Easy-Fit-Programm. Bei Werten $>10 \mathrm{mmol} / \mathrm{L}$ wurde die Probe verdünnt und erneut gemessen.

\subsubsection{Protein}

Der Proteingehalt wurde mithilfe des BCA Protein Assay's (Pierce Biotechnology, Rockford, IL, USA) bestimmt. Bovines Serumalbumin diente als Standard, entsprechend der Anleitung des Herstellers. Anstelle der empfohlenen Menge von $10 \mu \mathrm{l}$ verwendeten wir $5 \mu \mathrm{l}$ der jeweiligen Probe, um noch ausreichend Liquor für eventuelle Nachmessungen zur Verfügung zu haben. Die Proben wurden 1:20 mit den benötigten Reagenzien gemischt, und nach 30 min Inkubation bei Raumtemperatur wurde der Proteingehalt im Spektrophotometer gemessen. Die Proben, die $>2000$ $\mathrm{mg} / \mathrm{L}$ Gesamtprotein enthielten, wurden mit $\mathrm{NaCl}$ 1:5 auf ein Gesamtvolumen von $25 \mu$ l vorverdünnt und erneut gemessen. 


\subsubsection{Prostaglandin $\mathrm{E}_{2}$}

Prostaglandin $E_{2}$ wurde mit einem Enzym-Immunoassay (R\&D Systems, Minneapolis, MN, USA) entsprechend den Herstellerangaben bestimmt. Die erste Inkubation der Proben erfolgte bei $4^{\circ} \mathrm{C}$ für 16 Stunden nach Zugabe der erforderlichen Reagenzien. Nach Zugabe der letzten benötigten Lösungen folgte erneut die Inkubation bei Raumtemperatur für 20 min und anschließend die Messung der optischen Dichte bei $450 \mathrm{~nm}$.

\subsubsection{Glukose}

Der Liquor- und Plasmaglukosegehalt wurden mittels Beckman Glucose Analyzer 2 (Beckman Coulter, Krefeld, Deutschland) gemessen. Dabei wurde die in den Proben enthaltene Glukose durch Hexokinase unter Zusatz von Adenosintriphosphat (ATP) und Magnesiumionen phosphoryliert, wobei Glukose-6Phosphat (G-6-P) und Adenosindiphosphat (ADP) enstanden. Glukose-6-Phosphat-Dehydrogenase (G-6-PDH) oxidiert spezifisch G-6-P zu 6-Phosphoglukonat unter Reduktion von NicotinamidAdenin-Dinukleotid (NAD) zu reduziertem NAD (NADH). Die dabei gemessene, veränderte Absorption bei $340 / 380 \mathrm{~nm}$ verhielt sich proportional zu der Konzentration an Glukose in der entsprechenden Probe.

\subsubsection{Bakteriendichte}

Die Bakteriendichte im Liquor wurde mittels Ausplatten einer Verdünnungsreihe (s.o.) auf Blutagar und anschließendem Bebrüten bei $37^{\circ} \mathrm{C}$ für 24h bestimmt. Nach dem Bebrüten konnten die CFU (colony-formingunits) ausgezählt und die Keimzahl pro ml ermittelt werden. 


\subsection{Statistische Analyse}

Aufgrund unterschiedlicher bakterieller Inokulationsdosen während der einzelnen Versuche wurden für die statistische Analyse jeweils die Tiere des gleichen Versuchstages mit der gleichen Infektionsdosis gepaart (paired-t-test oder ANOVA gefolgt von Bonferroni's Multiple Comparison Test). Wenn eine Gauss'schen Normalverteilung mit annähernd gleichen Standardabweichungen vorlag, wurden die Werte in einem gepaarten parametrischen Test ausgewertet. Wenn nötig, wurden die Ergebnisse vor dem parametrischen Test logarithmiert. Wenn keine Gauss'sche Normalverteilung vorlag, wurde mittels gepaartem nicht-parametrischem Test ausgewertet. 


\section{Ergebnisse}

\subsection{In-vitro-Versuche}

In Flüssigkultur wachsende Pneumokokken wurden in der späten logarithmischen Wachstumsphase aufgeteilt. In der Kontrollprobe ohne Antibiotikazusatz erreichte die Keimzahl drei Stunden nach der Aufteilung $10^{8} \mathrm{CFU} / \mathrm{ml}$. Die bakterizide Aktivität von $8 \mu \mathrm{g} / \mathrm{ml}$ Ceftriaxon $(-0.47+/-0.03$ $\Delta \log \mathrm{CFU} / \mathrm{ml} / \mathrm{h}$ ) war höher als die von $3 \mu \mathrm{g} / \mathrm{ml}$ Rifampicin $(-0.37+/-0.11$ $\Delta \log \mathrm{CFU} / \mathrm{ml} / \mathrm{h}$ ) und als die der sequentiellen Antibiose mit Rifampicin (3 $\mu \mathrm{g} / \mathrm{ml})$ gefolgt von Ceftriaxon $(8 \mu \mathrm{g} / \mathrm{ml}) 30$ min später $(-0.37+/-0.11$ $\Delta \log \mathrm{CFU} / \mathrm{ml} / \mathrm{h}$ ). Trotz dieser Differenz waren die Unterschiede bezüglich der Bakterizidie nicht signifikant ( $p>0.05)$.

Signifikante Unterschiede fanden sich dagegen zwischen den verschiedenen Gruppen im Hinblick auf die Freisetzung der toxischen und proinflammatorischen bakteriellen Stoffwechselprodukte Pneumolysin und DNS. Im Vergleich zur Standardantibiose mit Ceftriaxon war die Freisetzung von Pneumolysin in den Überständen der Kulturen, die nur mit Rifampicin oder sequentiell zunächst mit Rifampicin und nach 30 min mit Ceftriaxon behandelt wurden, signifikant geringer, sowohl 3 Stunden ( $p<0.01$ für beide Gruppen) als auch 12 Stunden ( $p<0.001$ für beide Gruppen) nach Antibiotikazugabe (Abb 3). Der ausgeprägt bakteriolytische Effekt des B-Laktam-Antibiotikums wurde dadurch deutlich, dass die Pneumolysinkonzentration in den Überständen 3 Stunden nach Beginn der Antibiose in der Ceftriaxon-Gruppe wesentlich höher war als in der Kontrollgruppe ohne Antibiotika $(\mathrm{p}<0.01)$ (Abb 3). Nach Ende der logarithmischen Wachstumsphase kam es in der Kontrollgruppe zur spontanen Autolyse der Bakterien, so dass am Ende des Experiments die höchste Freisetzung von Pneumolysin in der Kontrollgruppe gemessen werden konnte $(p<0.001)(A b b 3)$. Es konnte kein signifikanter Unterschied in der Freisetzung von Pneumolysin zwischen der Rifampicin-Gruppe und der 
Rifa/CRO-Gruppe festgestellt werden ( $p>0.05)$. Die Freisetzung bakterieller DNS, die mittels Real-time-PCR gemessen wurde (andere Arbeitsgruppe), verhielt sich in den einzelnen Gruppen analog zur Pneumolysinfreisetzung. Unter Rifampicin und sequentieller Behandlung mit Rifa und CRO 30 min später nahm die DNS-Konzentration im Überstand im Vergleich zur Standardbehandlung binnen 3 Stunden nach Behandlungsbeginn signifikant $a b(p<0.01$ für beide) (Abb 4).

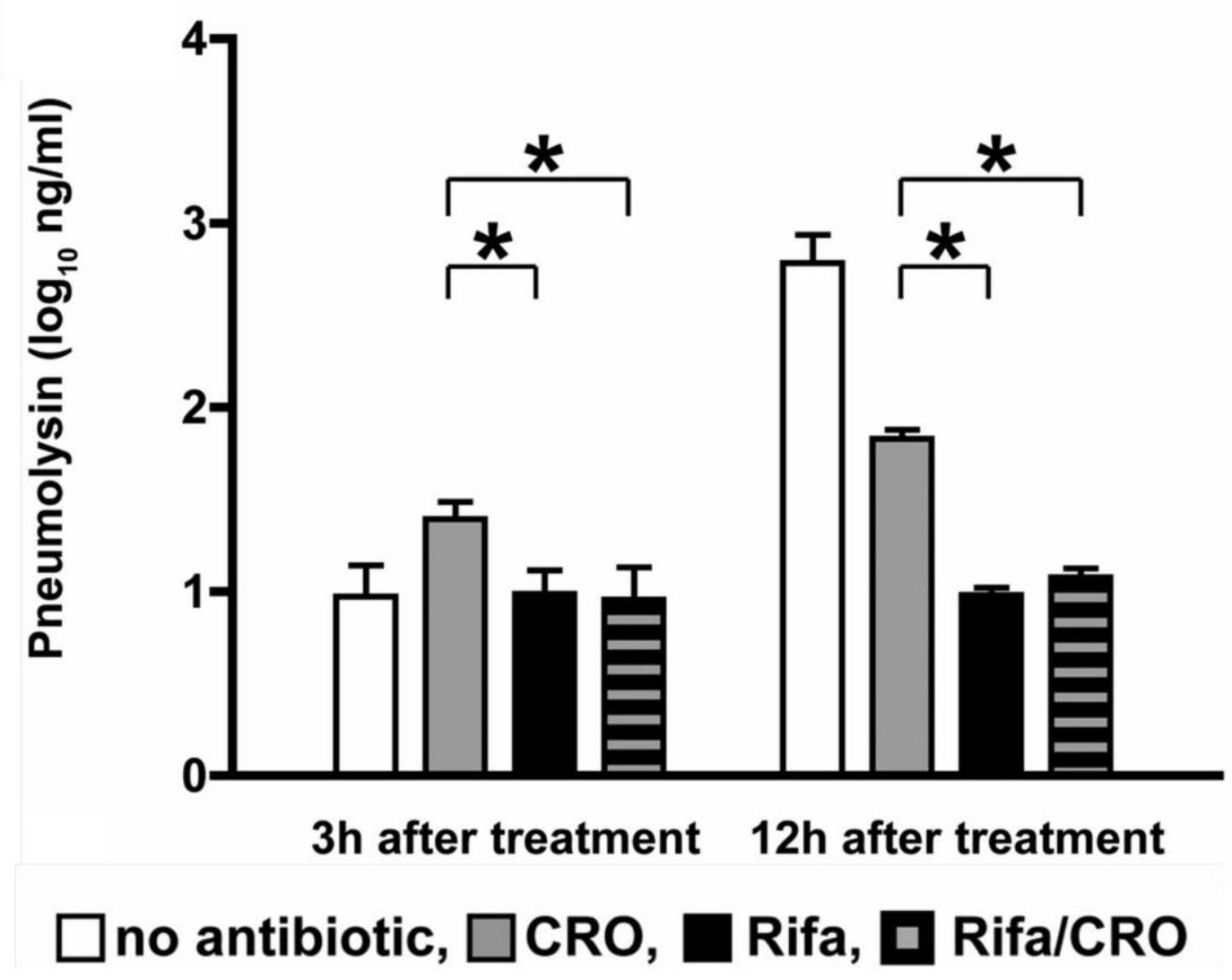

Abbildung 3: Pneumolysinkonzentration im Überstand in Abhängigkeit von der jeweiligen antibiotischen Therapie; nach 3 Stunden sowie nach 12 Stunden zeigte sich in der Rifa und Rifa/CRO-Gruppe eine signifikant geringere Konzentration an Pneumolysin im Vergleich zur CRO-Gruppe 
( $p<0,01$ nach 3 Stunden, $p<0,001$ nach 12 Stunden); es zeigte sich kein signifikanter Unterschied in der Freisetzung von Pneumolysin zwischen der Rifa-Gruppe und der Rifa/CRO-Gruppe ( $p>0.05)$; Ply-Konzentration $\log _{10} \mathrm{ng} / \mathrm{ml}$.

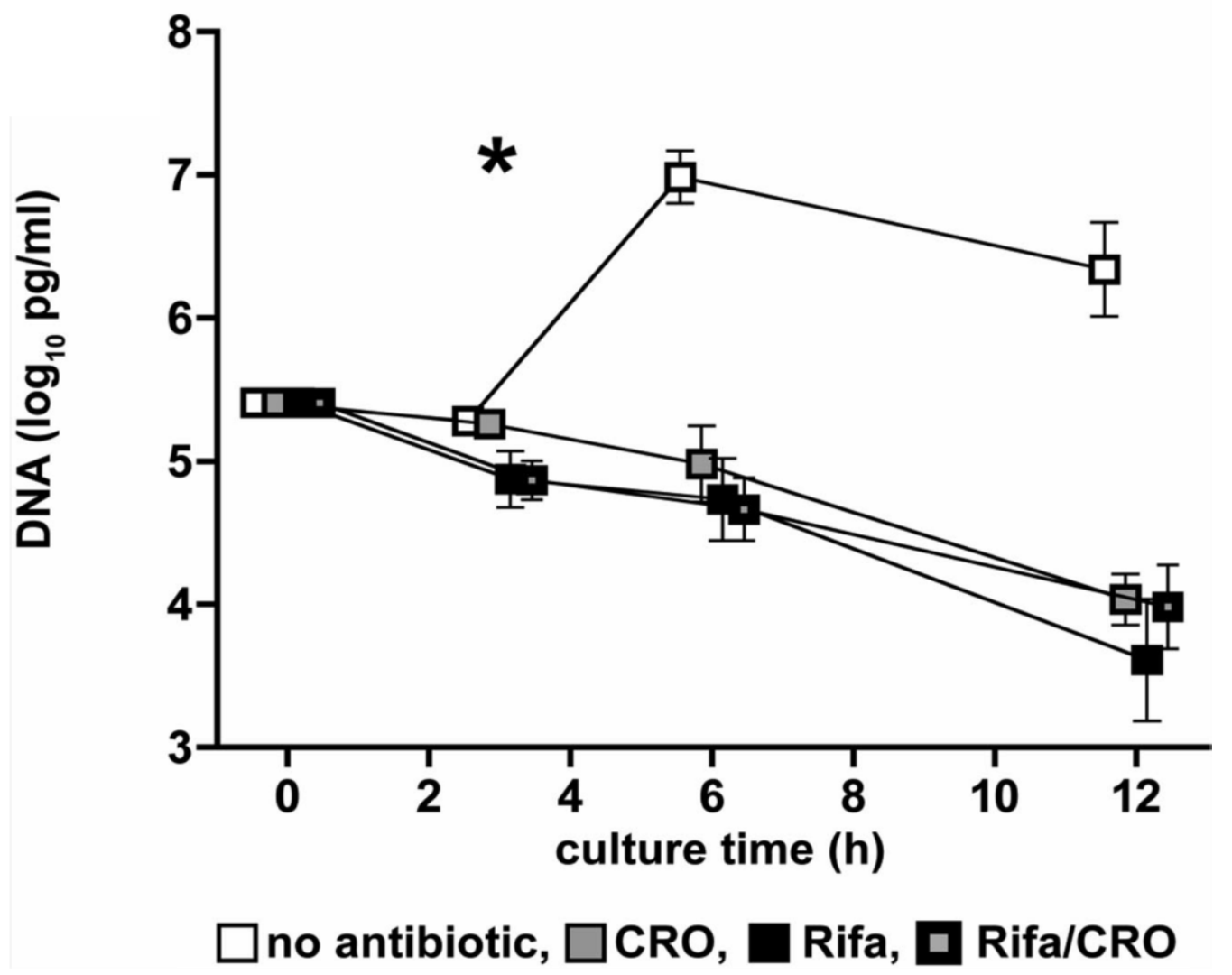

Abbildung 4: DNS-Konzentration im Überstand in Abhängigkeit von der jeweiligen antibiotischen Therapie. 3 Stunden nach Behandlungsbeginn zeigte sich Rifa-Gruppe und in der Rifa/CRO-Gruppe eine signifikant geringere Freisetzung von DNS im Vergleich zur CRO-Gruppe (jeweils $\mathrm{p}<0,01)$; DNS Konzentration in $\log _{10} \mathrm{pg} / \mathrm{ml}$. 
Bei den mit Tigezyklin behandelten Proben konnte im Vergleich zur Standardbehandlung mit Ceftriaxon 12 Stunden nach erfolgter antibiotischer Behandlung eine signifikant geringere Freisetzung von Ply nachgewiesen werden $(p<0,001)$.

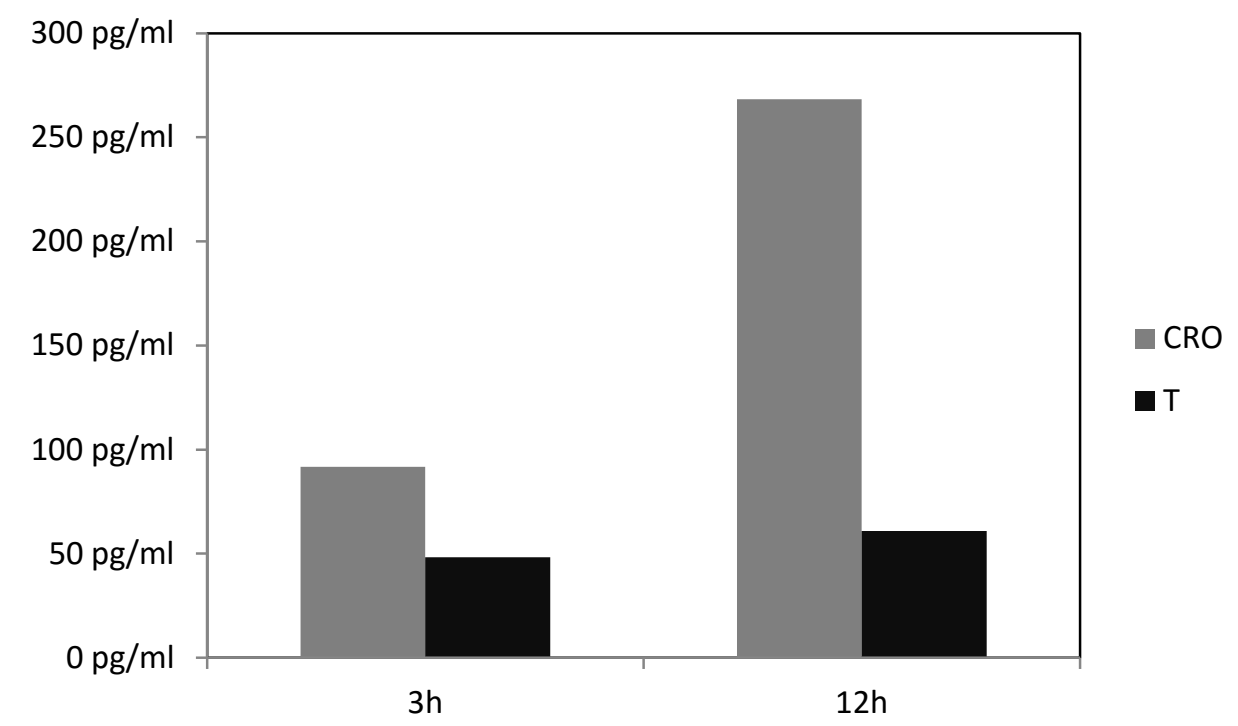

Abbildung 5: Pneumolysinkonzentration in Abhängigkeit von der antibiotischen Therapie. 12 Stunden nach Behandlungsbeginn zeigte sich in den mit Tigezyklin behandelten Proben eine signifikant geringere Konzentration an Pneumolysin im Vergleich zu den mit CRO behandelten Proben $(p<0,001)$; Ply in $\mathrm{pg} / \mathrm{ml}$.

\subsection{Tiermodell der bakteriellen Meningitis}

Die bereits in vitro beobachtete verminderte Freisetzung von Pneumolysin konnte auch in vivo nachgewiesen werden. Um den Einfluss dieser Freisetzung auf das Maß der Entzündung und den neuronalen Schaden zu überprüfen, kam das Kaninchenmodell der bakteriellen Meningitis zum Einsatz. 12 Stunden nach Inokulation von $S$. pneumoniae in den 
Liquorraum entwickelten alle Tiere das klinische Bild einer bakteriellen Meningitis. Bei allen Tieren zeigten sich im Liquor eine Pleozytose und eine hohe Bakteriendichte, erhöhte Werte für Laktat und Protein sowie ein verminderter Liquor/Serum-Glukose-Quotient. Dabei gab es keine Unterschiede dieser Parameter zwischen den Gruppen, die im Anschluss an diese Untersuchung unterschiedliche antibiotische Behandlung erhielten. Die Antibiose wurde 12 Stunden nach Infektion verabreicht, die Kontrollgruppe bekam Ceftriaxon i.v., die Versuchsgruppe bekam zunächst Rifampicin und nach 1 Stunde zusätzlich Ceftriaxon. Es wurde eine Vorbehandlungszeit von 1 Stunde mit Rifampicin gewählt, da man anhand pharmakokinetischer Untersuchungen beim Menschen weiß, dass die höchsten Liquor-Konzentrationen von Rifampicin etwa 1 Stunde nach i.v. Verabreichung des Antibiotikums erreicht werden (Nau et al. 1992). Obwohl die klinische Beurteilung der Tiere durch die Langzeitanästhesie eingeschränkt wurde, zeigten alle Kaninchen die Anzeichen einer schweren bakteriellen Infektion, unter anderem erhöhte Körpertemperatur und Opisthotonus. Die Schwere der Infektion spiegelte sich in einer hohen vorzeitigen Mortalitätsrate wider (21\%). In der Kontrollgruppe (CRO) starben 3/12 Tieren vor Ablauf von 24 Stunden, in der Versuchsgruppe (Rifa/CRO) starben $2 / 12$ Tieren vorzeitig ( $p>0.05)$. Obwohl die Kombination beider Antibiotika dazu führte, dass die Bakteriendichte im Liquor bei der Versuchsgruppe langsamer abnahm als in der Kontrollgruppe $(-0.41+/-0.13$ vs. $-0.83+/-0.26$, Mittelwert $+/-S D, p=0.002$ ), lag diese 12 Stunden nach Behandlungs-beginn bei beiden Gruppen unter der Nachweisgrenze von $100 \mathrm{CFU} / \mathrm{ml}$.

\subsection{Quantifizierung von Pneumolysin}

Vor Behandlungsbeginn der Tiere 12 Stunden nach Infektion gab es keine signifikanten Unterschiede zwischen beiden Gruppen bezüglich der 
Pneumolysinkonzentration im Liquor $(p>0.05)$. Durch die Behandlung mit dem B-Laktam-Antibiotikum Ceftriaxon kam es allerdings binnen 2 Stunden nach Behandlungsbeginn $\mathrm{zu}$ einer massiven Freisetzung von Pneumolysin und DNS. In der Versuchsgruppe, die mit Rifampicin vorbehandelt wurde, fand sich kein Anstieg von Ply im Liquor 2 Stunden nach Beginn der antibiotischen Therapie. Es zeigte sich allerdings ein signifikanter An-stieg in der CRO Gruppe verglichen mit der Rifa/CRO Gruppe 2 Stunden nach Behandlungsbeginn (Ply: $p=0.036$, DNA: $p=0.036$ ).

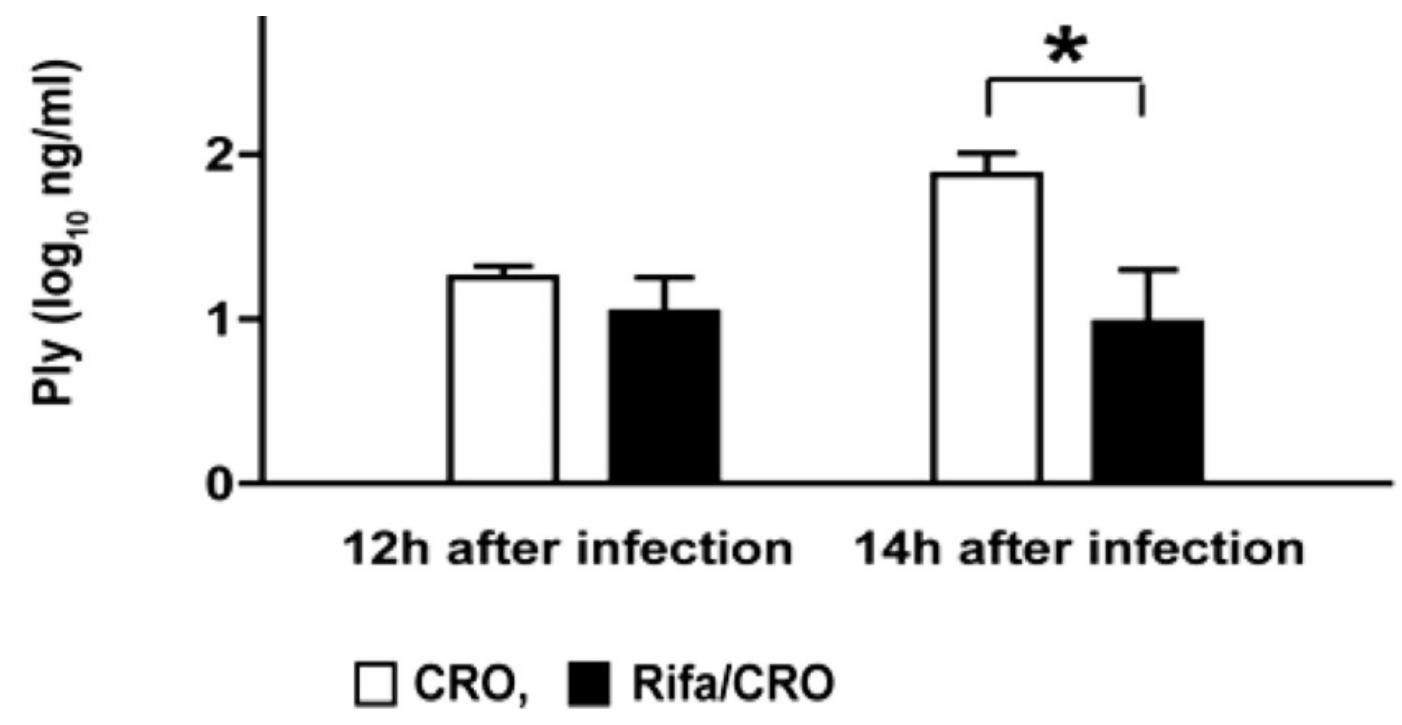

Abbildung 6: Pneumolysinkonzentration in Abhängigkeit von der antibiotischen Therapie. 12 Stunden nach Infektion zeigte sich zum Behandlungsbeginn kein signifikanter Unterschied zwischen der CRO und der Rifa/CRO-Gruppe ( $p>0,05)$. 14 Stunden nach Infektion beziehungsweise 2 Stunden nach Behandlungsbeginn zeigte sich eine signifikant höhere PlyFreisetzung in der CRO-Gruppe im Vergleich zur Rifa/CRO-Gruppe $(p=0,036)$; Ply-Konzentration in $\log _{10} \mathrm{ng} / \mathrm{ml}$. 


\subsection{Entzündungsparameter im Liquor}

Vor Beginn der antibiotischen Behandlung 12 Stunden nach Infektion gab es keine Unterschiede in den beiden Gruppen im Hinblick auf die typischerweise veränderten neurochemischen Parameter (Laktat, Protein, Prostaglandin $E_{2}$, Glukose, Leukozyten) oder die Bakteriendichte im Liquor. Allerdings fand sich auch hier ein signifikanter Unterschied 2 Stunden nach Behandlungsbeginn: In der Versuchsgruppe (Rifa/CRO) waren Prostaglandin $E_{2}$ und Proteingehalt signifikant niedriger (Prostaglandin $E_{2}: p=0.023$, Protein: $p=0.016$ ), der CSF/PlasmaGlukosequotient dagegen signifikant höher $(p=0.013)$ als in der Kontrollgruppe (CRO), s.u.

\subsubsection{Leukozyten}

Es zeigte sich kein signifikanter Unterschied der Leukozytenzahl im Liquor zwischen den beiden Gruppen zu keinem der gemessenen Zeitpunkte $(p>0.05)$.

\subsubsection{Laktat}

Zur Beurteilung der anaeroben Glykolyse im Krankheitsverlauf wurde der Laktatgehalt im Liquor bestimmt. Dabei fanden sich keine signifikanten Unterschiede ( $p>0.05)$ zwischen Kontroll- und Versuchsgruppe. 


\subsubsection{Protein}

Aufgrund der erhöhten Permeabilität der Blut-Hirn-Schranke und des verlangsamten Liquorflusses bei bakterieller Meningitis steigt der Proteingehalt im Liquor an. Dabei war der Proteingehalt im Liquor in der Kontrollgruppe (CRO) 2 Stunden nach Therapiebeginn signifikant höher $(p=$ 0.016) als in der Versuchsgruppe (Rifa/CRO).

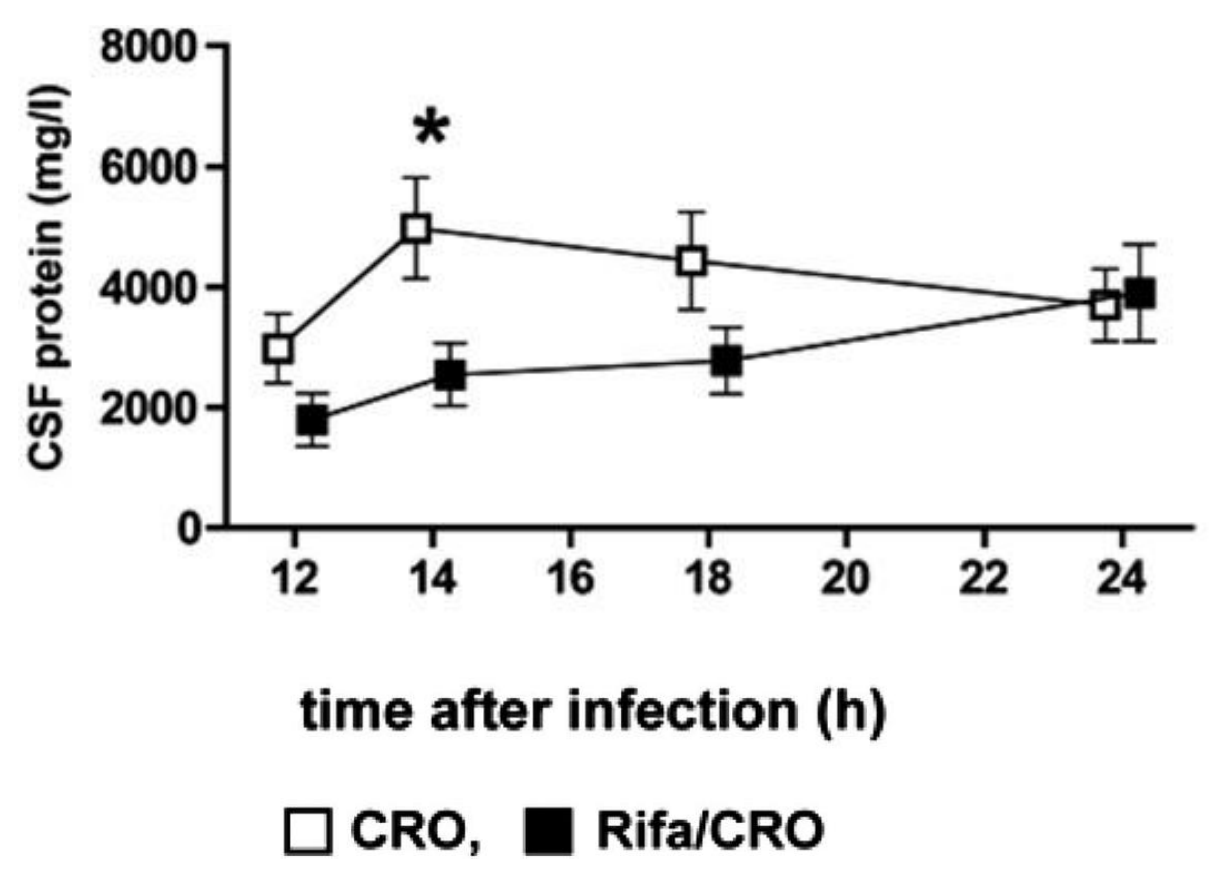

Abbildung 7: Proteinkonzentration im Überstand in Abhängigkeit von der antibiotischen Therapie. 14 Stunden nach Infektion zeigte sich in der CRO-Gruppe eine signifikant höhere Proteinkonzentration im Vergleich zur Rifa/CRO-Gruppe ( $p=0,016)$; Proteinkonzentration in $\mathrm{mg} /$. 


\subsubsection{Prostaglandin $E_{2}$}

Der Entzündungsmediator Prostaglandin $\mathrm{E}_{2}$ steigt im Rahmen eines entzündlichen Geschehens typischerweise an, wobei die Intensität des Anstiegs mit der Intensität der Entzündung korreliert. 2 Stunden nach Behandlungsbeginn konnte im Liquor der Kontrollgruppe (CRO) signifikant mehr Prostaglandin $E_{2}$ nachgewiesen werden $(p=0.023)$ als in der Versuchsgruppe (Rifa/CRO).

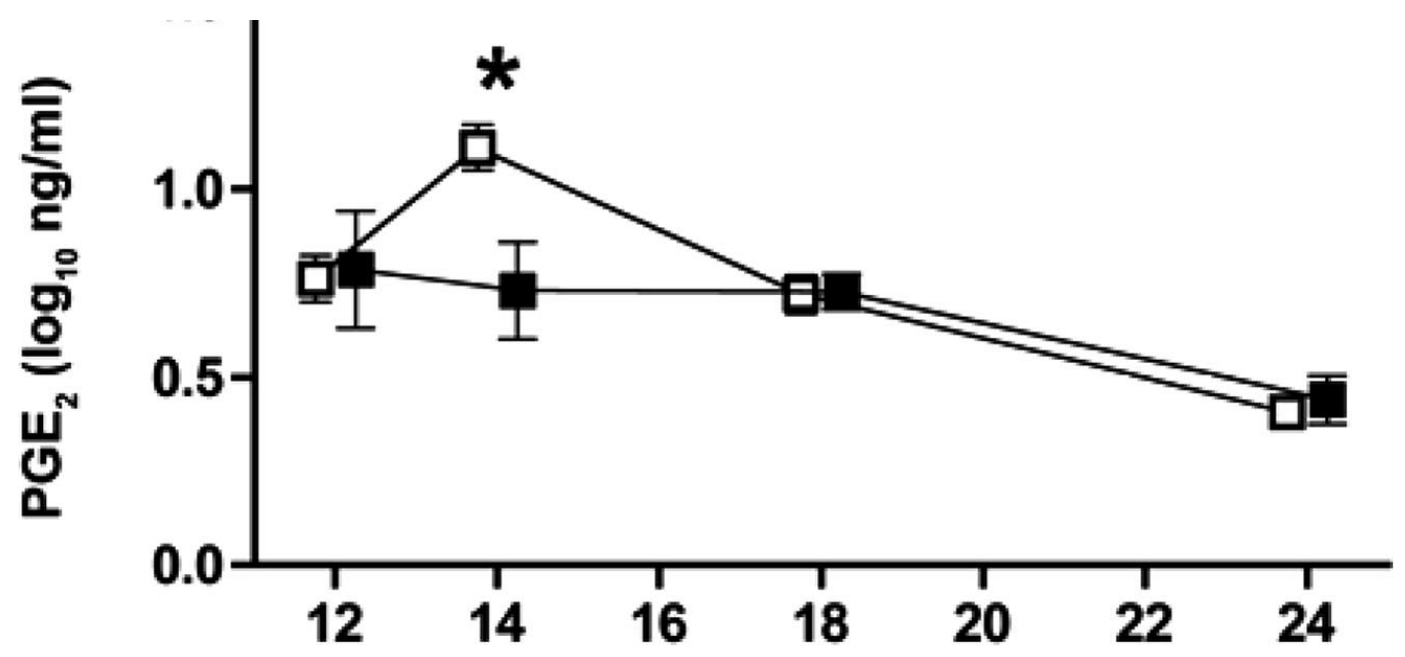

time after infection (h)

$\square$ CRO, $\square$ Rifa/CRO

Abbildung 8: Prostaglandin $E_{2}$-Konzentration im Überstand in Abhängigkeit von der antibiotischen Therapie. 14 Stunden nach Infektion zeigte sich in der CRO-Gruppe im Vergleich zur Rifa/CRO-Gruppe eine signifikant höhere Prostaglandin $E_{2}$-Konzentration $(p=0,023)$; Prostaglandin $E_{2^{-}}$ Konzentration in $\log _{10} \mathrm{ng} / \mathrm{ml}$. 


\subsubsection{Glukose}

Im Rahmen der bakteriellen Meningitis kommt es zu typischen Veränderungen des Glukose-CSF/Plasma-Quotienten. In der Kontrollgruppe kam es zu einem signifikant ausgeprägteren Abfall dieses Quotienten ( $p=$ 0.013) als in der Versuchsgruppe.

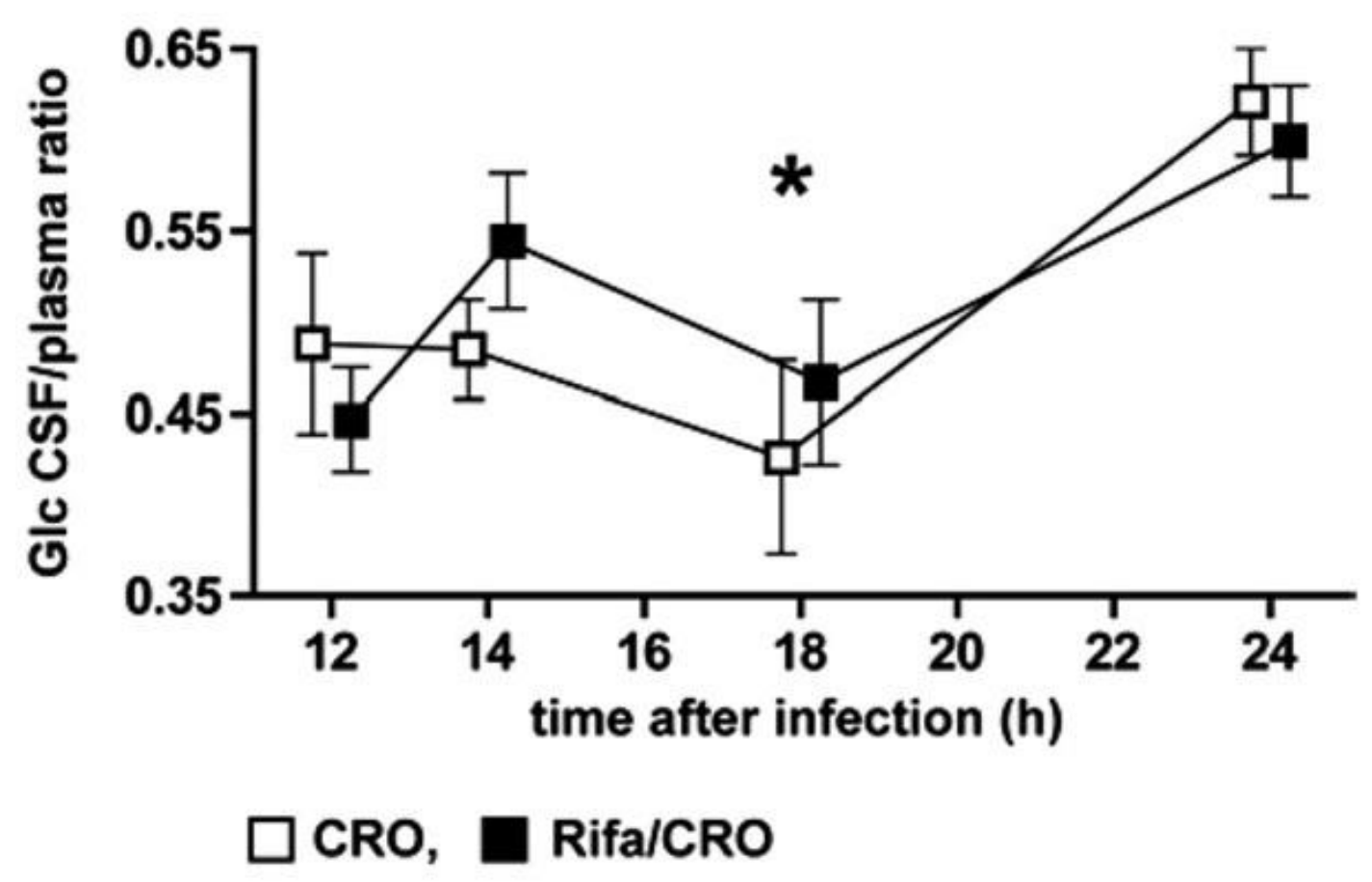

Abbildung 9: Glukosekonzentration im Überstand in Abhängigkeit von der antibiotischen Therapie. In der CRO-Gruppe kam es zu einem signifikant stärkeren Abfall dieses Quotienten als in der Rifa/CRO-Gruppe ( $p=$ $0,013)$. 


\subsubsection{Bakteriendichte}

In der Kontrollgruppe (CRO) kam es zu einem signifikant schnelleren Abfall der Bakteriendichte $(\Delta \log \mathrm{CFU} / \mathrm{ml} / \mathrm{h})$ im Liquor als in der Versuchsgruppe (Rifa/CRO) (-0.83+/- 0.26 gegenüber $-0.41+/-0.13, p=0.002)$. 12 Stunden nach Behandlungsbeginn lag die Bakteriendichte allerdings bei beiden Gruppen unter der Nachweisgrenze von $100 \mathrm{CFU} / \mathrm{ml}$.

\subsubsection{Körpertemperatur}

Während der Meningitis kam es bei allen Tieren zu einer Erhöhung der Körpertemperatur, es konnte aber kein signifikanter Unterschied im Vergleich der beiden Gruppen festgestellt werden ( $p>0.05)$.

\subsection{Apoptosen im Gyrus dentatus}

Nur die Hirne der Tiere, die volle 24 Stunden nach Infektion überlebten, wurden histopathologisch auf Apoptosen hin untersucht und ausgewertet, um einen möglichen Einfluss der Überlebenszeit auf die Anzahl der Apoptosen auszuschließen. Die Rate an apoptotischen Neuronen schwankte zwischen 36 und 315 (Mittelwert 137) pro mm² Fläche der Körnerzellschicht des Gyrus dentatus. In der mit Rifampicin vorbehandelten Vergleichsgruppe kam es zu einer signifikant niedrigeren Apoptoserate im Vergleich zur mit CRO allein behandelten Kontrollgruppe (118.7 +/$73.2 / \mathrm{mm}^{2}$ gegenüber $157.3+/-72.3 / \mathrm{mm}^{2}, p=0.017$, gepaarter t-test). 


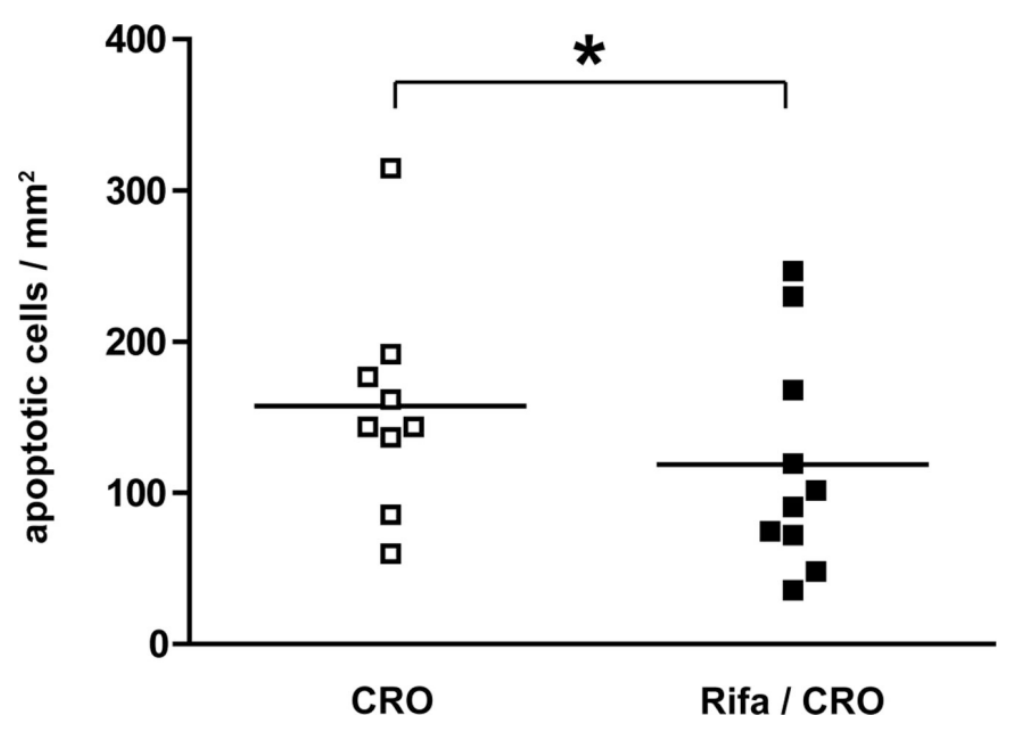

Abbildung 10: Darstellung der Apoptosen im Gyrus dentatus der Formatio hippocampi in Abhängigkeit von der antibiotischen Therapie. Nach erfolgter Antibiose zeigten sich in der Rifa/CRO-Gruppe signifikant weniger Apoptosen in diesem Areal als in der CRO-Gruppe $(p=0,017)$; angezeigt wird die Anzahl der apoptotischen Zellen $/ \mathrm{mm}^{2}$. 


\section{Diskussion}

\subsection{Optimierungsbedarf und aktuelle Ansätze in der Therapie der bakteriellen Meningitis}

Angesichts der hohen Rate an neurologischen Folgeschäden sowie der nach wie vor hohen Letalität der bakteriellen Meningitis trotz Verfügbarkeit wirksamer Antibiotika ist es von herausragender Bedeutung, Behandlungsansätze zu entwickeln, um die neurologischen und neuropsychologischen Folgeerkrankungen von betroffenen Patienten zu reduzieren.

Trotz intensiver Forschung sowie zahlreicher experimenteller und klinischer Studien hat bisher alleine die ebenfalls nicht unumstrittene additive Therapie mit Dexamethason vor oder mit Beginn der frühestmöglichen antibiotischen Therapie Einzug in die klinische Routine gehalten (de Gans und van de Beek 2002, Leitlinie DGN 2012). Durch die additive Gabe von Dexamethason als antiinflammatorischem und antiödematösem Ansatz soll die häufig beobachtete klinische Verschlechterung der Symptome nach Beginn der antibiotischen Therapie gemildert und Begleitschäden reduziert werden.

Bei europäischen Erwachsenen mit Pneumokokken-Meningitis erzielte die additive Gabe von Dexamethason eine Abnahme der systemischen Komplikationen und der Sterblichkeit (de Gans und van de Beek 2002).

Trotzdem ist die Gabe von Dexamethason nicht unumstritten, da in Tiermodellen wie dem Kaninchen-Meningitis-Modell der neuronale Schaden im Gyrus dentatus des Hippocampus zunahm, was sich im Rattenmodell auch auf die kognitive Funktion der Versuchstiere auswirkte (Zysk et al. 1996, Spreer et al. 2006, Leib et al. 2003). Ebenfalls wurden bei erwachsenen Patienten, die aufgrund chronisch-systemischer Erkrankungen im Rahmen einer Langzeittherapie mit Glukokortikoiden behandelt worden waren, negative Effekte auf die neuropsychologischen Funktionen beob- 
achtet (Keenan et al. 1996). Es konnte beobachtet werden, dass es unter einer Langzeittherapie mit Glukokortikoiden nicht selten zu kognitiven und psychischen Veränderungen wie Manie oder auch Depression kam, die sich nach Absetzen allerdings reversibel zeigten (Brown 2009).

Die Datenlage bleibt widersprüchlich: Eine Meta-Analyse von Placebokontrollierten Doppelblindstudien lieferte keinen signifikanten Unterschied bezüglich Letalität und neurologischen Langzeitschäden bei Patienten, die eine Dexamethasontherapie erhielten im Vergleich zu Patienten, die ein Placebo verabreicht bekamen (van de Beek et al. 2010).

Das Langzeit-Follow-up der randomisierten Doppelblind-Studie von De Gans und Van de Beek aus dem Jahre 2002 hingegen, in der Daten von Patienten ausgewertet wurden, die zwischen 1993 und 2001 zusätzlich mit Dexamethason beziehungsweise Placebo behandelt wurden, lieferte Hinweise darauf, dass Dexamethason sowohl in der akuten Phase der Erkrankung als auch langfristig in einem verbesserten Outcome resultieren kann (Fritz et al. 2012). Ähnliche Ergebnisse lieferte eine niederländische Kohortenstudie, bei der sich ein Rückgang von Letalität und Langzeitschäden unter begleitender Therapie mit Dexamethason zeigte (Brouwer et al. 2010).

Die aktuelle Datenlage unterstützt die These, dass eine adjuvante Glukokortikoidtherapie zumindest in den Industrienationen von Vorteil zu sein scheint (Brouwer et al. 2010, Brouwer et al. 2013). Die adjuvante Dexa-methasongabe wird daher auch in den aktuellen Behandlungsrichtlinien der DGN empfohlen.

Ein anderer in der Diskussion um Dexamethason befürchteter negativer Effekt der zusätzlichen Therapie mit diesem Wirkstoff ist, das die Erfolgsaussichten der antibiotischen Therapie geschmälert werden könnten, da die Pharmakokinetik mancher Antibiotika beeinträchtigt wird. So treten einige Antibiotika bei gleichzeitiger Verabreichung von Dexamethason deutlich schlechter in den Liquor über. 
In einer Studie, in der die Aufnahme von Rifampicin, Ceftriaxon und Vancomycin in den Liquor in Abhängigkeit von der gleichzeitigen Gabe von Dexamethason überprüft wurde, zeigte sich, dass die Liquorkonzentration von Vancomycin bei gleichzeitiger Gabe des Glukokortikoids signifikant niedriger war als bei alleiniger Gabe des Antibiotikums. Dagegen wurde die Aufnahme von Ceftriaxon nur geringfügig und die von Rifampicin gar nicht verringert, wenn diese Substanzen zusammen mit Dexamethason verabreicht wurden (Paris et al. 1994). In einem Kaninchen-Meningitis-Modell mit Penicillin- und Cephalosporinresistenten Keimen zeigte sich, dass unter der Therapie mit Vancomycin und Ceftriaxon bei gleichzeitiger Gabe von Dexamethason die Eliminierung der Keime aus dem Liquor deutlich langsamer verlief als ohne zusätzliche Gabe von Dexamethason. Wurde Vancomycin gegen Rifampicin ausgetauscht, konnte dieser Effekt nicht beobachtet werden (Paris et al. 1994). In erster Linie wird die Penetration hydrophiler Antibiotika in den Liquor reduziert, während die Liquorpenetration lipophiler Wirkstoffe in Kombination mit Dexamethason weitestgehend unbeeinflusst bleibt (Nau et al. 2010).

Ein anderer Ansatz zur Reduktion der Begleitschäden ist die osmotische Therapie mit Glycerol. Im Ratten/Mäusemodell konnte allerdings kein positiver Effekt einer oralen Substitution mit Glycerol nachgewiesen werden (Blaser et al. 2010), ebenso wenig bei einer Studie, die den Einfluss von Glycerol auf postmeningitische Hörschäden bei Kindern untersuchte (Peltola et al. 2010).

Eine prospektive, randomisierte Doppelblind-Studie, bei der Dexamethason und Glycerol sowie die Kombination beider Substanzen miteinander verglichen wurden, kam zu dem Ergebnis, dass sowohl Glycerol als auch Glycerol + Dexamethason das Potential haben, die Rate und das Ausmaß neurologischer Folgeschäden bei Kindern mit bakterieller Meningitis zu reduzieren (Peltola et al. 2007). 
In einer anderen Doppelblindstudie mit erwachsenen Patienten und hoher Prävalenz von HIV-Infektionen konnte kein positiver Effekt durch die zusätzliche Gabe von Glycerol beobachtet werden, es kam unter Glycerol sogar zu einer erhöhten Letalität (Ajdukiewicz et al. 2011).

Nach zunächst positiven Ergebnissen hat die orale Gabe von Glycerol als antiödematöse Therapie in einer aktuellen Metaanalyse keinen positiven Effekt gezeigt, so dass diese Therapie nicht empfohlen werden kann (Wall et al. 2013).

Ein in der Suche nach einer Verbesserung der Therapie der bakteriellen Meningitis vielversprechenderer Ansatz ist die Sterilisation des Liquors bei gleichzeitig möglichst geringer Freisetzung bakterieller Stoffwechselprodukte.

Dabei wird aufgrund der im Vergleich zu anderen Organsystemen geringeren Abwehrmöglichkeiten des Körpers im ZNS prinzipiell der Einsatz bakterizider Antibiotika empfohlen. Der Zustand der Blut-Liquor-Schranke bestimmt wesentlich den Übertritt der Antibiotika in den Liquor, in der Regel sind hohe Plasmaspiegel erforderlich, um die nötigen Konzentrationen im Liquor zu erreichen. Für einen optimalen bakteriziden Effekt sollte mindestens das 10-fache der MHK im Liquor erreicht werden, wobei dieses Ziel außer durch den Zustand der Blut-Liquor-Schranke durch die Serumproteinbindung, die jeweilige Lipophilie und das spezifische molekulare Gewicht des entsprechenden Antibiotikums beeinflusst wird ( $\mathrm{Nau}$ et al. 1998).

Die Blut-Hirn-Schranke besteht im Wesentlichen aus dem cerebrovaskulären Endothel (Reese and Karnovsky 1967), das eine selektive Permeabilität aufweist. Die Blut-Liquor-Schranke wird in erster Linie durch das Epithel des Plexus choroideus gebildet, das ebenfalls, unter anderem bedingt durch tight junctions zwischen den Zylinderepithelzellen, selektiv permeabel ist. Da die Membranen der entsprechenden Zellen einen hohen Lipid-anteil aufweisen, diffundieren lipophile Substanzen leichter in den Liquor. So gelangen beispielsweise Cephalosporine, die eine 
gewisse Lipophilie aufweisen, leichter in den Liquor cerebrospinalis (Radouane et al. 1996). Limitiert wird die Aufnahme auch der lipophilen Substanzen unter anderem durch die jeweilige Plasma-Protein-Bindung. Man geht davon aus, dass die an Plasma-Proteine gebundene Fraktion des Antibiotikums die Blut-Hirn-Schranke nur zu einem kleinen Anteil passieren kann (Norrby 1985), wodurch effektive Wirkstoffkonzentrationen schwerer erreicht werden.

Aufgrund der Wirkung bakteriolytischer Antibiotika kommt es im Rahmen der Behandlung durch Freisetzung bakterieller Stoffwechselprodukte vermutlich zu zusätzlichen Schäden des ZNS, weshalb sich unsere wissenschaftlichen Untersuchungen damit beschäftigen, durch eine Reduktion der Freisetzung auf eine Verminderung dieser Schäden hinzuwirken.

Hier erscheint der Ansatz von besonderem Interesse, durch eine Modifikation der antibiotischen Behandlung die induzierte Bakteriolyse abzumildern. Aufgrund bislang unzureichender und teils widersprüchlicher Ergebnisse bei adjuvanten Therapiekonzepten scheint es umso wichtiger und vielversprechender, den Fokus auf die antibiotische Therapie zu richten, um die damit einhergehende Lyse zu reduzieren. Dieser Ansatz wird auch von anderen Autoren und Arbeitsgruppen aufgegriffen und als vielversprechend favorisiert (Koedel et al. 2010, Nau et al. 2013).

Dass dieser Ansatz einen Einfluss auf den Verlauf und die histopathologische sowie laborchemische Schädigungskaskade bei einer bakteriellen Meningitis haben kann, zeigt die vorliegende Studie. 


\subsection{Die Bedeutung bakterieller Stoffwechsel- produkte und Zellwandbestandteile}

Ein entscheidender Schritt in der Auslösung der Entzündungskaskaden bei der bakteriellen Meningitis ist die Freisetzung toxischer und proinflammatorischer bakterieller Stoffwechselprodukte (Nau und Brück 2002, Weber und Tuomanen 2007). Die freigesetzten bakteriellen Zellwandbestandteile, bakterielle DNS und zytoplasmatische Faktoren stimulieren das angeborene und erworbene Immunsystem. Dies führt zur Aktivierung von lokalen und systemischen Zellen des Immunsystems wie Gliazellen und einwandernden Leukozyten und zur Freisetzung zahlreicher proinflammatorischer Mediatoren sowie freier Radikale. Die Inokulation von Lipopolysacchariden (LPS) führt binnen weniger Stunden zu einem starken Anstieg von Tumor-Nekrose-Faktor- $\alpha$ (TNF- $\alpha$ ), Interleukin 1 (IL-1) und Interleukin 6 (IL-6) (Waage et al. 1989). Sie verstärken die meningeale Entzündungsreaktion und können multifaktoriell zu einer Erhöhung des intrakraniellen Druckes mit der Gefahr eines Hirnödems führen (Burroughs et al. 1993).

Zusätzlich zu ihrer proinflammatorischen Potenz schädigen einige der von Bakterien freigesetzten Toxine auch direkt Gewebszellen des ZNS. So entfaltet der Virulenzfaktor Pneumolysin, der von Pneumokokken freigesetzt wird, direkt lytische Effekte auf eukaryontische Zellen und somit auch auf Neurone (Braun et al. 2002, Stringaris et al. 2002), zusätzlich zu seiner proinflammatorischen Wirkung (Mitchell 2000). Zudem kann die Reduktion der Pneumolysinfreisetzung auch stellvertretend betrachtet werden für die Reduktion anderer proinflammatorischer Substanzen aus dem Zytoplasma durch eine spontane oder induzierte Lyse der Bakterien.

Die meisten Stämme von $S$. pneumoniae synthetisieren Pneumolysin (Kanclerski und Möllby 1987). Es handelt sich um ein cholesterolabhängiges Zytolysin, das in der Lage ist, transmembranäre Poren auszu- 
bilden, die zur Lyse der betroffenen Zelle führen (Kelly und Jedrzejas 2000, Stringaris et al. 2002). Außerdem hat es apoptosefördernde Eigenschaften (Braun et al. 2002). Auf ortsständige Zellen des Immunsystems wie Mikrogliazellen wirkt Pneumolysin in geringeren Konzentrationen proinflammatorisch; in höheren Konzentrationen reduziert es das Überleben der Zellen deutlich (Ebert et al. 2005). Stämme von S. pneumoniae, die aufgrund einer Mutation die Fähigkeit zur Pneumolysinbildung eingebüßt haben, sind weniger virulent (Paton et al. 1993, Wellmer et al. 2002). Andere bakterielle Produkte mit vorwiegend proinflammatorischer Wirkung sind beispielsweise bakterielle DNS und Zellwandbestandteile. Bakterielle DNS hat einen indirekt toxischen Effekt über die Stimulation von mikroglialem TLR9 und über die daraus resultierende Freisetzung von NO und TNF- $\alpha$ (lliev et al. 2004). Bei Patienten mit bakterieller Meningitis werden proinflammatorische und toxische bakterielle Stoffwechselprodukte in den Liquor freigesetzt, wie es bereits für das Pneumolysin (Spreer et al. 2003) sowie die Lipoteichonsäuren und Teichonsäuren gezeigt werden konnte (Schneider et al. 1999).

Das Ausmaß der Freisetzung bakterieller Stoffwechselprodukte hängt unter anderem von der Keimlast im Liquor ab, bei spontanem Wachstum und Autolyse werden abhängig von der Erregerlast ansteigende Mengen davon freigesetzt.

$\mathrm{Zu}$ einer zusätzlichen Freisetzung kommt es jedoch durch den Beginn einer Behandlung mit einem zellwandaktiven Antibiotikum, dies führt zu einer plötzlich verstärkten Freisetzung dieser bakteriellen Komponenten (Nau und Eiffert 2005). So konnte gezeigt werden, dass nach Gabe bakteriolytischer Antibiotika wie Vancomycin oder B-Laktam-Antibiotika vermehrt proinflammatorische, bakterielle Stoffwechselprodukte in besonders hohen Konzentrationen freigesetzt wurden (Nau und Eiffert 2002).

In der vorliegenden Studie konnte die deutlich verstärkte Freisetzung von Pneumolysin und bakterieller DNS zwei Stunden nach Behandlungsbeginn mit Ceftriaxon im Vergleich zu einer Behandlung mit Rifa gefolgt 
von CRO belegt werden. Diese Freisetzung förderte die Entzündungskaskade und resultierte in deutlich erhöhten Entzündungsparametern, die in den Versuchstieren mit einem verstärkten neuronalen Schaden assoziiert waren. Es erscheint daher vorteilhaft, eine antibiotische Therapie so zu wählen, dass die Freisetzung von Zellwandbestandteilen und anderen bakteriellen Stoffwechselprodukten minimiert wird. Ein naheliegender und vielversprechender Ansatz ist daher der Einsatz eines nicht lytischen, bakteriziden Antibiotikums wie Rifampicin. Bereits in früheren Studien konnte gezeigt werden, dass die Verwendung von nicht-lytischen Substanzen die Freisetzung von toxischen bakteriellen Bestandteilen deutlich verringert (Stuerz et al. 1998, Nau et al. 1999 b, Böttcher et al. 2000, Spreer et al. 2003). Eine alleinige Therapie mit Rifampicin ist allerdings nicht ratsam, da hierbei ein erhebliches Risiko für Resistenzentwicklung gegeben wäre. Daher erfolgte die Evaluation einer sequentiellen Antibiotikagabe in der vorliegenden Studie. So konnte durch die sequentielle antibiotische Therapie eine deutlich reduzierte Freisetzung proinflammatorischer Stoffwechselprodukte, insbesondere des neurotoxischen Pneumolysins, erreicht werden, ohne das Risiko der Entwicklung resistenter Bakterien einzugehen.

Die Verschlechterung der klinischen Symptome nach Behandlungsbeginn mit einem $\beta$-Laktam-Antibiotikum ist ein in der Klinik bekanntes Problem.

Bei Kindern mit Haemophilus influenzae-Meningitis wurde nach Behandlung mit einem $\beta$-Laktam-Antibiotikum die vermehrte Freisetzung bakterieller Toxine in den Liquor beobachtet. Dies ging mit einer verstärkten Entzündungsreaktion sowie dem Anstieg von Laktat bei gleichzeitigem Absinken des Glukosegehalts im Liquor einher (Arditi et al. 1989). Ein niedriger Liquorglukosegehalt wird mit einer erhöhten Inzidenz von Hörschäden nach Pneumokokken-Meningitis in Verbindung gebracht (Eisenhut et al. 2003).

Kinder mit Meningokokken-Meningitis, die während der präklinischen Behandlung parenteral Penicillin verabreicht bekamen, waren bei Auf- 
nahme in die Klinik schwerer erkrankt als Kinder, die ohne Vorbehandlung in die Klinik kamen. Außerdem zeigte sich bei diesen Patienten eine erhöhte Letalität. Ursächlich dafür könnte bei den antibiotisch anbehandelten Kindern eine primär stärker ausgeprägte Klinik sein, wobei die durch Bakteriolyse induzierte Freisetzung von Endotoxinen als einer der wesentlichen Gründe für diesen Umstand diskutiert wird (Sorensen et al. 1998, Harnden et al. 2006) und somit unsere Hypothese unterstützende Argumente liefert.

Die durch $\beta$-Laktam-Antibiotika induzierte Freisetzung bakterieller Stoffwechselprodukte scheint also einen entscheidenden Einfluss auf den Krankheitsverlauf und wahrscheinlich auch auf die Langzeitergebnisse der betroffenen Patienten zu haben. Daher ist es von größter Wichtigkeit weitergehende Lösungsstrategien zu entwickeln, um den durch die Lyse induzierten zusätzlichen neuronalen Schaden zu reduzieren. Hier bietet die vorliegende Studie einen vielversprechenden Ansatz.

Ein weiteres Problem in der Behandlung stellt die in den letzten Jahrzehnten weltweit stark zunehmende Rate an Penicillin-resistenten Stämmen von S. pneumoniae dar (Linares et al. 2010). In einer Studie wurden Isolate aus 8 europäischen Ländern ausgewertet, die zwischen 2001 und 2003 gewonnen wurden. Dabei zeigte sich, dass knapp 25\% der Isolate von S. pneumoniae Penicillin G-resistent waren, $28 \%$ wiesen eine Resistenz gegenüber Makroliden auf (Reinert et al. 2005). Dabei schwankte die Resistenzlage in den einzelnen Ländern beträchtlich: Am höchsten waren die Resistenzraten gegenüber Penicillin G in Spanien (61.9\%) und Frankreich $(47.6 \%)$, die niedrigsten Resistenzraten wiesen Österreich (4.4\%) und Deutschland (6.0\%) auf (Reinert et al. 2005). Bereits in den 80er Jahren erhöhte sich die Rate der Penicillin-resistenten Pneumokokken in Spanien von 6\% auf über 40\% (Fenoll et al. 1998). In Deutschland wiesen Mitte der 90er Jahre $1.8 \%$ der getesteten Pneumokokkenstämme eine verminderte Empfindlichkeit gegenüber Penicillin auf (Reinert et al. 1995). 
Im Zuge dieser Entwicklungen ergeben sich Probleme bei der antibiotischen Behandlung der bakteriellen Meningitis. Es wird zunehmend schwieriger, eine schnelle Eliminierung der Keime im Liquor zu erreichen, sofern die Therapie nicht entsprechend umgestellt und angepasst wird. Zur Behandlung Penicillin-resistenter Pneumokokkenstämme wird daher bereits in zahlreichen Leitlinien die Kombination aus Rifampicin und Ceftriaxon oder Vancomycin und Ceftriaxon empfohlen (Tunkel et al. 2004, Weisfelt et al. 2006 a, DGN 2012).

Die zunehmenden Resistenzen stellen somit neben den häufigen neurologischen Folgeschäden ein weiteres ernst zu nehmendes Problem dar.

\subsection{Nicht-bakteriolytische Antibiotika}

Das in dieser Arbeit untersuchte Behandlungskonzept zielt auf eine verminderte Freisetzung proinflammatorischer und toxischer bakterieller Stoffwechselprodukte ab. Ziel ist die Reduktion der entzündungsbedingten ZNS-Schäden bei bakterieller Meningitis durch eine Reduktion der Freisetzung bakterieller Toxine. Grundlage ist die Verwendung von Antibiotika, die die Proteinbiosynthese der Bakterien hemmen. Diese wirken bakterizid, ohne dass es dabei zu einer Lyse der Bakterien kommt. In Folge dessen werden deutlich weniger proinflammatorische und toxische bakterielle Bestandteile freigesetzt als unter einer Therapie mit Zellwand-aktiven Substanzen (Böttcher et al. 2000, Spreer et al. 2003, Gerber et al. 2003). Als Vertreter dieser Klasse von Antibiotika wurde in der vorliegenden Studie Rifampicin ausgewählt, bei den in vitro Versuchen kam neben Rifampicin auch Tigezyklin zum Einsatz.

Rifamycine stellen eine Gruppe lipophiler Wirkstoffe mit einer molekularen Masse von etwa $800 \mathrm{Da}$ dar, die aufgrund dieser relativ hohen Masse und einer Plasma-Protein-Bindung von circa $80 \%$ zunächst nur zu einem rela- 
tiv geringen Anteil in den Liquor übertreten (Nau et al. 2010). Aufgrund ihrer ausgeprägten Lipophilie ist die Liquorkonzentration der Rifamycine allerdings nur unwesentlich vom Zustand der Blut-Liquor-Schranke abhängig (Nau et al. 1992). Unter Verwendung von Rifampicin in Kombination mit Ceftriaxon im Kaninchen-Meningitis-Modell im Falle einer Meningitis mit Penicillin-resistenten Pneumokokken erfolgte eine schnelle Eradikation der Erreger unabhängig von einer adjuvanten Dexamethasontherapie (Paris et al. 1994). Es wird empfohlen, in Gegenden mit einer hohen Prävalenz an Penicillin-resistenten Pneumokokken die Kombination Ceftriaxon + Rifampicin der von Ceftriaxon + Vancomycin vorzuziehen oder im Falle einer adjuvanten Therapie mit Dexamethason alle drei Wirkstoffe zugleich anzuwenden (Paris et al. 1994, Tunkel et al. 2004, DGN 2012).

Der biologische Nutzen einer geringeren Freisetzung bakterieller Bestandteile wurde für unterschiedliche bakterielle Infektionen belegt, unabhängig vom verursachenden Bakterienstamm. Im Unterschied zu Zellwandaktiven Antibiotika reduziert die Behandlung mit nicht-bakteriolytischen Antibiotika die Mortalität und Morbidität im Tiermodell mit Escherichia coli, Pseudomonas aeruginosa und Staphylococcus aureus bei Peritonitis und Sepsis (Nau und Eiffert 2005, Nau et al. 1999 b, Friedland et al. 1993 b, Azeh et al. 2002). Außerdem reduzierten die Antibiotika, die über eine Hemmung der Proteinbiosynthese ihre Wirkung entfalten (Rifampicin, Clindamycin, Doxycyclin und Daptomycin), in verschiedenen Tiermodellen der Pneumokokken-Meningitis die Letalität und das Ausmaß des neuronalen Schadens im Vergleich zu $\beta$-Laktam-Antibiotika (Böttcher et al. 2004, Nau et al. 1999 b, Böttcher et al. 2000, Grandgirard et al. 2007, Meli et al. 2006).

Für eine verbesserte Strategie bei der antibiotischen Behandlung von Patienten mit bakterieller Meningitis müssen das Spektrum mikrobiologischer Resistenzen, epidemiologische Daten sowie pharmakokinetische Erkenntnisse berücksichtigt werden. Prognostisch wichtige Faktoren in der 
Behandlung von Patienten mit schweren bakteriellen Infektionen sind die adäquate Auswahl des Antibiotikums und der frühzeitige Behandlungsbeginn.

Aufgrund des vergleichsweise engen Wirkungsspektrums von Clindamycin und Daptomycin sowie dem Risiko der Resistenzentwicklung bei einer Monotherapie mit Rifampicin ist von einer alleinigen Behandlung mit einem der oben genannten nicht-bakteriolytischen Antibiotika abzuraten. Eine Kombination verschiedener Antibiotika kann aber durchaus zur effektiven Therapie eingesetzt werden. Speziell bei der Behandlung Penicillinresistenter Pneumokokken-Stämme ist die Kombination aus Rifampicin und Ceftriaxon bereits in den Behandlungsrichtlinien empfohlen worden (Tunkel et al. 2004, Weisfelt et al. 2006 a, DGN 2012).

\begin{tabular}{|c|c|}
\hline Bakterieller Erreger & Üblicherweise wirksame Antibiotika ${ }^{1}$ \\
\hline Neisseria meningitidis & $\begin{array}{l}\text { Penicillin G, Ampicillin, Ceftriaxon (oder Cefotaxim), } \\
\text { Rifampicin }{ }^{2}\end{array}$ \\
\hline $\begin{array}{l}\text { Streptococcus pneumoniae } \\
\text { - } \quad \text { Penicillin-empfindlich }(\mathrm{MIC} \leq 0,06 \mu \mathrm{g} / \mathrm{ml}) \\
\text { - } \quad \text { Penicillin-resistent }(\mathrm{MIC}>0,06 \mu \mathrm{g} / \mathrm{ml})\end{array}$ & $\begin{array}{l}\text { - Penicillin G, Ceftriaxon (oder Cefotaxim) } \\
\text { Cefotaxim (oder Ceftriaxon) + Vancomycin oder } \\
\text { Cefotaxim (oder Ceftriaxon) + Rifampicin²; } \\
\text { Meropenem, Cefepim }\end{array}$ \\
\hline Haemophilus influenzae & Ceftriaxon (oder Cefotaxim), Ampicillin \\
\hline Gruppe-B-Streptokokken (Streptococcus agalactiae) & $\begin{array}{l}\left.\text { Penicillin G (+ Gentamicin }{ }^{2}\right) \text {, Ceftriaxon, Ampicillin } \\
\left(+ \text { Gentamicin }^{2}\right) \text {, Vancomycin }\end{array}$ \\
\hline $\begin{array}{l}\text { gramnegative Enterobacteriaceae (z. B. Klebsiella, } \\
\text { E. coli, Proteus) }\end{array}$ & Ceftriaxon (oder Cefotaxim), Meropenem, Cefepim \\
\hline Pseudomonas aeruginosa & $\begin{array}{l}\text { Ceftazidim + Aminoglykosid², Meropenem + Amino- } \\
\text { glykosid, Cefepim + Aminoglykosid, Ciprofloxacin }\end{array}$ \\
\hline Staphylokokken (Methicillin-empfindlich) & $\begin{array}{l}\text { Fosfomycin², Rifampicin }{ }^{2} \text {, Cefazolin, Vancomycin, } \\
\text { Linezolid }^{3} \text { (oder Flucloxacillin) }\end{array}$ \\
\hline Staphylokokken (Methicillin-resistent) & $\begin{array}{l}\text { Vancomycin, Fosfomycin oder Rifampicin }{ }^{2} \text { (in } \\
\text { Kombination mit Vancomycin), Linezolid }{ }^{3} \text {, } \\
\text { Trimethoprim-Sulfamethoxazol }\end{array}$ \\
\hline Listeria monocytogenes & $\begin{array}{l}\text { Ampicillin (+ Gentamicin²), Trimethoprim- } \\
\text { Sulfamethoxazol, Meropenem }\end{array}$ \\
\hline Bacteroides fragilis & Metronidazol, Meropenem, Clindamycin \\
\hline $\begin{array}{l}{ }^{1} \text { Die Wahl der Antibiotika richtet sich nach dem Erge } \\
{ }^{2} \text { Rifampicin, Fosfomycin und Aminoglykoside dürfen } \\
\text { Monotherapie gegeben werden. }\end{array}$ & $\begin{array}{l}\text { nis der Resistenzprüfung (Antibiogramm). } \\
\text { legen der Gefahr von Resistenzentwicklungen nicht in }\end{array}$ \\
\hline
\end{tabular}


Abbildung 11: Gezeigt wird die empfohlene antibiotische Therapie der bakteriellen Meningitis bei bekanntem Erreger. Modifizierter Auszug aus: „Leitlinien für Diagnostik und Therapie in der Neurologie" der DGN 2012.

Eine Empfindlichkeit gegenüber Rifampicin darf aufgrund der aktuellen Datenlage in Westeuropa angenommen werden im Falle ambulant erworbener typischer Meningitiserreger des Erwachsenen wie S. pneumoniae, $N$. meningitidis, $H$. influenzae und $L$. monozytogenes (Weisfelt et al. 2006 a, Hof 2003, Stille et al. 2005, Yogev und Guzman-Cottrill 2005). Es ist - wie die Fluorchinolone und Ceftriaxon - Teil der Therapieempfehlung für die antibiotische Prophylaxe von Personen, die zu Patienten mit einer $N$. meningitidis- oder $H$. influenzae-Infektion Kontakt hatten (Stille et al. 2005, DGN 2012).

\begin{tabular}{|c|c|}
\hline Antibiotikum und Altersgruppe & Dosierung \\
\hline $\begin{array}{l}\text { Rifampicin }{ }^{1,2} \text { : } \\
\text { - Jugendliche und Erwachsene ab } 60 \mathrm{~kg} \\
\text { - Säuglinge, Kinder und Jugendliche bis } 60 \mathrm{~kg} \\
\text { - Neugeborene }\end{array}$ & $\begin{array}{l}\text { - } \quad 600 \mathrm{mg} \text { alle } 12 \mathrm{~h} \text { für } 2 \text { Tage p. o. } \\
\text { - } \quad 10 \mathrm{mg} / \mathrm{kg} \text { alle } 12 \mathrm{~h} \text { für } 2 \text { Tage p. o. } \\
\text { - } \quad 5 \mathrm{mg} / \mathrm{kg} \text { alle } 12 \mathrm{~h} \text { für } 2 \text { Tage p. } 0 .\end{array}$ \\
\hline $\begin{array}{l}\text { Ciprofloxacin 2,3: } \\
\text { - Erwachsene }\end{array}$ & - 500 mg als Einzeldosis p. o. \\
\hline $\begin{array}{l}\text { Ceftriaxon: } \\
\text { - Erwachsene und Kinder } \geq 12 \text { Jahre } \\
\text { - Kinder bis } 12 \text { Jahre }\end{array}$ & $\begin{array}{l}\text { - } \quad 250 \mathrm{mg} \text { als Einzeldosis i. m. } \\
\text { - } \quad 125 \mathrm{mg} \text { als Einzeldosis i. m. }\end{array}$ \\
\hline
\end{tabular}

Abbildung 12: Gezeigt wird die empfohlene antibiotische Prophylaxe von Kontaktpersonen zu Patienten mit bakterieller Meningitis. Auszug aus: "Leitlinien für Diagnostik und Therapie in der Neurologie" der DGN 2012. 
Ein weiterer Vorteil von Rifampicin ist seine Lipophilie, es gelangt dadurch relativ schnell in den Liquor cerebrospinalis (Nahata et al. 1990, Nau et al. 1992). Auch bei der Therapie der tuberkulösen Meningitis wird Rifampicin mit Erfolg eingesetzt (Mitchinson 1992).

Des Weiteren werden Rifampicin immunsupressive Eigenschaften zugeschrieben. So wurde beschrieben, dass Rifampicin an Glukokortikoidrezeptoren binden und diese aktivieren kann (Calleja et al. 1998). Es ist also möglich, dass Rifampicin nicht nur deshalb neuroprotektiv ist, weil es die Bakterien nicht lysiert, sondern auch, weil es potentiell in der Lage ist, eine immunsupressive Wirkung, ähnlich der der Glukokortikoide, zu entfalten. Allerdings wird diese zusätzliche Wirkung von Rifampicin von anderen Autoren angezweifelt (Herr et al. 2000) und ist auch für die Praxis eher von untergeordneter Bedeutung.

Mit hoher Wahrscheinlichkeit aber führt die Vorbehandlung mit Rifampicin zu einer deutlich geringeren Freisetzung bakterieller Stoffwechselprodukte, so auch in der vorliegenden Studie, so dass bei diesem Therapiekonzept durchaus mit einem verminderten Begleitschaden gerechnet werden kann.

Wahrscheinlich durch den gleichen Effekt der verminderten Freisetzung von Erregerbestandteilen führte auch das Lipopeptid Daptomycin im Tiermodell der bakteriellen Meningitis im Vergleich zu Ceftriaxon zu signifikant geringeren neuronalen Schäden, einer geringeren Entzündungsreaktion im Liquor und einer schnelleren Keimelimination (Grandgirard et al. 2010). Zu beachten ist dabei allerdings das schmale Behandlungsspektrum, da es nur gegenüber grampositiven Erregern wirksam ist.

Aktuelle Studien untersuchten ebenfalls den potenziellen Nutzen einer sequentiellen Therapie mit Daptomycin. Im Ratten-Modell wurde gezeigt, dass es im Rahmen einer Pneumokokken-Meningitis unter der Verwendung von Daptomycin in Kombination mit Ceftriaxon zu signifikant weniger Hörschäden und hippocampalen Apoptosen kam als unter alleiniger Therapie mit Ceftriaxon oder der Kombination aus Rifampicin und Ceftriaxon (Grandgirard et al. 2012). 
Ähnlich vielversprechende Ergebnisse lieferte eine experimentelle Studie, bei der Clindamycin und Ceftriaxon miteinander verglichen wurden. Unter der Therapie mit Clindamycin kam es zur deutlich verminderten Freisetzung bakterieller Stoffwechselprodukte und weniger neuronalen Schäden des Hippocampus als unter der Therapie mit Ceftriaxon (Böttcher et al. 2004), auch hier gilt es allerdings, das schmale Wirkspektrum zu beachten.

Auch das in der vorliegenden Studie bei den In-vitro-Versuchen verwendete Glycylcyclin Tigezyklin führte zu einer signifikant geringeren Freisetzung proinflammatorischer bakterieller Stoffwechselprodukte. So zeigte sich eine deutlich geringere Freisetzung von Pneumolysin im Vergleich zur Therapie mit Ceftriaxon. Möglicherweise ließe sich daraus ein weiterer interessanter Therapieansatz herleiten, der zunächst bei Forschungsarbeiten zum Einsatz kommen könnte.

Der besondere und neue Aspekt unseres Behandlungskonzeptes liegt in der sequentiellen Applikation von Rifampicin und Ceftriaxon. Wie oben bereits erläutert, wäre eine Initialtherapie mit Rifampicin effektiv gegenüber den gängigen Erregern einer bakteriellen Meningitis. Trotzdem ist Rifampicin in den aktuellen Behandlungsrichtlinien kein Medikament der ersten Wahl, da die potenzielle Entwicklung von Resistenzen ein hohes Risiko darstellen würde.

In jedem Fall ist eine frühe effektive antibiotische Therapie von herausragender Bedeutung.

Es ist bekannt, dass die Rate schwerwiegend verlaufender Meningitiden umso höher ist, je später die Gabe effektiver Antibiotika erfolgt. Während kein Unterschied bei der Rate an schweren Verläufen bei Patienten mit bakterieller Meningitis festzustellen war, die während der ersten 2 Stunden, zwischen den ersten 2 bis 4 Stunden oder zwischen 4 bis 6 Stunden nach Eintreffen in der Klinik behandelt wurden, stieg die Rate an schweren Verläufen stark an, sobald das Zeitintervall 6 bis 8 Stunden oder mehr betrug (Proulx et al. 2005). 
Im Hinblick auf die Umsetzung dieses Konzeptes in die klinische Praxis wurde in der hier vorliegenden Arbeit ein sehr kurzes Zeitintervall zwischen dem Beginn der Vorbehandlung mit Rifampicin und der nachfolgenden Therapie mit Ceftriaxon untersucht. In diesem KaninchenMeningitis-Modell konnte gezeigt werden, das eine Vorbehandlung mit Rifampicin von nur 1 Stunde Dauer die durch Ceftriaxon induzierte Freisetzung schädlicher Stoffwechselprodukte von S. pneumoniae signifikant senkte und dadurch die Entzündungsreaktion und der Infekt-assoziierte Neuronenverlust deutlich abgeschwächt wurde. In früheren Experimenten wurde ein längeres Zeitintervall von 6 Stunden überprüft (Spreer et al. 2003, Gerber et al. 2003). Eine 6-stündige Vorbehandlung mit Rifampicin reduzierte die Rate apoptotischer Neurone um nahezu 60\% (Gerber et al. 2003). In der vorliegenden Studie konnte die Rate apoptotischer Neurone um knapp 30\%, von $157.3\left( \pm 72.3 / \mathrm{mm}^{2}\right)$ in der Kontrollgruppe (Ceftriaxon) auf $118.7\left( \pm 73.2 / \mathrm{mm}^{2}\right)$ in der Versuchsgruppe, gesenkt werden. Die Reduktion von Apoptosen ist insofern besonders wichtig, da erhöhte Apoptoseraten im Hippocampus mit Gedächtnis- und Lerndefiziten einhergehen (Hofer et al. 2011).

Anhand dieser Ergebnisse lässt sich schlussfolgern, dass der neuroprotektive Effekt in vivo bei einer Vorbehandlung mit Rifampicin abnimmt, wenn die Vorbehandlungszeit von 6 Stunden auf 1 Stunde verkürzt wird. Im Hinblick auf die Umsetzung dieser Erkenntnisse in einer klinischen Studie muss das Zeitintervall zwischen der Vorbehandlung mit Rifampicin und der anschließenden Behandlung mit Ceftriaxon einen Kompromiss darstellen sowohl bezüglich des Sicherheitsaspektes (empfohlene frühzeitige Gabe des etablierten Antibiotikums und somit möglichst kurzes Intervall zwischen der Gabe von Rifa und CRO) als auch bezüglich des zu erwartenden neuroprotektiven Effektes durch die Vorbehandlung mit einem nicht-bakteriolytischen Antibiotikum. 


\section{Zusammenfassung}

Bei der Pneumokokken-Meningitis handelt es sich um eine schwerwiegende und lebensbedrohliche ZNS-Infektion. Die Reduktion der hohen Sterblichkeit und der behindernden Langzeitfolgen betroffener Patienten ist Ziel der dieser Arbeit zugrundeliegenden Forschung.

Im Rahmen dieser experimentellen Arbeit wurde der Einfluss einer sequentiellen Kombination von etablierten Antibiotika auf den durch eine Pneumokokken-Meningitis bedingten Gewebeschaden in vitro und in vivo im Kaninchen-Meningitis-Modell untersucht.

So wurde der Einfluss des Antibiotikums Rifampicin, eines Hemmstoffes der bakteriellen Proteinbiosynthese, alleine und in Kombination mit dem die Zellwandsynthese hemmenden Standardantibiotikum Ceftriaxon auf die Freisetzung bakterieller Produkte, die induzierte Entzündungsreaktion und den neuronalen Schaden in der Formatio hippocampi untersucht.

Eine Quantifizierung der Freisetzung des Pneumokokkentoxins Pneumolysin erfolgte mittels quantitativem Immunoblot, das Ausmaß der Entzündungsreaktion wurde mittels Liquoranalytik bestimmt, und durch histochemische Analyse der Gehirne der Versuchstiere erfolgte die Bestimmung des neuronalen Gewebsuntergangs.

Eine sequentielle Kombination aus einer Rifampicin-Vorbehandlung und einer in der Folge ergänzten Ceftriaxon-Behandlung reduzierte die Freisetzung von Pneumolysin und bakterieller DNS sowohl in vitro als auch in vivo. Außerdem zeigte sich in vivo eine Reduktion der Entzündungsreaktion und der neuronalen Apoptoserate im hippokampalen Gyrus dentatus der Versuchstiere. Das hierbei gewählte Intervall von 1 Stunde erwies sich dabei als effektiv und ist mit der Maßgabe einer möglichst frühzeitigen antibiotischen Therapie mit einem rasch bakteriziden B-Laktam-Antibiotikum vereinbar.

Die Ergebnisse dieser Studie stellen eine vielversprechende Option dar, die derzeitigen Therapien der bakteriellen Meningitis zu verbessern und 
sind somit von klinischer Relevanz. Diese experimentelle Arbeit stellt die Grundlage dar, um das Konzept einer sequentiellen antibiotischen Behandlung auch im Rahmen weiterführender klinischer Studien zu überprüfen. 


\section{Literaturverzeichnis}

Abeyta M, Hardy GG, Yother J (2003): „Genetic alteration of capsule type but not PspA type affects accessibility of surface-bound complement and surface antigens of Streptococcus pneumoniae." Infect Immun 71(1), 21825

Ajdukiewicz KM, Cartwright KE, Scarborough M, Mwambene JB, Goodson P, Molyneux ME, Zijlstra EE, French N, Whitty CJ, Lalloo DG (2011): "Glycerol adjuvant therapy in adults with bacterial meningitis in a high HIV seroprevalence setting in Malawi: a double-blind, randomised controlled trial." Lancet Infect Dis 11(4), 293-300

Arditi M, Ables L, Yogev R (1989): „Cerebrospinal fluid endotoxin levels in children with $\mathrm{H}$. influenzae meningitis before and after administration of intravenous ceftriaxone." J Infect Dis $\underline{160}(6), 1005-11$

Auburtin M, Wolff M, Charpentier J, Varon E, Le Tulzo Y, Girault C, Mohammedi I, Renard B, Mourvillier B, Bruneel F, Ricard JD, Timsit JF (2006): „Detrimental role of delayed antibiotic administration and penicillinnonsusceptible strains in adult intensive care unit patients with pneumococcal meningitis : the PNEUMOREA prospective multicenter study." Crit Care Med 34(11), 2758-65

Azeh I, Gerber J, Wellmer A, Wellhausen M, Koenig B, Eiffert H, Nau R (2002): „Protein synthesis inhibiting clindamycin improves outcome in a mouse model of Staphylococcus aureus sepsis compared with the cell wall active ceftriaxone." Crit Care Med $\underline{30}(7), 1560-4$

Bagnoli F, Moschioni M, Donati C, Dimitrovska V, Ferlenghi I, Facciotti C, Muzzi A, Giusti F, Emolo C, Sinisi A, Hilleringmann M, Pansegrau W, 
Censini S, Rappuoli R, Covacci A, Masignani V, Barocchi MA (2008): „A second pilus type in Streptococcus pneumoniae is prevalent in emerging serotypes and mediates adhesion to host cells." J Bacteriol 190(15), 548092

Bergmann S, Lang A, Rohde M, Agarwal V, Rennemeier C, Grashoff C, Preissner KT, Hammerschmidt S (2009): „Integrin-linked kinase is required for vitronectin-mediated internalization of Streptococcus pneumoniae by host cells." J Cell Sci 122(Pt2), 256-67

Bermpohl D, Halle A, Freyer D, Dagand E, Braun JS, Bechmann I, Schröder NW, Weber JR (2005): „Bacterial programmed cell death of cerebral endothelial cells involves dual death pathways." J Clin Invest $\underline{115}(6), 1607-15$

Blaser C, Klein M, Grandgirard D, Wittwer M, Peltola H, Weigand M, Koedel U, Leib SL (2010): „Adjuvant glycerol is not beneficial in experimental pneumococcal meningitis." BMC Infect Dis $\underline{10}, 84$

Bogaert D, Engelen MN, Timmers-Reker AJ, Elzenaar KP, Peerbooms PG, Coutinho RA, de Groot R, Hermans PW (2001): „Pneumococcal carriage in children in The Netherlands: a molecular epidemiological study." J Clin Microbiol 39(9), 3316-20

Bogaert D, Thompson CM, Trzcinski K, Malley R, Lipsitch M (2010): „The role of complement in innate and adaptive immunity to pneumococcal colonization and sepsis in a murine model." Vaccine $\underline{28}(3), 681-5$

Bohr V, Paulson OB, Rasmussen N (1984): „Pneumococcal meningitis. Late neurologic sequelae and features of prognostic impact." Arch Neurol $\underline{41}(10), 1045-9$ 
Böttcher T, Gerber J, Wellmer A, Smirnov AV, Fakhrjanali F, Mix E, Pilz J, Zettl UK, Nau R (2000): „Rifampicin reduces production of reactive oxygen species of cerebrospinal fluid phagocytes and hippocampal neuronal apoptosis in experimental Streptococcus pneumoniae meningitis." J Infect Dis 181(6), 2095-8

Böttcher T, von Mering M, Ebert S, Meyding-Lamade U, Kuhnt U, Gerber J, Nau R (2003): „Differential regulation of Toll-like receptor mRNAs in experimental murine central nervous system infections." Neurosci Lett $\underline{344}(1), 17-20$

Böttcher T, Ren H, Goiny M, Gerber J, Lykkesfeldt J, Kuhnt U, Lotz M, Bunkowski S, Werner C, Schau I, Spreer A, Christen S, Nau R (2004): "Clindamycin is neuroprotective in experimental Streptococcus pneumoniae meningitis compared with ceftriaxone." J Neurochem 91(6), 1450-60

Braun JS, Sublett JE, Freyer D, Mitchell TJ, Cleveland JL, Tuomanen EL, Weber JR (2002): „Pneumococcal pneumolysin and $\mathrm{H}(2) \mathrm{O}(2)$ mediate brain cell apoptosis during meningitis." J Clin Invest 109(1), 19-27

Brouwer MC, van de Beek D (2012): „Bacterial meningitis.” Ned Tijdschr Tandheelkd 119(5), 238-42

Brouwer MC, van de Beek D, Heckenberg SG, Spanjaard L, de Gans J (2006): „Community-aquired Listeria monocytogenes meningitis in adults.“ Clin Infect Dis $\underline{43}(10), 1233-8$

Brouwer MC, Tunkel AR, van de Beek D (2010): „Epidemiology, diagnosis, and antimicrobial treatment of acute bacterial meningitis." Clin Microbiol $\operatorname{Rev} \underline{23}(3), 467-92$ 
Brouwer MC, Mclntyre P, Prasad K, van de Beek D (2013): „Corticosteroids for acute bacterial meningitis." Cochrane Database Syst Rev $\underline{4}, 6$ CD004405

Brown ES (2009): „Effects of glucocorticoids on mood, memory, and the hippocampus. Treatment and preventive therapy." Ann NY Acad Sci $\underline{1179}$, 41-55

Bryan CS, Reynolds KL, Crout L (1986): „Promptness of antibiotic therapy in acute bacterial meningitis." Ann Emerg Med 15(5), 544-7

Buja LM, Eigenbrodt ML, Eigenbrodt EH (1993): „Apoptosis and necrosis. Basic types and mechanisms of cell death." Arch Pathol Lab Med 117(12), 1208-14

Burnaugh AM, Frantz LJ, King SJ (2008): „Growth of Streptococcus pneumoniae on human glycoconjugates is dependent upon the sequential activity of bacterial exoglycosidases." J Bacteriol 190(1), 221-30

Burnette WN (1981): "Western blotting: electrophoretic transfer of proteins from sodium dodecyl sulfate-polyacrylamide gels to unmodified nitrocellulose and radiographic detection with antibody and radioiodinated protein A." Anal Biochem 112(2), 195-203

Burroughs M, Rozdzinski E, Geelen S, Tuomanen E (1993): „A structureactivity relationship for induction of meningeal inflammation by muramyl

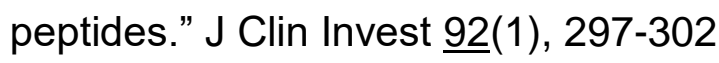

Calleja C, Pascussi JM, Mani JC, Maurel P, Vilarem MJ (1998): „The antibiotic rifampicin is a nonsteroidal ligand and activator of the human glucocorticoid receptor." Nat Med $\underline{4}(1)$, 92-6 
Cohen JJ (1993): „Apoptosis.” Immunol Today 14(3), 126-30

Cundell DR, Gerard NP, Gerard C, Idanpaan-Heikkila I, Tuomanen EI (1995): „Streptococcus pneumoniae anchor to activated human cells by the receptor for platelet-activating factor." Nature $\underline{377}(6548), 435-8$

Dailly E, Verdier MC, Deslandes G, Bouguie R, Tribut O, Bentue-Ferrer D (2012): „Level of evidenc for therapeutic drug monitoring of ceftriaxone." Therapie $\underline{67}(2), 145-9$

Davis KM, Akinbi HT, Standish AJ, Weiser JN (2008): „Resistance to mucosal lysozyme compensates for the fitness deficit of peptidoglycan modifications by Steptococcus pneumoniae." PloS Pathog. $\underline{4}(12)$, e1000241

De Gans J, van de Beek D (2002): "Dexamethasone in adults with bacterial meningitis" N Engl J Med $\underline{347(20), 1549-56}$

De Paolis F, Beghetto E, Spadoni A, Montagnani F, Felici F, Oggioni MR, Gargano N (2007): „Identification of a human immunodominant B-cell epitope within the immunoglobulin A1 protease of Streptococcus pneumoniae." BMC Microbiol $\underline{7}, 113$

Dery MA, Hasbun R (2007): „Changing epidemiology of bacterial meningitis." Curr Infect Dis Rep $\underline{9}(4), 301-7$

DGN-Leitlinie 2012: Leitlinien für Diagnostik und Therapie in der Neurologie. Kapitel: Entzündliche und erregerbedingte Krankheiten. Ambulant erworbene bakterielle (eitrige) Meningoenzephalitis. Stand September 2012. Zugriff: 11/2013. 
Dodge PR, Davis H, Feigin RD, Holmes SJ, Kaplan SL, Jubelirer DP, Stechenberg BW, Hirsh SK (1984): „Prospective evaluation of hearing impairment as a sequela of acute bacterial meningitis." $\mathrm{N}$ Engl $\mathrm{J}$ Med 311(14), 869-74

Ebert S, Gerber J, Bader S, Mühlhauser F, Brechtel K, Mitchell TJ, Nau R (2005): „Dose-dependent activation of microglial cells by Toll-like receptor agonists alone and in combination." J Neuroimmunol 159(1-2), 87-96

Echchannaoui H, Frei K, Schnell C, Leib SL, Zimmerli W, Landmann R (2002): „Toll-like receptor 2-deficient mice are highly susceptible to Streptococcus pneumoniae meningitis because of reduced bacterial clearing and enhanced inflammation." J Infect Dis 186(6), 798-806

Edmond K, Clark A, Korczak VS, Sanderson C, Griffiths UK, Rudan I (2010): „Global and regional risk of disabling sequelae from bacterial meningitis : a systematic review and meta-analysis." Lancet Infect Dis $\underline{10}(5)$, $317-28$

Eisenhut M, Meehan T, Batchelor L (2003): "Cerebrospinal fluid glucose levels and sensorineural hearing loss in bacterial meningitis." Infection 31(4), 247-50

Elm C, Braathen R, Bergmann S, Frank R, Vaerman JP, Kaetzel CS, Chhatwal GS, Johansen FE, Hammerschmidt S (2004): „Ectodomains 3 and 4 of human polymeric Immunoglobulin receptor (hplgR) mediate Invasion of Streptococcus pneumoniae into the epithelium." J Biol Chem $\underline{279}(8), 6296-304$

Esposito S, Semino M, Picciolli I, Principi N (2013): „Should corticosteroids be used in bacterial meningitis in children?" Eur J Paediatr Neurol 17(1), 24-8 
Estler CJ: Pharmaka zur Behandlung und Verhütung von Infektionen (Chemotherapeutika, Antibiotika, Desinfektionsmittel); in: Estler CJ (Hrsg.): Pharmakologie und Toxikologie: Lehrbuch für Mediziner, Veterinärmediziner und Naturwissenschaftler. Schattauer, Stuttgart 1995, 525-902

Feldman C, Anderson R, Cockeran R, Mitchell T, Cole P, Wilson R (2002): "The effects of pneumolysin and hydrogen peroxide, alone and in combination, on human ciliated epithelium in vitro." Respir Med $\underline{96}$ (8), 580-5

Fenoll A, Jado I, Vicioso D, Perez A, Casal J (1998): „Evolution of Streptococcus pneumoniae serotypes and antibiotic resistance in Spain: update (1990 to 1996)." J Clin Microbiol $\underline{36}(12), 3447-54$

Figueiredo AM, Connor JD, Severin A, Vaz Pato MV, Tomasz A (1992): „A pneumococcal clinic isolate with high-level resistance to cefotaxime and ceftriaxone." Antimicrob Agents Chemother $\underline{36}(4), 886-9$

Fishman RA (1982): „Steroids in the treatment of brain edema.” N Engl $J$ Med $\underline{306}(6), 359-60$

Friedland IR, Paris M, Ehrett S, Hickey S, Olsen K, McCracken GH Jr. (1993 a): „Evaluation of antimicrobial regimens for treatment of experimental penicillin- and cephalosporin-resistant pneumococcal meningitis." Antimicrob Agents Chemother 37(8), 1630-6

Friedland IR, Jafari $H$, Ehrett $S$, Rinderknecht $S$, Paris $M$, Coulthard $M$, Saxen H, Olsen K, McCracken GH Jr (1993 b): „Comparison of endotoxin release by different antimicrobial agents and the effect on inflammation in experimental Escherichia coli meningitis." J Infect Dis 168(3), 657-62

Fritz D, Brouwer MC, van de Beek D (2012) : „Dexamethasone and longterm survival in bacterial meningitis." Neurology $\underline{79}(22), 2177-9$ 
Gerber J, Pohl K, Sander V, Bunkowski S, Nau R (2003): „Rifampicin followed by ceftriaxone for experimental meningitis decreases lipoteichoic acid concentrations in cerebrospinal fluid and reduces neuronal damage in comparison to ceftriaxone alone." Antimicrob Agents Chemother $\underline{47}(4)$, 1313-7

Grandgirard D, Schürch C, Cottagnoud P, Leib SL (2007): „Prevention of brain injury by the nonbacteriolytic antibiotic daptomycin in experimental pneumococcal meningitis." Antimicrob Agents Chemother 51(6), 2173-8

Grandgirard D, Oberson K, Bühlmann A, Gäumann R, Leib SL (2010): „Attenuation of cerebrospinal fluid inflammation by the nonbacteriolytic antibiotic daptomycin versus that by ceftriaxone in experimental pneumococcal meningitis." Antimicrob Agents Chemother 54(3), 1323-6

Grandgirard D, Burri M, Agyeman P, Leib SL (2012): „Adjunctive daptomycin attenuates brain damage and hearing loss more efficiently than rifampicin in infant rat pneumococcal meningitis." Antimicrob Agents Chemother 56(8), 4289-95

Harnden A, Ninis N, Thompson M, Perera R, Levin M, Mant D, MayonWhite $R$ (2006): „Parenteral penicillin for children with meningococcal disease before hospital admission: case-control study." BMJ 332(7553), $1295-8$

Heckenberg SG, Brouwer MC, van der Ende A, van de Beek D (2012): "Adjunctive dexamethasone in adults with meningococcal meningitis." Neurology 79(15), 1563-9

Heffron R (1939): „Pneumonia, with special reference to pneumococcus lobar pneumonia." J Am Med Assoc 113(24), 2175 
Hemmi H, Takeuchi O, Kawai T, Kaisho T, Sato S, Sanjo H, Matsumoto M, Hoshino K, Wagner H, Takeda K, Akira S (2000): „A Toll-like receptor recognizes bacterial DNA." Nature $\underline{408}(6813), 740-5$

Herr AS, Wochnik GM, Rosenhagen MC, Holsboer F, Rein T (2000): „Rifampicin is not an activator of glucocorticoid receptor." Mol Pharmacol $\underline{57}(4), 732-7$

Hof H (2003): „Listeriosis: therapeutic options.” FEMS Immunol Med Microbiol $\underline{35}(3), 203-5$

Hofer S, Grandgirard D, Burri D, Fröhlich TK, Leib SL (2011): „Bacterial meningitis impairs hippocampal neurogenesis." J Neuropathol Exp Neurol 70(10), 890-9

Holmes AR, McNab R, Millsap KW, Rohde M, Hammerschmidt S, Mawdsley JL, Jenkinson HF (2001): "The pavA gene of Streptococcus pneumoniae encodes a fibronectin-binding protein that is essential for virulence." Mol Microbiol $\underline{41}(6)$, 395-408

Hsieh HL, Wang HH, Wu CY, Tung WH, Yang CM (2010): „Lipoteichoic acid induces matrix metalloproteinase- 9 expression via transactivation of PDGF receptors and NF-kappaB activation in rat brain astrocytes." Neurotox Res $17(4), 344-59$

Iliev AL, Stringaris AK, Nau R, Neumann H (2004): „Neuronal injury mediated via stimulation of microglial toll-like receptor-9 (TLR9)." FASEB $\mathrm{J}$ $\underline{18}(2), 412-4$

Iliev AL, Djannatian JR, Opazo F, Gerber J, NauR, Mitchell TJ, Wouters FS (2009): „Rapid microtubule bundling and stabilization by the Streptococcus pneumonia neurotoxin pneumolysin in a cholesterol-dependent, 
non-lytic and Src-kinase dependent manner inhibits intracellular trafficking." Mol Microbiol 71(2), 461-77

Jarva H, Janulczyk R, Hellwage J, Zipfel PF, Björck L, Meri S (2002): „Streptococcus pneumoniae evades complement attack and opsonophagocytosis by expressing the $\mathrm{pspC}$ locus-encoded Hic protein that binds to short consensus repeats 8-11 of factor H." J Immunol 168(4), 1886-94

Kadioglu A, Weiser JN, Paton JC, Andrew PW (2008): „The role of Streptococcus pneumoniae virulence factors in host respiratory colonization and disease." Nat Rev Microbiol $\underline{6}(4), 288-301$

Kanclerski K, Möllby R (1987): „Production and purification of Streptococcus pneumoniae hemolysin (pneumolysin)." J Clin Microbiol 25(2), 222-5

Kastenbauer S, Pfister HW (2003): „Pneumococcal meningitis in adults: spectrum of complications and prognostic factors in a series of 87 cases." Brain 126(5), 1015-25

Keenan PA, Jacobson MW, Soleymani RM, Mayes MD, Stress ME, Yaldoo DT (1996): „The effect on memory of chronic prednisone treatment in patients with systemic disease." Neurology $\underline{47}(6), 1396-402$

Kelly SJ, Jedrzejas MJ (2000): „Structure and molecular mechanism of a functional form of pneumolysin: a cholesterol-dependent cytolysin from Streptococcus pneumoniae." J Struct Biol 132(1), 72-81

Kerr JF, Wyllie AH, Currie AR (1972): „Apoptosis: a basic biological phenomenon with wide-ranging implications in tissue kinetics." $\mathrm{Br} \mathrm{J}$ Cancer 26(4), 239-57 
Klein M, Koedel U, Pfister HW (2006): „Oxidative stress in pneumococcal meningitis: a future target for adjunctive therapy?" Prog Neurobiol $\underline{80}(6)$, 269-80

Klugman KP (1990): „Pneumococcal resistance to antibiotics.” Clin Microbiol $\operatorname{Rev} \underline{3}(2), 171-96$

Klugman KP, Friedland IR, Bradley JS (1995): „Bactericidal activity against cephalosporin-resistant Streptococcus pneumoniae in cerebrospinal fluid of children with acute bacterial meningitis." Antimicrob Agents Chemother 39(9), 1988-92

Koedel U: Experimentelle Untersuchungen zur Pathophysiologie der Pneumokokken Meningitis an der Ratte: Bedeutung von reaktiven Sauerstoffspezies und Stickstoffmonoxid sowie Behandlungseffekte von Glukokortikoiden und „antiinflammatorischen Zytokinen“. Med. Diss. München 1996

Koedel U, Angele B, Rupprecht T, Wagner H, Roggenkamp A, Pfister HW, Kirschning CJ (2003): „Toll-like receptor 2 participates in mediation of immune response in experimental pneumococcal meningitis." J Immunol $\underline{170}(1), 438-44$

Koedel U, Rupprecht T, Angele B, Heesemann J, Wagner H, Pfister HW, Kirschning CJ (2004): „MyD88 is required for mounting a robust host immune response to Streptococcus pneumoniae in the CNS." Brain 127(Pt6), 1437-45

Koedel U, Klein M, Pfister HW (2010): „Modulation of brain injury as a target of adjunctive therapy in bacterial meningitis." Curr Infect Dis Rep 12(4), 266-73 
Lee A, Whyte MK, Haslett C (1993): „Inhibition of apoptosis and prolongation of neutrophil functional longevity by inflammatory mediators." J Leukoc Biol $\underline{54}(4), 283-8$

Leib SL, Täuber MG (1999): „Meningitis (II) - akute bakterielle Meningitis.“ Ther Umsch $\underline{56}(11), 640-6$

Leib SL, Kim YS, Chow LL, Sheldon RA, Täuber MG (1996): „Reactive oxygen intermediates contribute to necrotic and apoptotic neuronal injury in an infant rat model of bacterial meningitis due to group B streptococci." J Clin Invest $\underline{98}(11), 2632-9$

Leib SL, Heimgartner C, Bifrare YD, Loeffler JM, Täuber MG (2003): „Dexamethasone aggravates hippocampal apoptosis and learning deficiency in pneumococcal meningitis in infant rats." Pediatr Res $\underline{54}(3), 353-7$

Linares J, Ardanuy C, Pallares R, Fenoll A (2010): „Changes in antimicrobial resistance, serotypes and genotypes in Streptococcus pneumoniae over a 30-year period." Clin Microbiol Infect 16(5), 402-10

Malley R, Henneke P, Morse SC, Cieslewicz MJ, Lipsitch M, Thompson CM, Kurt-Jones E, Paton JC, Wessels MR, Golenbock DT (2003): „Recognition of pneumolysin by Toll-like receptor 4 confers resistance to pneumococcal infection." Proc Natl Acad Sci USA 100(4), 1966-71

Marriott HM, Mitchell TJ, Dockrell DH (2008): „Pneumolysin: a doubleedged sword during the host-pathogen interaction." Curr Mol Med $\underline{8}(6)$, 497-509

McConkey DJ, Hartzell P, Amador-Perez JF, Orrenius S, Jondal M (1989): "Calcium-dependent killing of immature thymocytes by stimulation via the CD3/T cell receptor complex." J Immunol 143(6), 1801-6 
Meli DN, Christen S, Leib SL, Tauber MG (2002): „Current concepts in the pathogenesis of meningitis caused by Streptococcus pneumoniae." Curr Opin Infect Dis 15, 253-7

Meli DN, Coimbra RS, Erhart DG, Loquet G, Bellac CL, Täuber MG, Neumann U, Leib SL (2006): „Doxycycline reduces mortality and injury to the brain and cochlea in experimental pneumococcal meningitis." Infect Immun $\underline{74}(7), 3890-6$

Merkelbach S, Sittinger H, Schweizer I, Müller M (2000): „Cognitive outcome after bacterial meningitis." Acta Neurol Scand 102(2), 118-23

Mitchell TJ (2000): „Virulence factors and the pathogenesis of disease caused by Streptococcus pneumoniae." Res Microbiol 151(6), 413-9

Mitchell L, Smith SH, Braun JS, Herzog KH, Weber JR, Tuomanen El (2004): „Dual phases of apoptosis in pneumococcal meningitis.” J Infect Dis $\underline{190}(11), 2039-46$

Mitchinson DA (1992): „The Garrod Lecture. Understanding the chemotherapy of tuberculosis-current problems." J Antimicrob Chemother 29 (5), 477-93

Morris AC, Hagler HK, Willerson JT, Buja LM (1989): „Relationship between calcium loading and impaired energy metabolism during $\mathrm{Na}+\mathrm{K}+$ pump inhibition and metabolic inhibition in cultured neonatal rat cardiac

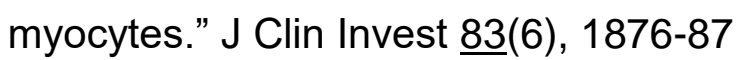

Nahata MC, Durrell DE, Barson WJ (1986): "Ceftriaxone kinetics and cerebrospinal fluid penetration in infants and children with meningitis." Chemotherapy $\underline{32}(2), 89-94$ 
Nahata MC, Fan-Havard P, Barson WJ, Bartkowski HM, Kosnik EJ (1990): „Pharmacokinetics, cerebrospinal fluid concentration, and safety of intravenous rifampicin in pediatric patients undergoing shunt placements." Eur J Clin Pharmacol $\underline{38}(5), 515-7$

Nau R (1992): „Pharmakokinetische Untersuchungen zum Übertritt verschiedener Antibiotika und Osmotherapeutika in den ventrikulären Liquor cerebrospinalis des Menschen." Med. Habil.-Schr. Göttingen 1992

Nau R, Brück W (2002): „Neuronal injury in bacterial meningitis: mechanisms and implications for therapy." Trends Neurosci $\underline{25}$ (1), 38-45

Nau R, Eiffert H (2002): „Modulation of release of proinflammatory bacterial compounds by antibacterials: potential impact on course of inflammation and outcome in sepsis and meningitis." Clin Microbiol Rev 15(1), 95110

Nau R, Eiffert H (2005): „Minimizing the release of proinflammatory and toxic bacterial products within the host: a promising approach to improve outcome in life-threatening infections." FEMS Immunol Med Microbiol $\underline{44}(1), 1-16$

Nau R, Prange HW, Menck S, Kolenda H, Visser K, Seydel JK (1992): „Penetration of rifampicin into the cerebrospinal fluid of adults with uninflamed meninges." J Antimicrob Chemother 29 (6), 719-24

Nau R, Prange HW, Muth P, Mahr G, Menck S, Kolenda H, Sörgel F (1993): „Passage of cefotaxime and ceftriaxone into cerebrospinal fluid of patients with uninflamed meninges." Antimicrob Agents Chemother $\underline{37}(7)$, 1518-24 
Nau R, Zysk G, Schmidt H, Fischer FR, Stringaris AK, Stuertz K, Brück W (1997): „Trovafloxacin delays the antibiotic-induced inflammatory response in experimental pneumococcal meningitis." J Antimicrob Chemother $\underline{39}(6)$, $781-8$

Nau R, Sörgel F, Prange HW (1998): „Pharmacokinetic optimisation of the treatment of bacterial central nervous system infections." Clin Pharmacokinet $\underline{35}(3), 223-46$

Nau R, Soto A, Brück W (1999 a): „Apoptosis of neurons in the dentate gyrus in humans suffering from bacterial meningitis." J Neuropathol Exp Neurol $\underline{58}(3), 265-74$

Nau R, Wellmer A, Soto A, Koch K, Schneider O, Schmidt H, Gerber J, Michel U, Brück W (1999 b): „Rifampicin reduces early mortality in experimental Streptococcus pneumoniae meningitis." J Infect Dis 179(6), 155760

Nau R, Sörgel F, Eiffert H (2010): „Penetration of drugs through the bloodcerebrospinal fluid/blood-brain barrier for treatment of central nervous system infections." Clin Microbiol Rev $\underline{23}(4), 858-83$

Nau R, Djukic M, Spreer A, Eiffert H (2013): „Bacterial meningitis: new therapeutic approaches." 11(10), 1079-95

Norrby SR (1985): „Role of cephalosporins in the treatment of bacterial meningitis in adults. Overview with special emphasis on ceftazidime." Am J Med $\underline{79}(2 A), 56-61$

Noske N, Kämmerer U, Rohde M, Hammerschmidt S (2009): „Pneumococcal interaction with human dentritic cells: phagocytosis, survival, and 
induced adaptive immune response are manipulated by PavA." J Immunol $\underline{183}(3), 1952-63$

Nunez G, London L, Hockenbery D, Alexander M, McKearn JP, Korsmeyer SJ (1990): „Deregulated Bcl-2 gene expression selectively prolongs survival of growth factor-deprived hemopoietic cell lines." J Immunol 144(9), 3602-10

Odio CM, Faingezicht I, Paris M, Nassar M, Baltodano A, Rogers J, SaezLlorens X, Olsen KD, McCracken GH Jr. (1991): „The beneficial effects of early dexamethasone administration in infants and children with bacterial meningitis." N Engl J Med $\underline{324}(22)$, 1525-31

Orihuela C, Mahdavi J, Thornton J, Mann B, Wooldridge KG, Abouseada N, Oldfield NJ, Self T, Ala'Aldeen DA, Tuomanen El (2009): „Laminin receptor initiates bacterial contact with the blood brain barrier in experimental meningitis models." J Clin Invest 119(6), 1638-46

Paris MM, Hickey SM, Uscher MI, Shelton S, Olsen KD, McCracken GH Jr. (1994): „Effect of dexamethasone on therapy of experimental penicillinand cephalosporin-resistant pneumococcal meningitis." Antimicrob Agents Chemother $\underline{38}(6), 1320-4$

Paton JC, Andrew PW, Boulnois GJ, Mitchell TJ (1993): „Molecular analysis of the pathogenicity of Streptococcus pneumoniae: the role of pneumococcal proteins." Annu Rev Microbiol 47, 89-115

Peltola H, Roine I, Fernandez J, Zavala I, Ayala SG, Mata AG, Bologna R, Mino G, Goyo J, Lopez E, de Andrade SD, Sarna S (2007): „Adjuvant glycerol and/or dexamethasone to improve the outcomes of childhood bacterial meningitis: a prospective, randomized, double-blind, placebocontrolled trial." Clin Infect Dis $\underline{45}(10), 1277-86$ 
Peltola H, Roine I, Fernandez J, Gonzales Mata A, Zavala I, Gonzales Ayala S, Arbo A, Bologna R, Goyo J, Lopez E, Mino G, Dourado de Andrade S, Sarna S, Jauhiainen T (2010): „Hearing impairment in childhood bacterial meningitis is little relieved by dexamethasone or glycerol." Pediatrics $\underline{125}(1), 1-8$

Pracht D, Elm C, Gerber J, Bergmann S, Rohde M, Seiler M, Kim KS, Jenkinson HF, Nau R, Hammerschmidt S (2005): „PavA of Streptococcus pneumoniae modulates adherence, invasion and meningeal inflammation." Infect Immun $\underline{73}(5), 2680-9$

Proulx N, Frechette D, Toye B, Chan J, Kravcik S (2005): „Delays in the administration of antibiotics are associated with mortality from adult acute bacterial meningitis." QJM $\underline{98}(4), 291-8$

Quagliarello VJ, Scheld WM (1992): "Bacterial meningitis: pathogenesis, pathophysiology, and progress." N Engl J Med $\underline{327}(12), 864-72$

Quagliarello VJ, Wispelwey B, Long WJ Jr, Scheld WM (1991): „Recombinant human interleukin-1 induces meningitis and blood-brain barrier injury in the rat. Characterization and comparison with tumor necrosis factor." $\mathrm{J}$ Clin Invest $\underline{87}(4), 1360-6$

Quin LR, Moore QC $3^{\text {rd }}$, Mc Daniel LS (2007): „Pneumolysin, PspA, and PspC contribute to pneumococcal evasion of early innate immune responses during bacteremia in mice." Infect Immun 75(4), 2067-70

Radouane A, Pehourcq F, Tramu G, Creppy EE, Bannwarth B (1996): „Influence of lipophilicity on the diffusion of cephalosporins into the cerebrospinal fluid." Fundam Clin Pharmacol 10(3), 309-13 
Ramilo O, Saez-Llorens X, Mertsola J, Jafari H, Olsen KD, Hansen EJ, Yoshinaga M, Ohkawara S, Nariuchi H, McCracken GH Jr (1990): „Tumor necrosis factor alpha/cachectin and interleukin 1 beta initiate meningeal inflammation." J Exp Med 172(2), 497-507

Reese TS, Karnovsky MJ (1967): „Fine structural localization of a bloodbrain barrier to exogenous peroxidase." J Cell Biol 34(1), 207-17

Regev-Yochay G, Raz M, Dagan R, Porat N, Shainberg B, Pinco E, Keller N, Rubinstein E (2004): „Nasopharyngeal carriage of Streptococcus pneumoniae by adults and children in community and family settings." Clin Infect Dis 38(5), 632-9

Reinert RR, Queck A, Kaufhold A, Kresken M, Lütticken R (1995): „Antimicrobial resistance and type distribution of Streptococcus pneumoniae isolates causing systemic infections in Germany, 1992-1994." Clin Infect Dis 21(6), 1398-401

Reinert RR, Reinert S, van der Linden M, Cil MY, Al-Lahham A, Appelbaum $P$ (2005): „Antimicrobial susceptibility of Streptococcus pneumoniae in eight European countries from 2001 to 2003." Antimicrob Agents Chemother $\underline{49}(7), 2903-13$

Ribes S, Regen T, Meister T, Tauber SC, Schütze S, Mildner A, Mack M, Hanisch UK, Nau R (2013): „Resistance of the brain to Escherichia coli K1 infection depends on MyD88 signaling and the contribution of neutrophils and monocytes." Infect Immun 81(5), 1810-9

Ring A, Weiser JN, Tuomanen El (1998): „Pneumococcal trafficking across the blood-brain barrier. Molecular analysis of a novel bidirectional pathway. “ J Clin Invest 102(2), 347-60 
Robert Koch-Institut (2013): "Epidemiologisches Bulletin" www.rki.de 26.August 2013/Nr.34; Zugriff: 07/2014

Rockowitz J, Tunkel AR (1995): „Bacterial meningitis. Practical guidelines for management." Drugs $\underline{50}(5), 838-53$

Rodvold KA, Gotfried MH, Cwik M, Korth-Bradley JM, Dukart G, EllisGrosse EJ (2006): „Serum, tissue and body fluid concentrations of tigecycline after a single $100 \mathrm{mg}$ dose." J Antimicrob Chemother $\underline{58(6), 1221-9}$

Rose WE, Rybak MJ (2006): „Tigecycline: first of a new class of antimicrobial agents." Pharmacotherapy $\underline{26}(8), 1099-110$

Scheld WM, Koedel U, Nathan B, Pfister HW (2002): „Pathophysiology of bacterial meningitis: mechanism(s) of neuronal injury." J Infect Dis $\underline{186}$ Suppl 2, 225-33

Schmidt H, Heimann B, Djukic M, Mazurek C, Fels C, Wallesch CW, Nau R (2006): „Neuropsychological sequelae of bacterial and viral meningitis.“ Brain 129(Pt 2), 333-45

Schneider O, Michel U, Zysk G, Dubuis O, Nau R (1999): „Clinical outcome in pneumococcal meningitis correlates with CSF lipoteichoic acid concentrations." Neurology $\underline{53}(7), 1584-7$

Schröder NW, Morath S, Alexander C, Hamann L, Hartung T, Zähringer U, Göbel UB, Weber JR, Schumann RR (2003): „Lipoteichoic acid (LTA) of Streptococcus pneumoniae and Staphylococcus aureus acivates immune cells via Toll-like receptor (TLR)-2, lipopolysaccharide-binding protein (LBP), and CD 14, whereas TLR-4 and MD-2 are not involved." J Biol Chem 278(18), 15587-94 
Schwartz LM, Osborne BA (1993): „Programmed cell death, apoptosis and killer genes." Immunol Today 14 (12), 582-90

Scoville WB, Milner B (1957): „Loss of recent memory after bilateral hippocampal lesions. 1957." J Neuropsychiatry Clin Neurosci 12 (1), 103-13

Sellins KS, Cohen JJ (1991): „Cytotoxic T lymphocytes induce different types of DNA damage in target cells of different origins." J Immunol $\underline{147(3), 795-803}$

Sellner J, Leib SL (2006): „In baterial meningitis cortical brain damage is associated with changes in parenchymal MMP-9/TIMP-1 ratio and increased collagen type IV degradation." Neurobiol Dis $\underline{21}(3)$, 647-56

Shaw P, Bovey R, Tardy S, Sahli R, Sordat B, Costa J (1992): „Induction of apoptosis by wild-type p53 in a human colon tumor-derived cell line." Proc Natl Acad Sci USA 89(10), 4495-9

Shimada J, Moon SK, Lee HY, Takeshita T, Pan H, Woo Jl, Gellibolian R, Yamanaka N, Lim DJ (2008): „Lysozyme M deficiency leads to an increased susceptibility to Streptococcus pneumoniae-induced otitits media." BMC Infect Dis $\underline{8}, 143$

Sorensen HT, Nielsen GL, Schonheyder HC, Steffensen FH, Hansen I, Sabroe S, Dahlerup JF, Hamburger H, Olsen J (1998): „Outcome of prehospital antibiotic treatment of meningococcal disease." J Clin Epidemiol 51(9), 717-21

Spreer A, Kerstan H, Böttcher T, Gerber J, Siemer A, Zysk G, Mitchell TJ, Eiffert H, Nau R (2003): „Reduced release of pneumolysin by Streptococcus pneumoniae in vitro and in vivo after treatment with nonbacteriolytic 
antibiotics in comparison to ceftriaxone." Antimicrob Agents Chemother $\underline{47}(8), 2649-54$

Spreer A, Gerber J, Hanssen M, Schindler S, Hermann C, Lange P, Eiffert H, Nau R (2006): „Dexamethasone increases hippocampal neuronal apoptosis in a rabbit model of Escherichia coli meningitis." Pediatr Res $\underline{60}(2)$, 210-5

Stille W, Brodt HR, Groll A, Just-Nübling G: Antibiotika-Therapie. In: Stille W (Hrsg.): Antibiotika-Therapie: Klinik und Praxis der antiinfektiösen Behandlung. 11. Auflage. Schattauer, Stuttgart 2005

Stringaris AK, Geisenhainer J, Bergmann F, Balshüsemann C, Lee U, Zysk G, Mitchell TJ, Keller BU, Kuhnt U, Gerber J, Spreer A, Bähr M, Michel U, Nau R (2002): „Neurotoxicity of pneumolysin, a major pneumococcal virulence factor, involves calcium influx and depends on activation of p38 mitogen-activated protein kinase." Neurobiol Dis 11(3), 355-68

Stuertz K, Schmidt H, Eiffert H, Schwartz P, Mäder M, Nau R (1998): „Differential release of lipoteichoic and teichoic acids from Streptococcus pneumoniae as a result of exposure to beta-lactam antibiotics, rifamycins, trovafloxacin, and quinupristin-dalfopristin." Antimicrob Agents Chemother 42(2), 277-81

Swartz MN (1984): „Bacterial meningitis: more involved than just the meninges." N Engl J Med 311(14), 912-4

Tauber SC, Ebert S, Weishaupt JH, Reich A, Nau R, Gerber J (2009): „Stimulation of Toll-like receptor 9 by chronic intraventricular unmethylated cytosine-guanine DANN infusion causes neuroinflammation and impaired spatial memory." J Neuropathol Exp Neurol 68 (10), 1116-24 
Tenenbaum T, Papandreou T, Gellrich D, Friedrichs U, Seibt A, Adam R, Wewer C, Galla HJ, Schwerk C, Schroten H (2009) : „Polar bacterial invasion and translocation of Streptococcus suis across the bloodcerebrospinal fluid barrier in vitro." Cell Microbiol 11(2), 323-36

Tunkel AR, Hartman BJ, Kaplan SL, Kaufman BA, Roos KL, Scheld WM, Whitley RJ (2004): „Practice guidelines for the management of bacterial meningitis." Clin Infect Dis $\underline{39}(9), 1267-84$

Tuomanen E, Liu H, Hengstler B, Zak O, Tomasz A (1985 a): „The induction of meningeal inflammation by components of the pneumococcal cell wall." J Infect Dis 151(5), 859-68

Tuomanen E, Tomasz A, Hengstler B, Zak O (1985 b): „The relative role of bacterial cell wall and capsule in the induction of inflammation in pneumococcal meningitis." J Infect Dis $\underline{151(3), 535-40}$

Tureen JH, Dworkin RJ, Kennedy SL, Sachdeva M, Sande MA (1990): "Loss of cerebrovascular autoregulation in experimental meningitis in rabbits." J Clin Invest 85(2), 577-81

Van de Beek D, de Gans J, Spanjaard L, Weisfelt M, Reitsma JB, Vermeulen M (2004): „Clinical features and prognostic factors in adults with bacterial meningitis." N Engl J Med. 351(18), 1849-59

Van de Beek D, Farrar JJ, de Gans J, Mai NT, Molyneux EM, Peltola H, Peto TE, Roine I, Scarborough M, Schultsz C, Thwaites GE, Tuan PQ, Zwindermann AH (2010): „Adjunctive dexamethasone in bacterial meningitis: a meta-analysis of individual patient data." Lancet Neurol $\underline{9}(3), 254-63$ 
Vaux DL, Cory S, Adams JM (1988): „Bcl-2 gene promotes haemopoietic cell survival and cooperates with c-myc to immotalize pre-B cells." Nature 335(6189), 440-2

Vaux DL, Haecker G, Strasser A (1994): „An evolutionary perspective on apoptosis." Cell $\underline{76}(5), 777-9$

Vergouwen MD, Schut ES, Troost D, van de Beek D (2010): „Diffuse cerebral intravascular coagulation and cerebral infarction in pneumococcal meningitis." Neurocrit Care $\underline{13}(2), 217-27$

Vesely JJ, Pien FD, Pien BC (1998): „Rifampicin, a useful drug for nonmycobacterial infections." Pharmacotherapy 18(2), 345-57

Waage A, Halstensen A, Shalaby R, Brandtzaeg P, Kierulf P, Espevik T (1989): „Local production of tumor necrosis factor alpha, interleukin 1, and interleukin 6 in meningococcal meningitis. Relation to the inflammatory response." J Exp Med 170(6), 1859-67

Wall EC, Ajdukiewicz KM, Heyderman RS, Garner P (2013): „Osmotic therapies added to antibiotics for acute bacterial meningitis." Cochrane Database Syst Rev. 28;3, CD008806

Weber JR, Tuomanen El (2007): „Cellular damage in bacterial meningitis: an interplay of bacterial and host driven toxicity."

J Neuroimmunol 184(1-2), 45-52

Weisfelt M, de Gans J, van der Poll T, van de Beek D (2006 a): „Pneumococcal meningitis in adults: new approaches to management and prevention." Lancet Neurol $\underline{5}(4), 332-42$ 
Weisfelt M, Hoogman M, van de Beek D, de Gans J, Dreschler WA, Schmand BA (2006 b): „Dexamethasone and long-term outcome in adults with bacterial meningitis." Ann Neurol $\underline{60}(4), 456-68$

Wellmer A, Zysk G, Gerber J, Kunst T, Von Mering M, Bunkowski S, Eiffert H, Nau R (2002): „Decreased virulence of a pneumolysin-deficient strain of Streptococcus pneumoniae in murine meningitis." Infect Immun $\underline{70}(11)$, 6504-8

Williams GT (1991): „Programmed cell death: apoptosis and oncogenesis.” Cell $\underline{65}(7), 1097-8$

Winkelmann NW, Eckel JL (1935): „Pathology of acute purulent meningitis." Ann Surg 101(1), 383-90

Wittwer M, Grandgirard D, Rohrbach J, Leib SL (2010): „Tracking the transcriptional host response from the acute to the regenerative phase of experimental pneumococcal meningits." BMC Infect Dis $\underline{10}, 176$

Wyllie AH (1981): Cell death: A new classification seperating apoptosis from necrosis. In: v. Bowen ID, Lockshin RA u.a. (Hrsg.): Cell death in biology and pathology. Chapman \& Hall, New York 1981, 9-34

Yogev R, Guzman-Cottrill J (2005): "Bacterial meningitis in children: critical review of current concepts.” Drugs $\underline{65}(8), 1097-112$

Yonish-Rouach E, Resnitzky D, Lotem J, Sachs L, Kimchi A, Oren M (1991): "Wild-type p 53 induces apoptosis of myeloid leukaemic cells that is inhibated by interleukin-6." Nature $\underline{352}$ (6333), 345-7 
Zhanel GG, Homenuik K, Nichol K, Noreddin A, Vercaigne L, Embil J, Gin A, Karlowski JA, Hoban DJ (2004): "The glycylcyclines: a comparative review with the tetracyclines." Drugs $\underline{64}(1), 63-88$

Zilles K: Graue und weiße Substanz des Hirnmantels. In: v. Leonardt $\mathrm{H}$, Tillmann B, Töndury G, Zilles K u.a. (Hrsg): Anatomie des Menschen. Band 3. Georg Thieme Verlag, Stuttgart 1987, 260-318

Zysk G, Brück W, Gerber J, Brück Y, Prange HW, Nau R (1996): „Antiinflammatory treatment influences neuronal apoptotic cell death in the dentate gyrus in experimental pneumococcal meningitis." J Neuropathol Exp Neurol $\underline{55}(6), 722-8$

Zysk G, Schneider-Wald BK, Hwang JH, Bejo L, Kim KS, Mitchell TJ, Hakenbeck R, Heinz HP (2001) : "Pneumolysin is the main inducer of cytotoxicity to brain microvascular endothelial cells caused by Streptococcus pneumoniae." Infect Immun $\underline{69}$ (2), 845-52 


\section{Abkürzungsverzeichnis}

$\begin{array}{lll}\text { AK } & - & \text { Antikörper } \\ \text { APC } & - & \text { antigen presenting cell } \\ \text { BgaA } & - & \beta \text {-Galaktosidase A } \\ \text { CRO } & - & \text { Ceftriaxon } \\ \text { CFU } & - & \text { colony-forming units } \\ \text { CSF } & - & \text { cerebrospinal fluid } \\ \mathrm{H}_{2} \mathrm{O}_{2} & - & \text { Wasserstoffperoxid } \\ \mathrm{HE} & - & \text { Hämatoxylin-Eosin } \\ \text { IL1 } & - & \text { Interleukin 1 } \\ \text { IL1 } \beta & - & \text { Interleukin } 1 \beta \\ \text { IL6 } & - & \text { Interleukin } 6 \\ \text { IST } & - & \text { In- Situ-Tailing } \\ \text { i.V. } & - & \text { intravenös } \\ \text { LPS } & - & \text { Lipopolysaccharid } \\ \text { LTA } & - & \text { lipoteichioc acid } \\ \text { mA } & - & \text { milli-Ampere } \\ \text { MBK } & - & \text { minimal bakterizide Konzentration } \\ \text { MHK } & - & \text { minimale Hemmkonzentration } \\ \text { MyD88 } & - & \text { Myeloid differentiation primary response gene 88 } \\ \text { NanA } & - & \text { Neuraminidase A } \\ \text { NanB } & - & \text { Neuraminidase B } \\ \text { NO } & - & \text { Stickstoffmonoxid } \\ \text { PavA } & - & \text { Pneumococcal adherence and virulence factor A } \\ \text { Ply } & - & \text { Pneumolysin } \\ \text { PspA } & - & \text { Pneumococcal surface protein A } \\ \text { PspC } & - & \text { Pneumococcal surface protein C } \\ \text { Rifa } & - & \text { Rifampicin } \\ \text { StrH } & - & \beta \text {-N-Acetylglucosaminidase } \\ \text { TLR } & - & \text { Toll-like-Rezeptor } \\ & & \end{array}$




$\begin{array}{lll}\text { TNFa } & - & \text { Tumornekrosefaktor } \alpha \\ \text { V } & - & \text { Volt } \\ \text { ZNS } & - & \text { zentrales Nervensystem }\end{array}$




\section{Lebenslauf}

Am 29. Juni 1983 wurde ich als zweites Kind von Maria Stoltefaut, geb. Klein, und Walter Stoltefaut, in Frankfurt am Main geboren.

Von 1989 bis 1993 besuchte ich die Grundschule in Idstein (Taunus) und von 1993 bis 1995 die Orientierungsstufe (Limesschule Idstein). AnschlieBend wechselte ich auf das Pestalozzi-Gymnasium Idstein und erwarb dort im Juni 2002 die allgemeine Hochschulreife.

Von Oktober 2002 bis August 2003 leistete ich meinen Zivildienst in einer Behindertenwerkstatt des Landeswohlfahrtsverbandes Hessen ab.

Zum Wintersemester 2003/2004 immatrikulierte ich mich an der GeorgAugust-Universität Göttingen. Zu Beginn des Sommersemesters 2005 wechselte ich an die Albert-Ludwigs-Universität Freiburg, wo ich im März 2006 den Ersten Abschnitt der Ärztlichen Prüfung ablegte. Anschließend führte ich das Studium ab dem Sommersemester 2006 an der GeorgAugust-Universität fort und legte dort im Mai 2010 den Zweiten Abschnitt der Ärztlichen Prüfung ab. Das Praktische Jahr verbrachte ich in Göttingen (Chirurgie), in Immenhausen (Innere) und in Debstedt bei Bremerhaven (Orthopädie). Seit 2011 befinde ich mich in der Facharztausbildung für Orthopädie und Unfallchirurgie. 


\section{Danksagung}

Mein besonderer Dank gilt Herrn Prof. Dr. med. Roland Nau für die Überlassung des Themas und sein Interesse an der Fortführung dieser Arbeit sowie für seine stete Bereitschaft, mir im Falle von Fragen und Problemen Unterstützung zu gewähren.

Mein herzlicher Dank gilt ebenfalls Frau PD Dr. med. Annette Spreer, die mich im Rahmen dieser Arbeit stets unterstützt und motiviert hat und für alle Fragen praktischer und theoretischer Art jederzeit zur Verfügung stand.

Ich danke dem Laborpersonal für eine freundliche und angenehme Arbeitsatmosphäre und hierbei besonders Frau Bunkowski, die mich bei der Herstellung der histologischen Präparate und anderer Labortätigkeiten sehr unterstützt hat. Auch danke ich den anderen Mitdoktoranden für ein herzliches und kollegiales Arbeitsklima. 